NBER WORKING PAPER SERIES

\title{
MATH OR SCIENCE? USING LONGITUDINAL EXPECTATIONS DATA TO EXAMINE THE PROCESS OF CHOOSING A COLLEGE MAJOR
}

\author{
Todd R. Stinebrickner \\ Ralph Stinebrickner \\ Working Paper 16869 \\ http://www.nber.org/papers/w16869
NATIONAL BUREAU OF ECONOMIC RESEARCH
1050 Massachusetts Avenue
Cambridge, MA 02138
March 2011

This work was made possible by generous funding from The Mellon Foundation, The Spencer Foundation, The National Science Foundation, SSHRC, and Berea College. We are grateful for the helpful comments that we received from Peter Arcidiacono, Wilbert van der Klaauw, Basit Zafar, and numerous seminar participatns. The views expressed herein are those of the authors and do not necessarily reflect the views of the National Bureau of Economic Research.

NBER working papers are circulated for discussion and comment purposes. They have not been peerreviewed or been subject to the review by the NBER Board of Directors that accompanies official NBER publications.

(C) 2011 by Todd R. Stinebrickner and Ralph Stinebrickner. All rights reserved. Short sections of text, not to exceed two paragraphs, may be quoted without explicit permission provided that full credit, including $(\odot)$ notice, is given to the source. 
Math or Science? Using Longitudinal Expectations Data to Examine the Process of Choosing a College Major

Todd R. Stinebrickner and Ralph Stinebrickner

NBER Working Paper No. 16869

March 2011

JEL No. I21,J24

\begin{abstract}
$\underline{\text { ABSTRACT }}$
Due primarily to the difficulty of obtaining ideal data, much remains unknown about how college majors are determined. We take advantage of longitudinal expectations data from the Berea Panel Study to provide new evidence about this issue, paying particular attention to the choice of whether to major in math and science. The data collection and analysis are based directly on a simple conceptual model which takes into account that, from a theoretical perspective, a student's final major is best viewed as the end result of a learning process. We find that students enter college as open to a major in math or science as to any other major group, but that a large number of students move away from math and science after realizing that their grade performance will be substantially lower than expected. Further, changes in beliefs about grade performance arise because students realize that their ability in math/science is lower than expected rather than because students realize that they are not willing to put substantial effort into math or science majors. The findings suggest the potential importance of policies at younger ages which lead students to enter college better prepared to study math or science.
\end{abstract}

Todd R. Stinebrickner

Department of Economics

University of Western Ontario

London, Ontario, N6A 5C2

CANADA

and NBER

trstineb@uwo.ca

Ralph Stinebrickner

Berea College

ralph_stinebrickner@berea.edu 


\section{Section I. Introduction}

There exist important differences in earnings across college majors. In addition, policymakers often discuss the possibility of increasing the number of students in certain disciplines, such as those in math and science, which are viewed as being particularly important for the future path of the economy (COSEPUP, 2007). Nonetheless, much remains unknown about how college majors are determined.

The absence of a full understanding about how students choose a college major can be attributed primarily to the difficulty of obtaining ideal data. A simple, static conceptual model has students choose a major by comparing the expected benefits and costs across the set of possible alternatives (Montmarquette et. al, 2002)). This simple theory highlights a primary difficulty faced by researchers studying the choice of college major using standard data sources - that beliefs about expected benefits and costs (e.g., expected earnings) are not observed directly for either the major that is chosen by a particular person or for any of the majors that the person considers but does not choose. Further, data requirements become even more prohibitive when one enriches the conceptual model to take into account that, from a theoretical perspective, a student's final major is best viewed as the end result of a process in which he learns about the quality of his match with each possible major. Viewing the major decision as a process that begins at the time of college entrance implies that a researcher needs access to not only beliefs about the expected benefits and costs associated with each major throughout the entire time a student is in college, but also to appropriate information describing beliefs about the dependent variable itself, college major, throughout the entire time a student is in college.

In this paper we provide some of the first evidence about the process by which a student chooses a college major, with a particular focus on understanding the choice of math/science, by taking advantage of unique data that we collected specifically to meet the challenges described in the previous paragraph. The data come from the Berea Panel Study, a longitudinal survey of students at Berea College that was initiated to allow an in-depth study of a variety of decisions and outcomes in higher education. Generally, the data from the BPS are well-suited for the type of analysis in this paper because the data collection was guided closely by theoretical models of learning. More specifically, the data contain two unique features that are of central importance for this study. First, the survey is unique among surveys of college students in its frequency of contact with respondents; each student was surveyed approximately twelve times each year while in school, with the first survey taking place immediately before the beginning of the student's freshman year. Second, taking advantage of recent methodological advances in the elicitation of beliefs (Dominitz, 1998; Dominitz and Manski, 1996, 1997; Manski, 2004), the BPS was perhaps the first sustained longitudinal survey to have a strong focus on the collection of expectations data. Together, these two features imply that, at the beginning of each semester starting at the time of entrance, the BPS elicited 
the individual-specific beliefs that are necessary to understand the process determining a college major.

Our objective of providing evidence about the process by which a person arrives at a college major, in general, and whether this major is in math/science, in particular, involves two primary components. The first component, examined in Section III, involves characterizing how an appropriate dependent variable for college major changes over time. Generally, in contexts where uncertainty exists about a choice that will be made in the future, it is desirable to allow agents to express beliefs about the future choice in probabilistic form. In our context, we recognize that the object of interest is one's final major and our survey questions are designed to elicit the amount of uncertainty that each person has about this object in each semester. We find that much uncertainty exists about one's final major at the time of college entrance. For example, grouping specific majors into a smaller number of major "groups" (hereafter typically referred to simply as majors), students assign an average probability of only .43 at the time of entrance to the major group that they ultimately end up choosing. After entrance, uncertainty decreases at a roughly constant rate over the first three years.

Examining trends separately by major, we find that students are quite open to the idea of majoring in math/science at the start of college. Indeed, in our sample at the time of entrance: A) the proportion of students who believe that math/science is the most likely major is higher than the proportion for any other major and B) the average perceived probability (across students) of choosing math/science is as high as the average perceived probability for any other major. However, by the second semester of the third year in college, the proportion of students who believe that math/science is the most likely major has decreased by $45 \%$ and the average perceived probability of choosing math/science has decreased by $38 \%$ so that math/science is ultimately one of the least commonly chosen majors. We find that these changes take place in a non-linear fashion with much of the decrease having occurred by the beginning of the second year even though students are not required to formally choose a major by this time. In contrast to the findings for math/science, for all other majors both the proportion of students who believe the major is most likely and the average perceived probability of choosing the major either increase or remain roughly unchanged across semesters. As such, the results in Section III strongly underscore a common theme in the paper - that the math/science field is unique among the set of majors - and motivate further our specific focus on the choice of math/science.

The second component of providing evidence about the process by which a person arrives at a college major, examined in Section IV, involves attempting to understand why the dependent variable measuring a person's beliefs about his final major changes over time. In terms of factors that may influence the expected benefits of the various majors, we focus primarily on a student's beliefs about his academic performance/ability in each particular major and the future income he would receive if he had each 
particular major.

Descriptive statistics suggest strongly that these factors will be important in explaining the patterns for math/science seen in Section III. For the sample as a whole we find that, while on average students enter college believing that their academic performance/ability will be lower in math/science than any other major, this belief is strengthened considerably over time. Perhaps more informative are our findings obtained after stratifying the sample on the basis of the dependent variable from Section III. For example, particularly dramatic changes in beliefs about academic performance in math/science are observed for students who start school thinking that math/science is most likely but subsequently "leave” math/science. These students start school with beliefs that look very similar to students who begin school thinking that math/science is most likely and "stay" in math/science, but finish school with beliefs that look very similar to those who begin school thinking that a major other than math/science is most likely. Further, we find that these changes occur because students realize that their ability in math/science is lower than expected rather than because students realize that they are not willing to put the required effort into the math/science major. In general, the results related to academic performance/ability suggest a situation in which students are "pushed” rather than "pulled” out of math/science.

The remainder of Section IV involves estimating models which quantify the importance of the major-specific factors in determining major choice. In the later semesters of college, when uncertainty about one’s final college major has been resolved, the appropriate models are of the standard discrete choice variety. However, in early semesters of college these models are not appropriate, and we formulate a Maximum Likelihood Estimator that explicitly accounts for the reality that much uncertainty about one’s final college major often exists at this stage of school.

Our results indicate that future grade performance in a major and future income in a major both play important roles in determining whether a student chooses that major, with the former being of especially strong importance. These results, when combined with our finding that the likelihood of majoring in the math/science major declines substantially over time for the sample as a whole and for particular subgroups of interest, allow this paper to contribute some of the strongest direct evidence to-date to a recent literature which recognizes the importance of learning in determining schooling outcomes (Manski, 1989; Altonji, 1993; Carneiro et al., 2005; Cunha et al., 2005, Stinebrickner and Stinebrickner, 2009). We find that the proportion of students predicted to have a final major in math/science would increase by as much as $68 \%$ under the counterfactual in which no learning takes place about academic performance/ability during school. In the Conclusion (Section V) we briefly discuss the potential policy importance of our primary findings - that students enter school quite open to a major in math or science, but that a large movement away from math and science occurs as many students realize that their grade performance will be 
substantially lower than expected.

In terms of other papers examining the choice of college major, our work is most related to that of Zafar (2008, forthcoming) and Arcidiacono et al. (2010) in that several years after the initiation of the BPS, these projects also took the approach of collecting expectations data specifically for the purpose of studying college major. However, while these projects serve as helpful background by illustrating that expectations data can allow a useful next step beyond what is possible using traditional data, they are not able to provide evidence related to the central motivation for this paper - that obtaining a comprehensive understanding requires viewing the final major as the end result of a learning process which starts at the time of entrance. This is the case both because these projects do not involve the type of longitudinal aspect that is present in the BPS and because, although students were often interviewed at relatively early stages of college, the survey instruments used in these other projects did not allow students to express uncertainty about their final major. ${ }^{1}$ Thus, for example, there currently exists no evidence about how much uncertainty is present about one's major at the time of college entrance, no evidence about the rate at which uncertainty dissipates over time, and no evidence about how uncertainty is resolved. ${ }^{2}$ In addition, due to sample sizes that are substantially smaller than what is available in the BPS, these projects are also not well-suited to study the choice of particular majors of interest such as math/science.

From a methodological standpoint, our work received helpful guidance from the study of electricity demand in Blass et al. (2010) which, to the best of our knowledge, is the only other work using survey questions that allow agents to express uncertainty about a choice that will be made in the future. ${ }^{3}$ Our work complements Blass et al. (2010) by taking the natural next descriptive and modelling steps. From a descriptive standpoint, because we collected longitudinal data and because we study a real-world situation

${ }^{1}$ Arcidiacono et al. (2010) uses a single cross-section of 173 students from Duke University across different stages of college. Zafar (2008, forthcoming) collects information in the sophomore and junior years at Northwestern University, with 161 students participating in their sophomore year and 117 participating in both years.

The BPS was initiated in 2000. The surveys of Zafar, which took place starting in 2006, and the survey of Arcidiacono et al., which took place in 2009, were designed without the benefit of seeing our earlier BPS survey design and its focus on collecting beliefs about the dependent variable, final college major, in probabilistic form. Instead, using the terminology in Blass et al. (2010), these surveys asked respondents to "state" their current major. Blass et al. (2010) provide an in-depth discussion of the methodological concerns of using "stated” choices when the object of interest is a choice that will be finalized sometime in the future.

${ }^{2}$ Even with observations at two points in time, Zafar (forthcoming) is not able to examine how uncertainty is resolved per se because his survey questions do not allow students to express uncertainty about different majors. However, of relevance for thinking about how uncertainty might be resolved, Zafar (forthcoming) does examine how beliefs about factors that influence the choice of major evolve between his two sample periods.

${ }^{3}$ Blass et al. (2010) study preferences for electricity reliability by eliciting choice probabilities under a variety of hypothetical scenarios that differ in the duration and frequency of electricity outages and in the price of electricity. 
in which the future decision is actually observed, we are able to further illustrate the potential benefits of collecting information about a dependent variable of interest in probabilistic form. Of importance from a policy standpoint we are able to, for example: a) characterize the amount of uncertainty that is present at the time of entrance; b) examine whether, on average, students have correct beliefs at the time of entrance; and c) examine the rate at which uncertainty dissipates over time. From a modelling standpoint, because in our context it is reasonable to take a stand on the underlying factors that may cause uncertainty about a final decision (e.g., academic performance/ability and future income) and because we can use additional survey questions to characterize the person-specific distributions representing beliefs about these factors, we are able to show how desirable realism might be added to a model which incorporates uncertainty about a future choice. Specifically, we are able to relax the assumption in Blass et al. (2010) that the amount of uncertainty about underlying factors is unobservable and homogeneous across people.

\section{Section II. The Berea Panel Study and the sample used in this paper}

Designed and administered by Todd Stinebrickner and Ralph Stinebrickner, the BPS is a multipurpose longitudinal survey that takes place at Berea College and elicits information of relevance for understanding a wide variety of issues in higher education, including those related to drop-out, college major, time-use, social networks, peer effects, and transitions to the labor market. The BPS consists of two cohorts. Baseline surveys were administered to the first cohort (the 2000 cohort) immediately before it began its freshman year in the fall of 2000 and baseline surveys were administered to the second cohort (the 2001 cohort) immediately before it began its freshman year in the fall of 2001. In addition to collecting detailed background information, the baseline surveys were designed to take advantage of recent advances in survey methodology (see, e.g., Barsky et al., 1997; Dominitz, 1998; and Dominitz and Manski, 1996, 1997) in order to collect expectations towards uncertain outcomes and the factors that might influence these outcomes. Substantial follow-up surveys that were administered at the beginning and end of each subsequent semester document how expectations towards uncertain outcomes and the factors that might influence these outcomes have changed. In addition, time-use surveys were administered eight times a year. Thus, in all, students were surveyed between ten and twelve times a year while in school.

Here we study college major choice using data from the first three years of college. We refer to the start of semesters $1,2,3,4,5$, and 6 as $t=1, t=2, t=3, t=4, t=5, t=6$, respectively. Thus, $t=1$ is the time of entrance and $\mathrm{t}=6$ is the beginning of the second semester of the third year. Combining the 2000 and 2001 cohorts, 664, 561, 451, 419, 383, and 376 students provided legitimate responses to our primary survey question (Question 1, Appendix, discussed in detail in Section III) at $\mathrm{t}=1, \mathrm{t}=2, \mathrm{t}=3, \mathrm{t}=4, \mathrm{t}=5$, and $\mathrm{t}=6$, respectively. Approximately 86\% of all Berea students in the two cohorts participated in the baseline BPS 
survey and subsequent participation rates remained between .85 and .95 for students who continued to be enrolled at Berea. Thus, the decrease above in the number of students responding is due primarily to the overall drop-out rate of approximately .40 at Berea (S\&S, 2008a, 2009).

Because we are ultimately interested in how the choice of major evolves over time, it is often most useful for our purposes to hold the sample composition constant across the six semesters that we examine. Thus, we focus primarily on the 371 individuals who provided legitimate responses to our primary survey question on both the baseline survey and the survey at the beginning of the sixth semester. ${ }^{4}$ We refer to this as our “composition-constant” sample.

The BPS survey data are linked to administrative data to obtain information about a variety of observable characteristics, $\mathrm{X}_{\mathrm{i}}$. We focus primarily on a student's sex and his/her score on the American College Test (ACT). For the composition-constant sample, the proportion of students that are male is $34.7 \%$, the average (std. deviation) score on the ACT math test is 21.95 (4.08), and the average (std. deviation) score on the ACT verbal test is 23.202 (4.47). As discussed in Stinebrickner and Stinebrickner (2008a), college entrance exam scores at Berea are similar to those at the University of Kentucky and the University of Tennessee.

\section{Characterizing an appropriate dependent variable for college major III.A. An appropriate dependent variable for college major}

The first component of providing evidence about the process by which a student arrives at a college major involves characterizing how an appropriate dependent variable for college major changes across semesters, starting at the time of college entrance. Our data collection was motivated by the reality that our object of ultimate interest is a student's major at graduation, which we refer to as his "final" major. The final major is known with certainty starting at a time $t^{*}$ when the school requires a student to finalize his choice. However, if one wishes to understand the process leading to a final major, it is necessary to collect information about the final major at times before $t^{*}$ (e.g., at the time of entrance) when uncertainty about the final major may remain. Blass et al. (2010) describe the problems that can arise when a respondent is forced to "state" a choice in a context in which uncertainty exists about a decision that will take place in the future. Then, an important feature of our data is that, at the time of entrance, the first column of Survey Question 1 (Appendix A) allows a respondent to express uncertainty about his final major by asking him to report the percent chance that he will ultimately end up with a major in each of seven mutually exclusive and collectively exhaustive major groups: Agriculture and Physical Education (AG), Business (BUS),

\footnotetext{
${ }^{4}$ The 371 number differs from the 376 number seen for $t=6$ above because five people who responded with legitimate values at $\mathrm{t}=6$ had illegitimate values in $\mathrm{t}=1$.
} 
Education (ED), Humanities (HUM), Science including Math (SCI), Professional programs (PRO), and Social Science (SS). ${ }^{5}$ Further, we repeated Question 1 at the beginning of every subsequent semester. This allows us to examine how uncertainty changes over time on the path to a final major. To the best of our knowledge, our survey approach is unique - nothing is known about how much uncertainty exists about college major at any stage of college.

We often refer to student i's reported probability at time $t$ of ending up with a final major of $j \in\{A G$, BUS, ED, HUM, SCI, PRO, SS \} as i’s perceived probability at t of choosing $\mathrm{j}$ and denote this probability $\operatorname{Pr}_{\mathrm{i}, \mathrm{j}}^{\mathrm{t}}$

\section{Section III.B. Uncertainty about major at different stages of college}

Question 1 (Appendix A) was first administered immediately before the start of the first year. Juster (1966) and Manski (1990) reasoned that, when asked to declare the outcome of a future decision in a case where uncertainty will be resolved before the final decision is made, survey respondents will tend to state the alternative with the highest probability as of the time of the survey. Hereafter, we follow this literature by referring to the most likely major at time t (i.e., $\arg \max _{\mathrm{j} \in\{\mathrm{AG}, \mathrm{BUS}, \ldots, \mathrm{SS}\}} \mathrm{Pr}_{\mathrm{i}, \mathrm{j}}^{\mathrm{t}}$ ) as the "stated" major at time $\mathrm{t}$, although we note that this is somewhat of a misnomer in our context since we construct the stated major ourselves from Question 1. Hereafter, we refer to the stated major at the time of entrance $(t=1)$ as the "starting" major and the stated major in our last observed semester $(\mathrm{t}=6)$ as the "final" major. We note that the former is somewhat of a misnomer because a student is not really forced to start in any particular major, although, of relevance later, students may disproportionately choose elective courses in the first semester/year from their stated major area. The latter would be a misnomer if a non-trivial number of students do not determine their final major until the fourth year of school. We examine whether this is the case later in this subsection.

If no uncertainty existed about college major at entrance, each student would assign a probability of one to the starting major. Instead, for our composition-constant sample, the $t=1$ entry in Figure $1 \mathrm{~A}$ shows that, on average, students assign at $\mathrm{t}=1$ a probability of approximately .60 to the starting major. Further, many students may ultimately choose a major that is different than the one that they believe is most likely at entrance. The $\mathrm{t}=1$ entry in Figure $1 \mathrm{~B}$ shows that, on average, students perceive at $\mathrm{t}=1$ that the probability associated with their final major is only .44 , and we find that at $\mathrm{t}=1$ only $5 \%$ of students assign a probability of one to the final major. Thus, much uncertainty exists about college major at entrance.

\footnotetext{
${ }^{5}$ This “percent chance” question was answered after students completed classroom training which, among other things, discussed this type of question in non-education contexts. For this paper, "illegitimate” responses in the first column of Question 1 are responses where the sum of the percent chances was more than 110 or less than 90. For sums that were between 90 and 110, but not equal to 100, we adjusted each percent chance proportionally to make the sum equal 100 .
} 
The $\mathrm{t}=2, \ldots, \mathrm{t}=6$ entries in Figures $1 \mathrm{~A}$ and $1 \mathrm{~B}$ indicate the degree to which uncertainty is resolved across semesters after entrance. Both figures show uncertainty decreasing at a fairly constant rate over the six semesters. Then, the reasonable notion that there exists a specific period when students are thinking most closely about their college major (Zafar, forthcoming) does not seem like the appropriate interpretation. Even if students are forced to declare a major by a particular time, it appears that the major choice is a process that begins at entrance. ${ }^{6}$

As to whether it is a misnomer to refer to the stated major at $t=6$ as the final major, we see in Figure $1 \mathrm{~A}$ that, at $\mathrm{t}=6$, students assign, on average, a probability of approximately .84 to the stated major. Further, we note that Question 1 does not allow an explicit way for a student to indicate that he believes that he will have majors in more than one final major group. In debriefing sessions that took place during the later stages of college we found that students who knew with certainty that they would have two final major groups tended to write a probability of .50 for each major group. In the data, we find that, at $t=6,5 \%$ of students assigned a probability of .50 to two major groups. Then, adjusting Figure 1A to reflect the fact that these students likely do not have uncertainty at $\mathrm{t}=6$, the $\mathrm{t}=6$ entry in Figure $1 \mathrm{~A}$ increases to approximately .87. Thus, while a small amount of uncertainty does remain as of $t=6$, to a rough approximation it seems reasonable in our analysis of Section IV to make the simplifying assumption that uncertainty about major has been resolved by $\mathrm{t}=6$.

\section{Section III.C Major-specific patterns}

The uncertainty about major at entrance discussed in Section III.B raises the possibility that there may be a net inflow from or a net outflow to particular majors over time. To examine major-specific patterns, we begin by constructing, for each semester $t$ and each major $\mathrm{j}$, the proportion of students who have stated major $\mathrm{j}$.

For the composition-constant sample, Figure 2A shows these major-specific proportions across the six semesters. At $t=1$, the proportion of students with a stated major of Science is higher than the proportion for any other major. However, Figure 2A shows a dramatic change of -.09 (.202 to .112), or 45\%, in the proportion associated with Science between $t=1$ and $t=6$. In contrast, the changes in the proportions for the

\footnotetext{
${ }^{6}$ For example, discussing the survey that takes place in the middle of students' sophomore year Zafar (forthcoming) writes "Since Northwestern University requires students to officially declare their majors by the beginning of their junior year, the timing of the initial survey corresponds to the period when students are actively thinking about which major to choose."

The sample in Arcidiacono et al. (2010) combines students from all stages of college. The results here suggest that an "intended" major (used in that paper to describe someone at an early stage of college) may mean something quite different than a "chosen” major (used in that paper to describe someone at a later stage).
} 
other majors between $\mathrm{t}=1$ and $\mathrm{t}=6$ range from a low of only -.016 to a high $+.064 .^{7}$ In terms of timing, despite the fact that Figures 1A and 1B show fairly constant changes over time, Figure 2A shows that much of the decrease in the Science proportion between $\mathrm{t}=1$ and $\mathrm{t}=6$ takes place quickly; $(.059 / .090) \%=66 \%$ of the decrease occurs by the beginning of the second year $(\mathrm{t}=3)$. This further strengthens the conclusion in Section III.B that the choice of major is best viewed as a process in which important changes may occur early.

While the stated choice is convenient from a descriptive standpoint, the decline across time in the proportion having the stated major of Science does not necessarily imply that students, on average, had misperceptions at entrance about the likelihood of choosing Science (Manski, 2004). ${ }^{8}$ Instead, to conclude that misperceptions about Science existed at entrance one needs to establish that a similar decline is present when the data are examined in their original probabilistic form. Figure 2B does this by displaying the perceived probability at t of each major $\mathrm{j}$, $\mathrm{Pr}_{\mathrm{i}, \mathrm{j}}^{\mathrm{t}}$, averaged over all students $\mathrm{i}$ in the composition-constant sample. Despite the potential for differences between Figures 2A and 2B, the two figures are quite similar. At $t=1$, the average $\operatorname{Pr}_{i, j}^{t}$ in the sample is as high for $\mathrm{j}=$ Sci as for any other major. However, the average $\operatorname{Pr}_{\mathrm{i}, \mathrm{SCI}}^{\mathrm{t}}$ changes by -.069 (from .181 to .112 ), or $38 \%$, between $\mathrm{t}=1$ and $\mathrm{t}=6$, with the average change in $\operatorname{Pr}_{\mathrm{i}, \mathrm{j}}^{\mathrm{t}}$ for the other majors $(\mathrm{j} \neq \mathrm{SCI})$ ranging from a low of only - .014 to a high of $.048 .^{9}$ Again we find that much of the change for Science happens rather quickly; (.04/.069)\%=58\% of the decrease in the average perceived probability of Science between the start of school $(\mathrm{t}=1)$ and the middle of the third year $(t=6)$ occurs by the beginning of the second year $(t=3) .{ }^{10}$

${ }^{7}$ We reject, at all traditional significance levels, the null hypothesis that there is no change in the proportion with a stated major of Science between $t=1$ and $t=6$ with the test having a $t$-statistic of 3.39 . For each $j \neq S$ Science, we reject at .05 the null hypothesis that the change in the stated proportion (between $t=1$ and $t=6$ ) for $j$ is the same as the change in the stated proportion (between $\mathrm{t}=1$ and $\mathrm{t}=6$ ) for Science.

${ }^{8}$ For example, if all students had $\operatorname{Pr}^{1}{ }_{\mathrm{i}, \mathrm{ScI}}=.51$ and these perceptions were correct, then the proportion of students with a stated major of Science would be 1.0 at $\mathrm{t}=1$ and .51 at the end of school.

${ }^{9}$ We reject, at all traditional significance levels, the null hypothesis that there is no change in the average perceived probability associated with Science between $t=1$ and $t=6$ with the test having a t-statistic of 3.519. For each $\mathrm{j} \neq$ Science, we reject at .05 the null hypothesis that the change in the average perceived probability (between $\mathrm{t}=1$ and $\mathrm{t}=6$ ) for $\mathrm{j}$ is the same as the change in the stated proportion (between $\mathrm{t}=1$ and $\mathrm{t}=6$ ) for Science.

${ }^{10}$ Recalculating Figures $2 \mathrm{~A}$ and $2 \mathrm{~B}$ after stratifying the sample on the basis of sex we find that the sample proportion of males with a stated major of Science decreases from .281 to .118 between $t=1$ and $t=6$, while the sample proportion of females with a stated major of Science decreases from .160 to .109 between $t=1$ and $t=6$. Similarly, the average $\operatorname{Pr}_{i, S C I}^{t}$ decreases from .217 to .118 between $t=1$ and $t=6$ for males, while the average $\operatorname{Pr}_{i, S C I}^{t}$ decreases from .162 to .108 between $t=1$ and $t=6$ for females. Thus, while there do not ultimately exist differences in the number of Science majors by gender, this occurs largely because males' views about Science change quite dramatically between $t=1$ and $t=6$. Given issues related to small sample size that result when we stratify on the basis of sex, we do not pursue gender differences in the remainder of the paper. We do note, however, that these descriptive results are consistent with the findings of S\&S (2009) which found that higher drop-out rates of males 
Figures 2A and 2B show that, relatively speaking, students tend to start school thinking that a major in Science is quite likely, but few students ultimately choose a final major of Science. It is worth delving further into why Science is unique among majors in this respect. The number of students who end up with a final major of $\mathrm{j}$ depends on both: A) the actual probability of having a final major of $\mathrm{j}$ conditional on having a starting major of $\mathrm{j}$ (i.e., the probability of "staying” in j) and B) the actual probability of having a final major of $\mathrm{j}$ conditional on having a starting major of $\mathrm{k} \neq \mathrm{j}$ (i.e., the probability of “changing” to $\mathrm{j}$ ). With respect to A), Figure 3A shows that the proportion in the sample who stay in $\mathrm{j}$ is lower when $\mathrm{j}$ is Science than when $\mathrm{j}$ is any of the other majors. With respect to B), Figure 4A shows that the proportion in the sample who change to $\mathrm{j}$ is lower when $\mathrm{j}$ is Science than when $\mathrm{j}$ is any of the other majors. Misperceptions will exist if beliefs about the probability of staying in $\mathrm{j}$ and changing to $\mathrm{j}$ do not correspond to the actual probabilities in Figures 3A and 4A. In contrast to Figure 3A, Figure 3B indicates that, at $\mathrm{t}=1$, students who start in Science believe they are as likely to stay in their starting major as are students who start in other majors. In contrast to Figure 4A, Figure 4B shows that, at $t=1$, students believe they are as likely to change into Science as they are to change into any other major. ${ }^{11}$ Thus, Figures $3 \mathrm{~A}$ and $4 \mathrm{~A}$ show that starting in Science is close to necessary but far from sufficient for having a final major of Science, but Figures 3B and 4B show that students do not fully realize that this is the case.

\section{Understanding why the dependent variable changes over time}

\section{IV.A. A conceptual model and basic data needs}

As mentioned in Section I, the second component of providing evidence about the process by which a person arrives at a college major involves attempting to understand why the dependent variable measuring a person's beliefs about his final major changes over time. A simple conceptual model guided our data collection and guides our analysis.

A student i enters college $(t=1)$ uncertain about his college major. At a time $t^{*}$ he must finalize his choice of major by choosing a major from the set (AG, BUS, ED, HUM, SCI, PRO, SS). For the sake of the discussion of the conceptual model we think of $t^{*}$ as occurring relatively quickly and abstract from issues related to the utility obtained while in college but before $t^{*}$. Denote as $U^{\mathrm{j}}\left(\mathrm{X}_{\mathrm{i}}, \mathrm{M}_{\mathrm{i}, \mathrm{j}}, \epsilon_{\mathrm{i}, \mathrm{j}}\right)$ the lifetime utility starting at $t^{*}$ that student $i$ receives from choosing major $j . \mathrm{X}_{\mathrm{i}}$ is a vector of observable permanent characteristics. $\epsilon_{\mathrm{i}, \mathrm{j}}$ represents the effect on $\mathrm{U}^{\mathrm{j}}$ of individual factors that are not observed by the

arise because males are more likely to learn that they started school with overoptimistic beliefs about academic ability.

\footnotetext{
${ }^{11}$ Figure 3B shows the sample average of $\mathrm{Pr}^{1}{ }_{i, j}$ for all students who have $\mathrm{j}$ as their starting major. Figure 4B shows the sample average of $\operatorname{Pr}_{i, j}^{1}$ for all students who do not have $\mathrm{j}$ as their starting major.
} 
econometrician. $\mathrm{M}_{\mathrm{i}, \mathrm{j}}$ is a major-specific schooling or job characteristic/outcome that influences the lifetime benefits of choosing major $\mathrm{j}$. For example, $\mathrm{M}_{\mathrm{i}, \mathrm{j}}$ may be a person's future grade performance or the future income if he had major $\mathrm{j}$. We stress that $\mathrm{M}_{\mathrm{i}, \mathrm{j}}$ is a constant representing the true value of some characteristic, but that this true value may not be known with certainty by the student. Here we assume that $\mathrm{M}_{\mathrm{i}, \mathrm{j}}$ is onedimensional, but we relax this assumption in our empirical work.

Our primary interest is in understanding the importance of the $\mathrm{M}_{\mathrm{i}, \mathrm{j}}$ 's. Hereafter, we refer to the elements of $M_{i, j}$ as major-specific "factors" and define $M_{i}=\left\{M_{i, A G}, M_{i, B U S}, \ldots, M_{i, s S}\right\} . M_{i, j}$ may influence both the utility received while in school and the utility received after leaving school. Then, if one wanted to understand why a particular major-specific factor mattered or did not matter at its most basic level, it would be necessary to identify the impact of the factor on utility in both the schooling and post-schooling periods. Largely because of the difficulty of this identification task, our objective is more modest - to examine whether and to what extent factors matter in determining changes in the dependent variable. As such, we further simplify by assuming a simple reduced form for the utility function. ${ }^{12}$

$$
\mathrm{U}^{\mathrm{j}}\left(\mathrm{X}_{\mathrm{i}}, \mathrm{M}_{\mathrm{i}, \mathrm{j}}, \epsilon_{\mathrm{i}, \mathrm{j}}\right)=\alpha_{\mathrm{j}} \mathrm{X}_{\mathrm{i}}+\beta \mathrm{M}_{\mathrm{i}, \mathrm{j}}+\epsilon_{\mathrm{i}, \mathrm{j}}
$$

In terms of estimation of the parameters in (1), the approach we take differs depending on whether the dependent variable is measures at $t^{*}$ (when, by assumption, no uncertainty about the final choice remains) or before $t^{*}$.

$\underline{\text { Analysis at } t^{*}}$

At time t* no uncertainty remains about a student's final major because the student is forced to make his final choice. Although we relax this assumption somewhat in our empirical work, for the discussion here we maintain the assumption that $\epsilon_{\mathrm{i}}=\left\{\epsilon_{\mathrm{i}, \mathrm{AG}}, \epsilon_{\mathrm{i}, \mathrm{BUS}}, \ldots, \epsilon_{\mathrm{i}, \mathrm{SS}}\right\}$ is fully known by the student. Then, in terms of the sources of uncertainty faced by the student, we focus on the possibility that the student may be uncertain about $\mathrm{M}_{\mathrm{i}}$ at any stage of college. If uncertainty about $\mathrm{M}_{\mathrm{i}}$ remains "unresolved" at $t^{*}$, the student makes his choice by choosing the option with the highest expected utility. Denoting the expected utility of option $\mathrm{j}$ as $\mathrm{E}^{\mathrm{t}^{*}} \mathrm{U}^{\mathrm{j}}()$, the person is observed to choose $\mathrm{j}$ if

$\mathrm{E}^{\mathrm{t}^{*}} \mathrm{U}^{\mathrm{j}}()-\mathrm{E}^{\mathrm{t}^{*}} \mathrm{U}^{\mathrm{k}}()>0$ for all $\mathrm{k} \neq \mathrm{j}$.

We let $\mathbf{M}_{\mathrm{i}, \mathrm{j}}^{\mathrm{t}}$ be a random variable which represents a student's beliefs at $t$ about $\mathrm{M}_{\mathrm{i}, \mathrm{j}}$ so that $\mathbf{M}^{\mathrm{t}^{*}, \mathrm{j}}$ denotes the unresolvable uncertainty at $t^{*}$. To compute $E^{t^{*}} U^{j}()$ for each $j$, the student integrates $U^{j}\left(X_{i}, M_{i, j}\right.$, $\epsilon_{i, j}$ ) over the distribution of the random variable $\mathrm{M}^{\mathrm{t}^{*}}{ }_{\mathrm{i}, \mathrm{j}}$. Given the linear specification in equation (1), this

\footnotetext{
${ }^{12}$ If, as in Arcidiacono et al. (2010), one assumes that some major-specific factors only influence utility in school and other characteristics only influence utility after school, then it is possible to put a stronger interpretation on individual coefficients. This would not be an unreasonable approximation for the types of characteristics used here, although, as discussed later, it would not be guaranteed by theory.
} 
integration results in

(3) $E^{t^{*}} U^{j}\left(X_{i}, M_{i, j}, \epsilon_{i, j}\right)=\alpha_{j} X_{i}+\beta E\left(M^{t^{*}}{ }_{i, j}\right)+\epsilon_{i, j}$.

The econometric analysis at $t^{*}$ follows the standard discrete choice framework. We assume throughout that the econometrician knows the student's beliefs about $\mathrm{M}_{\mathrm{i}, \mathrm{j}}$ at all times. However, because the econometrician does not observe $\epsilon_{\mathrm{i}}$, he does not know with certainty which option $\mathrm{j}$ has the highest expected utility. Using his knowledge of the distribution of $\epsilon_{\mathrm{i}}$, the econometrician basis estimation on the likelihood that $\epsilon_{\mathrm{i}}$ falls within an interval such that observed choice $\mathrm{j}$ is optimal,

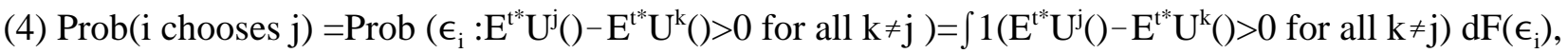
where $1(\bullet)$ is an indicator function that has a value of one if its expression is true. For example, assuming that $\epsilon_{\mathrm{i}, \mathrm{j}}$ has an Extreme Value distribution yields the standard logit closed form for the probability in equation (4).

\section{Analysis before $t^{*}$}

At $\mathrm{t}=1$ and subsequent times before $\mathrm{t}^{*}$ a person may be uncertain about his final major. This uncertainty arises because, in addition to the possibility of uncertainty about $\mathrm{M}_{\mathrm{i}}$ that will not be resolved by $t^{*}$, there may also exist uncertainty about $M_{i}$ that will be "resolved” by $t^{*}$. Let $E\left(M_{i}^{t}\right)=\left\{E\left(M_{i, A G}^{t}\right)\right.$, $\mathrm{E}\left(\mathrm{M}_{\mathrm{i}, \mathrm{BUS}}^{\mathrm{t}}\right), \ldots, \mathrm{E}\left(\mathrm{M}_{\mathrm{i}, \mathrm{SS}}^{\mathrm{t}}\right)$ \}. The final decision at $\mathrm{t}^{*}$ will be made taking into account $\mathrm{E}\left(\mathrm{M}^{\mathrm{t}^{*}}{ }_{\mathrm{i}}\right)$. However, at time $\mathrm{t}$ the student does not know exactly what the value of $\mathrm{E}\left(\mathrm{M}^{\mathrm{t}^{*}}{ }_{\mathrm{i}}\right)$ will turn out to be, and, therefore does not know what choice will turn out to be optimal. What he can compute at given his knowledge of $\epsilon_{\mathrm{i}}$ and his beliefs at $\mathrm{t}$ about $\mathrm{E}\left(\mathrm{M}^{\mathrm{t}^{*}}{ }_{\mathrm{i}}\right)$ is the perceived probability that each possible final major will turn out to be optimal. Specifically, the perceived probability at t of having a final major of $\mathrm{j}, \operatorname{Pr}_{\mathrm{i}, \mathrm{j}}^{\mathrm{t}}$, is the probability at $\mathrm{t}$ that the person will arrive at $t^{*}$ with a value of $E\left(M^{t^{*}}\right)$ such that, given his $\epsilon_{i}$, j is the optimal choice. Letting $\mathrm{E}\left(\mathrm{M}^{\mathrm{t}^{*}}\right)^{\mathrm{t}}$ be a random variable that represents a student's beliefs at time $\mathrm{t}$ about $\mathrm{E}\left(\mathrm{M}^{\mathrm{t}^{*}}{ }_{\mathrm{i}}\right)$ and letting $\mathrm{G}$ represent the distribution of $\mathrm{E}\left(\mathrm{M}^{\mathrm{t}^{*}}\right)^{\mathrm{t}}, \mathrm{Pr}_{\mathrm{i}, \mathrm{j}}^{\mathrm{t}}$, is given by (5) $\int 1\left(E^{t^{*}} U^{j}()-E^{t^{*}} U^{k}()>0\right.$ for all $\left.k \neq j\right) g\left(E\left(M^{t^{*}}{ }_{i}\right)^{t}\right) d E\left(M^{t^{*}}{ }^{t}{ }^{t}\right.$.

The econometric analysis is analogous to equation (4) from the standard discrete choice case. Our earlier assumption that the econometrician knows the student's beliefs about $\mathrm{M}_{\mathrm{i}, \mathrm{j}}$ at all times implies here that the econometrician knows $\mathrm{E}\left(\mathrm{M}^{\mathrm{t}^{*}}{ }_{\mathrm{i}}\right)^{\mathrm{t}}$. Then, using his knowledge of the distribution of $\epsilon_{\mathrm{i}}$ the econometrician bases estimation on the likelihood that $\epsilon_{\mathrm{i}}$ is such that a person would have the $\operatorname{Pr}_{\mathrm{i}, \mathrm{j}}^{\mathrm{t}}$ that he reported:

(6) Prob(i reports his perceived probability at time t of having final major of $\mathrm{j}$ to be $\operatorname{Pr}_{\mathrm{i}, \mathrm{j}}^{\mathrm{t}}$ )

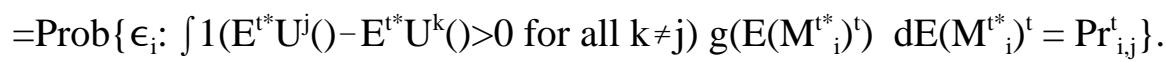

\section{Summary of basic data needs}

Then, for estimation at $t^{*}$ we require information about the mean $\mathrm{E}\left(\mathrm{M}^{\mathrm{t}^{*}}{ }_{\mathrm{i}}\right)$. As will be discussed, this 
is observed directly in our data. However, for estimation at $\mathrm{t}=1$ or other times $\mathrm{t}$ before $\mathrm{t}^{*}$ we require the entire distribution describing a student's beliefs at $\mathrm{t}$ about $\mathrm{E}\left(\mathrm{M}^{\mathrm{t}^{*}}{ }_{\mathrm{i}}\right)$. This is not observed directly in our data, but can be constructed, under certain assumptions, from $\mathrm{E}\left(\mathrm{M}_{\mathrm{i}}^{\mathrm{t}}\right)$ and other unique information in the BPS. Our effort to be explicit about the source of uncertainty about a student's final major and to allow this uncertainty to be heterogeneous across students represents a natural next step in the very small literature which allows agents to express uncertainty about a choice that will be made in the future. For example, in Blass et. al (2010) the source of uncertainty is not explicit and agents are assumed to have homogenous beliefs about this source.

The next subsection (IV.B) is devoted to describing $\mathrm{E}\left(\mathrm{M}_{\mathrm{i}}^{\mathrm{t}}\right), \mathrm{t}=1, \ldots, 6$. In Section IV.C, when we discuss details of estimation for the $t=1$ case, we describe how we use this and other information to construct the distribution describing beliefs about $\mathrm{E}\left(\mathrm{M}^{\mathrm{t}^{*}}\right)$ at times before $\mathrm{t}^{*}$.

\section{Section IV.B E( $\left(\mathbf{M}_{\mathrm{i}}^{\mathrm{t}}\right)$, Beliefs about major-specific factors influencing major choice IV.B.1 $\mathrm{E}\left(\mathrm{M}_{\mathrm{i}}^{\mathrm{t}}\right)$ : Survey questions and full-sample means}

In terms of the major-specific factors in $\mathrm{M}_{\mathrm{i}, \mathrm{j}}$ that influence the lifetime utility of $\mathrm{i}$, we focus primarily on student i's future academic performance/ability if he had major $\mathrm{j}$ and student i's future income if he had major j. ${ }^{13}$ The latter is presumably a primary determinant of post-college utility, but could also influence utility while in school if students are able to smooth consumption between the schooling and working portions of their lives. The former is likely to play an important role in determining utility while in school struggling academically may make studying frustrating, may make it difficult to become interested in course material, and may make school stressful due to a concern about failing out of school - but may also influence a student's post-college utility both by being a determinant of future income and by being related to the extent to which a person enjoys his/her job.

Elements of $M_{i, j}$ : beliefs about future academic performance and ability in major $j$

Assume that $\mathrm{i}$ 's grade point average (GPA) in major $\mathrm{j}$ in some future semester $\mathrm{t}^{\prime}$ is given by (7) $\mathrm{GPA}_{\mathrm{i}, \mathrm{j}, \mathrm{t}^{\prime}}=\mathrm{AGPA}_{\mathrm{i}, \mathrm{j}}+v_{\mathrm{i}, \mathrm{j}, \mathrm{t}^{\prime}}$,

where $\mathrm{AGPA}_{\mathrm{i}, \mathrm{j}}$ is a constant representing the average semester grade point average (GPA) that a person would receive in major $\mathrm{j}$ and $v_{\mathrm{i}, \mathrm{j}, \mathrm{t}^{\prime}}$ is a mean-zero random variable representing the transitory portion of grades in $\mathrm{t}^{\prime}$.

\footnotetext{
${ }^{13}$ See Arcidiacono (2004) and Beffy et al. (forthcoming ), respectively, for work that uses traditional types of data (i.e., non-expectations data) to focus on the role of ability and expected income, respectively, in determining college major.
} 
In terms of academic performance/ability, $\mathrm{AGPA}_{\mathrm{i}, \mathrm{j}}$ is an obvious measure of interest. ${ }^{14}$ At time $\mathrm{t}$, a person may be uncertain about $\mathrm{GPA}_{\mathrm{i}, \mathrm{j}, \mathrm{t}^{\prime}}$ both because he is uncertain about his true value of $\mathrm{AGPA}_{\mathrm{i}, \mathrm{j}}$ and because he does not know the future realization of $v_{\mathrm{i}, \mathrm{j}, \mathrm{t}^{\prime}}$. Drawing on the notation from Section IV.A, we let $\mathrm{GPA}_{\mathrm{i}, \mathrm{j}, \mathrm{t}^{\prime}}^{\mathrm{t}}, \mathrm{AGPA}_{\mathrm{i}, \mathrm{j}}^{\mathrm{t}}$, and $v_{\mathrm{i}, \mathrm{j}, \mathrm{t}^{\prime}}^{\mathrm{t}}$, respectively, be random variables representing a person's beliefs at time $\mathrm{t}$ about $\mathrm{GPA}_{\mathrm{i}, \mathrm{j}, \mathrm{t}^{\prime}}, \mathrm{AGPA}_{\mathrm{i}, \mathrm{j}}$, and $v_{\mathrm{i}, \mathrm{j}, \mathrm{t}^{\prime}}$, respectively, so that

(8) $\mathrm{GPA}_{\mathrm{i}, \mathrm{j}, \mathrm{t}^{\prime}}^{\mathrm{t}}=\mathrm{AGPA}_{\mathrm{i}, \mathrm{j}}^{\mathrm{t}}+v_{\mathrm{i}, \mathrm{j}, \mathrm{t}^{\prime}}^{\mathrm{t}}$

Then with $v_{\mathrm{i}, \mathrm{j}, \mathrm{t}^{\prime}}^{\mathrm{t}}$ mean-zero, $\mathrm{E}\left(\mathrm{AGPA}_{\mathrm{i}, \mathrm{j}}^{\mathrm{t}}\right)$ is equal to $\mathrm{E}\left(\mathrm{GPA}_{\mathrm{i}, \mathrm{j}, \mathrm{t}^{\prime}}^{\mathrm{t}}\right)$ and is elicited by the second column of Question 1 (Appendix A) which asks a student about the GPA that he "would expect to receive in a typical semester in the future” if he had major j.

Figure 5A shows the sample average of $E\left(\mathrm{AGPA}_{i, j}^{\mathrm{t}}\right)$ for each $\mathrm{j}$ and each $t$. Most striking is the pattern related to the Science major. While students do begin school $(t=1)$ with a belief that their grades will be lowest in Science, this belief is strengthened substantially over time. ${ }^{15}$ Thus, at first glance, changes after entrance in beliefs about grade performance in Science have at least the potential to explain the negative slopes of the Science lines in Figures 2A and 2B.

Theory does not suggest whether beliefs about grade performance or beliefs about academic ability per se should be more important in determining major choice. Regardless, given the importance of study effort found in S\&S (2004) and S\&S (2008b), whether E(AGPA $\mathrm{i}_{\mathrm{i}, \mathrm{j}}$ ) should be thought of as measuring beliefs about academic ability per se depends to a large extent on what students believe about their study effort in different majors. On one hand, if students tend to believe that they would expend little effort if they were forced to choose certain majors that might not be of particular interest, low values of E(AGPA $\left.{ }_{i, j}^{t}\right)$ might arise primarily due to low anticipated effort in $\mathrm{j}$ rather than due to beliefs that academic ability is low in $\mathrm{j}$. On the other hand, if students believe that receiving good grades is important regardless of major, they may tend to believe that they will study (at least) as much when they find courses difficult. In this case differences in $\mathrm{E}\left(\mathrm{AGPA}_{\mathrm{i}, \mathrm{j}}^{\mathrm{t}}\right)$ across majors will tend to reflect differences in academic ability across majors.

Which of the two scenarios is most relevant is an empirical question that can be examined because at time $\mathrm{t}$ we elicited the expected number of hours per day that a person would study in a future semester if

\footnotetext{
${ }^{14}$ Technically speaking, lifetime utility associated with $\mathrm{j}$ might depend on not only $\mathrm{AGPA}_{\mathrm{i}, \mathrm{j}}$ but also on $v_{\mathrm{i}, \mathrm{j}, \mathrm{t}^{\prime}}$. However, the simplifying focus on the average can be motivated by the reality that knowing AGPA $_{i, j}$ is close to sufficient for knowing one's cumulative grade point average at the end of college for $\mathrm{j}$ since the sum of $v_{\mathrm{i}, \mathrm{j}, \mathrm{t}^{\prime}}$ will tend towards zero with the number of semesters.

${ }^{15} \mathrm{~A}$ test rejects, at all traditional significance levels, the null that there is no change in $\mathrm{E}\left(\mathrm{AGPA}_{\mathrm{i}, \mathrm{SCI}}^{\mathrm{t}}\right)$ over time. For each major $\mathrm{j} \notin\{\mathrm{SCI}$, BUS, $\mathrm{HUM}\}$, a test rejects, at all traditional significance levels, the null that the difference between $E\left(A G P A_{i, S C I}^{t}\right)$ and $E\left(A G P A_{i, j}^{t}\right)$ is the same at $t=6$ as at $t=1$. For each major $j \in\{B U S, H U M\}$ a test rejects at significance levels greater than .07 the null that the difference between $E\left(A_{G P A}^{t}{ }_{i, S C I}\right)$ and $E\left(A G P A_{i, j}^{t}\right)$ is the same at $\mathrm{t}=6$ as at $\mathrm{t}=1$.
} 
he had each potential major group j (survey question not shown). Denoting i's report for major group $\mathrm{j}$ at time $t$ as $E\left(A S T U D Y_{i, j}^{t}\right)$, Figure 5B shows evidence that the second scenario above is more relevant as it pertains to the Science major; while we found in Figure 5A that for all t the sample average of E(AGPA $\left.{ }_{i, j}^{t}\right)$ is lowest when $\mathrm{j}=\mathrm{Sci}$, Figure $5 \mathrm{~B}$ shows that for all the sample average of $\mathrm{E}\left(\mathrm{ASTUDY}_{\mathrm{i}, \mathrm{j}}^{\mathrm{t}}\right.$ ) is highest when $\mathrm{j}=$ Sci. ${ }^{16}$

We can approach the interpretation of $\mathrm{E}\left(\mathrm{AGPA}_{\mathrm{i}, \mathrm{j}}^{\mathrm{t}}\right)$ more formally by considering a measure ABILITY $_{i, j}$ which represents the average GPA that a person would receive in major $\mathrm{j}$ if study effort were held constant across majors. Here we hold study effort constant at 3.0 hours per day, which is approximately the sample average at $\mathrm{t}=1$ across all students and all majors. Since the causal relationship between studying and grade performance in each major $\mathrm{j}$ is not observed in our data, it is necessary to make an assumption in order to construct E(ABILITY $\left.{ }_{i, j}^{t}\right)$, the mean of the distribution describing i's beliefs at time $t$ about ABILITY A $_{\mathrm{i},}$. We assume that the causal effect of studying is homogenous across both $\mathrm{i}$ and $\mathrm{j}$ and use the estimate of the causal effect of studying from Stinebrickner and Stinebrickner (2008b). ${ }^{17}$ Not surprisingly given Figure 5B, the message from the sample averages for E(ABILITY ${ }_{i, j}$ ) shown in Figure 5C is the same as the message from Figure 5A. Thus, our results support the notion that differences in $\mathrm{E}\left(\mathrm{AGPA}_{\mathrm{i}, \mathrm{j}}^{\mathrm{t}}\right)$ tend to largely represent differences that are not attributable to effort. Given the general similarities between $5 \mathrm{C}$ and $5 \mathrm{~A}$ and the reality that creating $5 \mathrm{C}$ requires assumptions about the causal effect of studying, in the remainder of the paper we choose to use $E\left(A_{G P A}^{t}{ }_{i, j}\right)$ rather than $E\left(A B I L I T Y_{i, j}^{t}\right)$ as our primary measure of beliefs about academic quality.

\section{Elements of $M_{i, j}$ : beliefs about future income associated with major $j$}

With respect to future income, our measure of interest is $\mathrm{AINCOME}_{\mathrm{i}, \mathrm{j}}$, which represents the average income a person would receive at age 28 if he had major $\mathrm{j}$. The mean of the distribution describing i's beliefs about AINCOME $E_{i, j}$, which we denote E(AINCOME $E_{i, j}$ ), comes from the third column of Question 1. Figure 5D shows large decreases in the sample average of $\mathrm{E}\left(\mathrm{AINCOME}_{\mathrm{i}, \mathrm{SCI}}^{\mathrm{t}}\right)$ over time. However, unlike what is seen in Figures 5A and 5C, the decreases for the other majors are similar in nature to those observed for Science.

\section{IV.B.2. $\mathrm{E}\left(\mathrm{M}_{\mathrm{i}}^{\mathrm{t}}\right)$ : Heterogeneity in beliefs about major-specific factors}

\footnotetext{
${ }^{16}$ Consistent with our notation for the GPA variable, ASTUDY As $_{\mathrm{j}}$ is a constant measuring the true average amount a person would study in the future in major $\mathrm{j}, \operatorname{ASTUDY}_{\mathrm{i}, \mathrm{j}}^{\mathrm{i}}$ is a random variable representing a person's beliefs about ASTUDY $\mathrm{i}_{\mathrm{i}, \mathrm{j}}$ at time $\mathrm{t}$, and $\mathrm{E}\left(\mathrm{ASTUDY}_{\mathrm{i}, \mathrm{j}}^{\mathrm{t}}\right)$ is the mean of the distribution describing beliefs.

${ }^{17}$ Informed by S\&S (2008b), which takes advantage of variation in study effort created by whether a student's roommate brought a video game to school, we assume that studying an extra hour per day increase a student's grade point average by .30 . Then, $\mathrm{E}\left(\right.$ ABILITY $\left._{\mathrm{i}, \mathrm{j}}^{\mathrm{t}}\right)=\mathrm{E}\left(\mathrm{AGPA}_{\mathrm{i}, \mathrm{j}}^{\mathrm{t}}\right)-.30 *\left[\mathrm{E}\left(\operatorname{ASTUDY}_{\mathrm{i}, \mathrm{j}}^{\mathrm{t}}\right)-3.0\right], \mathrm{t}=1, \ldots, 6$.
} 


\section{Differences across groups stratified on basis of the dependent variable}

That beliefs about certain factors in $\mathrm{M}_{\mathrm{i}}$ (e.g., $\mathrm{AGPA}_{\mathrm{i}, \mathrm{SCI}}$ and $\mathrm{ABILITY}_{\mathrm{i}, \mathrm{SCI}}$ ) become less positive over time for the sample as a whole suggests that these beliefs may have the potential to help explain the negative slopes of the Science lines in Figures 2A and 2B. To further investigate this potential we examine time patterns (across semesters) in beliefs about $\mathrm{M}_{\mathrm{i}}$ for three mutually exclusive and collectively exhaustive groups which have very different time patterns (across semesters) for the dependent variables in Figures 2A and 2B: those who started in Science and stayed in Science (Stay_Science), those who started in Science but did not stay in Science (Leave_Science), and those who started in a major other than Science (Start_Other). ${ }^{18}$ Given our findings in IV.B.1, we focus on our measures of academic performance and ability.

Intuitively speaking, a belief variable such as $\mathrm{E}\left(\mathrm{AGPA}_{\mathrm{i}, \mathrm{SCI}}^{\mathrm{t}}\right)$ will tend to be successful in explaining a dependent variable such as the perceived probability of Science from Figure 2B, $\operatorname{Pr}_{\mathrm{i}, \mathrm{SCI}}^{\mathrm{t}}$, if each of the three groups above has a time pattern for $\mathrm{E}\left(\mathrm{AGPA}_{\mathrm{i}, \mathrm{SCI}}^{\mathrm{t}}\right)$ that is similar to that group's time pattern for $\operatorname{Pr}_{\mathrm{i}, \mathrm{SCI}}^{\mathrm{t}}$. More specifically, as can be seen in Figure 6, which is obtained by recalculating the Science component of Figure 2B for each of the three groups, what is needed is that: 1 ) at $\mathrm{t}=1$ the average value of E $\left(\mathrm{AGPA}_{\mathrm{i}, \mathrm{SCI}}^{\mathrm{t}}\right)$ should be similar for the Leave_Science and Stay_Science groups and the average values for these groups should be substantially different than the average value for the Start_Other group; 2) by $\mathrm{t}=6$ the average value of E(AGPA $\left.{ }_{\mathrm{i}, \mathrm{SCI}}^{\mathrm{t}}\right)$ should be similar for the Leave_Science and Start_Other groups and the average values for these groups should be substantially different than the average values for the Stay_Science group.

Figure 7A, which shows the sample average of $\mathrm{E}\left(\mathrm{AGPA}_{\mathrm{i}, \mathrm{SCI}}^{\mathrm{t}}\right)$ from Figure 5A disaggregated into the three groups, suggests that $\mathrm{E}\left(\mathrm{AGPA}_{\mathrm{i}, \mathrm{SCI}}^{\mathrm{t}}\right)$ may be a particularly promising explanatory variable. At $\mathrm{t}=1$ the Stay_Science group has views about grade performance in Science that are substantially more positive than the Start_Other group and the gap between the two groups remains relatively constant across semesters. However, the sample average E(AGPA $\left.{ }_{i, S C I}^{t}\right)$ for the Leave_Science group changes dramatically over semesters. Students in this group begin college with beliefs that are very similar to the Stay_Science group, but by $\mathrm{t}=6$ have beliefs that are much more similar to the Start_Other group. ${ }^{19}$

\footnotetext{
${ }^{18}$ It would be desirable to separate the Start_Other group into a Stay_Other and Leave_Other group. However, this is not practical due to the very small number of students who change into Science (Figure 4A).

${ }^{19}$ For $\mathrm{t}=1$, we reject the null that the average $\mathrm{E}\left(\mathrm{AGPA}_{\mathrm{i}, \mathrm{SCI}}^{\mathrm{t}}\right)$ is the same for Stay_Science and Start_Other ( $\mathrm{t}$ statistic 10.071) and reject the null that the average E(AGPA $\left.{ }_{\mathrm{i}, \mathrm{SCI}}^{\mathrm{t}}\right)$ is the same for Leave_Science and Start_Other ( $\mathrm{t}$ statistic 11.379). We cannot reject the null hypothesis that the average E( $\left(\mathrm{AGPA}_{\mathrm{i}, \mathrm{SCI}}^{\mathrm{t}}\right)$ is the same for Stay_Science and Leave_Science ( $t$-statistic .607). For $t=6$, we reject the null that the average $E\left(\mathrm{AGPA}_{\mathrm{i}, \mathrm{SCI}}^{\mathrm{f}}\right)$ is the same for Stay_Science and Start_Other (t-statistic 11.387) and reject the null that the average E(AGPA $\left.{ }_{i, S C I}\right)$ is the same for Stay_Science and Leave_Science (t-statistic 5.41). A test of the null hypothesis that the average E(AGPA $\left.{ }_{\mathrm{i}, \mathrm{SCI}}^{\mathrm{t}}\right)$ is the
} 
The decision of whether to major in Science will depend on not only beliefs about grade performance in Science, but also beliefs about grade performance in the alternative majors. To construct an analog to Figure 7A which describes the beliefs of the three groups about grade performance in the alternative majors, we simplify by aggregating the alternative majors into a single Non-Science major (NON-SCI). To create E(AGPA $\left.{ }_{i, N O N-S C I}^{t}\right)$ for person $i$ at time $t$ we take a weighted average of E(AGPA $\left.{ }_{i, j}^{t}\right)$ across all $\mathrm{j} \neq \mathrm{SCI}$, where the weight associated with $\mathrm{j}$ is the student's reported probability that he will choose $\mathrm{j}$ conditional on $\mathrm{j} \neq \mathrm{SCI}{ }^{20}{ }^{20}$ Figure $7 \mathrm{~B}$ reveals no evidence of the types of patterns observed in Figure 6 ; the three groups start school with very similar views about $\mathrm{E}\left(\mathrm{AGPA}_{\mathrm{i}, \mathrm{NON}-\mathrm{SCI}}^{\mathrm{t}}\right)$ and the views of each group remain quite constant across semesters.

Figure 8A shows the sample averages of $\mathrm{E}\left(\mathrm{ASTUDY}_{\mathrm{i}, \mathrm{SCI}}^{\mathrm{t}}\right)$ for the three groups. The lines are quite similar, thereby indicating that the differences between the lines in Figure 7A reflect something closer to differences in ability than differences in effort. This point is made more formally in Figure 9A where the sample average of $\mathrm{E}\left(\mathrm{ABILITY}_{\mathrm{i}, \mathrm{SCI}}^{\mathrm{t}}\right)$ is found to have patterns for the three groups that are similar to the patterns seen in Figure 7A. Consistent with what was seen in Figure 7B, Figures 8B and 9B reveal relatively little difference in $\mathrm{E}\left(\mathrm{ASTUDY}_{\mathrm{i}, \mathrm{NON}-\mathrm{SCI}}^{\mathrm{t}}\right)$ and $\mathrm{E}\left(\mathrm{ABILITY}_{\mathrm{i}, \mathrm{NON}-\mathrm{SCI}}\right)$ across the three groups.

Thus, in terms of beliefs about grade performance/ability, differences between the groups exist primarily because of differences in beliefs about Science rather than differences in beliefs about the NonScience alternatives. At least in terms of what one learns about academic performance/ability, the evidence suggests that students are "pushed" rather than "pulled” out of Science.

\section{Heterogeneity within the Start_Other group}

Section IV.B.2 finds substantial heterogeneity in $\mathrm{E}\left(\mathrm{AGPA}_{\mathrm{i}, \mathrm{SCI}}^{\mathrm{t}}\right)$ across the three groups (Stay_Science, Leave_Science, and Start_Other) which were created by stratifying the sample on the basis of a person's starting and final majors. It is also worthwhile to understand how much heterogeneity exists within each of these groups. Given the relatively small number of students in the Leave_Science and Stay_Science groups, we focus on the Start_Other group.

Even though the sample average value of $E\left(\mathrm{AGPA}_{\mathrm{i}, \mathrm{SCI}}^{\mathrm{t}}\right)$ is seen in Figure 7A to be low in all periods for the Start_Other group, one might expect a subset of students in this group to have quite positive beliefs. Then, examining heterogeneity within the Start_Other group is useful, for example, for understanding why we found in Section III.C (Figure 4A) that very few students in this group change into the Science major.

same for Leave_Science and Start_Other has a t-statistic of 1.97.

${ }^{20}$ If the probabilities associated with the alternative majors are all zero for a particular t, we construct the weights using the probabilities from the most recent period in which the probabilities were not all zero. The variables $\mathrm{E}\left(\mathrm{AINCOME}_{\mathrm{i}, \mathrm{NON}-\mathrm{SCI}}^{\mathrm{t}}\right)$, E(ABILITY $\left.\mathrm{i}_{\mathrm{i}, \mathrm{NON}-\mathrm{SCI}}\right)$, E(ASTUDY $\left.{ }_{\mathrm{i}, \mathrm{NON}-\mathrm{SCI}}\right)$ are constructed in the same way. 
Students in this group can be exposed to some Science as part of the Liberal Arts curriculum at Berea, but are likely to predominantly choose elective courses outside of the Science area. Then, it is an empirical question whether, under these circumstances, a student can learn that he/she may be talented in Science. We examine the size of updates to $\mathrm{E}\left(\mathrm{AGPA}_{\mathrm{i}, \mathrm{SCI}}^{\mathrm{t}}\right)$, starting with changes that take place between the beginning of the first year $(\mathrm{t}=1)$ and the middle of the first year $(\mathrm{t}=2)$. The first entry in Column 1 of Table 1 shows that the sample average of $\mathrm{E}\left(\mathrm{AGPA}_{\mathrm{i}, \mathrm{SCI}}^{2}\right)-\mathrm{E}\left(\mathrm{AGPA}_{\mathrm{i}, \mathrm{SCI}}\right)$ is - .17 for the 486 individuals in the Start_Other group who reported legitimate values at both $\mathrm{t}=1$ and $\mathrm{t}=2$. Thus, students tend to revise beliefs about grade performance/ability in Science downwards when they are not focusing on Science. However, the standard deviation of the update in the sample is relatively large, .68, and the second entry of Column 1 of Table 1 shows that $28 \%$ of students in the Start_Other group have positive updates.

To understand why these positive updates do not lead to more changes into Science, we disaggregate further in Columns 2 and 3 of the first panel of Table 1 by stratifying on whether a person was in the bottom quartile (Column 2) or top three quartiles (Column 3 ) in terms of E(AGPA ${ }_{\mathrm{i}, \mathrm{SCI}}$ ). Columns 2 and 3 reveal that the positive updating tends to be concentrated to a large extent in the (former) group of students who had very low initial expectations. For example, the sample average value of $\mathrm{E}\left(\mathrm{AGPA}_{\mathrm{i}, \mathrm{SCI}}^{2}\right)-\mathrm{E}\left(\mathrm{AGPA}_{\mathrm{i}, \mathrm{SCI}}^{1}\right)$ is .30 for students in the bottom quartile and - .34 for students in the top three quartiles. Over half of students in the bottom quartile had positive updates while only .19 of students in the top three quartiles had positive updates. Thus, the positive updating tends to take place primarily within a group which is likely not close to the margin of choosing Science; even after the updating, students in the bottom quartile have a sample average value of $\mathrm{E}\left(\mathrm{AGPA}_{\mathrm{i}, \mathrm{SCI}}^{2}\right), 2.24$, which is almost a full point lower than this group's sample average value of $\mathrm{E}\left(\mathrm{AGPA}_{\mathrm{i}, \mathrm{NON}-\mathrm{SCI}}^{2}\right)$, 3.26. Columns 4-6 of the first panel of Table 1 show similar results when we examine updating between $t=1$ and $t=6$. For example, .66 of students in the bottom quartile in terms of $\mathrm{E}\left(\mathrm{AGPA}_{\mathrm{i}, \mathrm{SCI}}\right)$ have positive updates between $\mathrm{t}=1$ and $\mathrm{t}=6$, but only .17 of students in the top three quartiles have positive updates. The second panel of Table 1 shows results that are similar to those in the first panel when we examine $\left[\mathrm{E}\left(\mathrm{AGPA}_{\mathrm{i}, \mathrm{SCI}}^{2}\right)-\mathrm{E}\left(\mathrm{AGPA}_{\mathrm{i}, \mathrm{NON}-\mathrm{SCI}}\right)\right]-\left[\mathrm{E}\left(\mathrm{AGPA}_{\mathrm{i}, \mathrm{SCI}}\right)^{2}\right.$ $\left.\mathrm{E}\left(\mathrm{AGPA}_{\mathrm{i}, \mathrm{NON}-\mathrm{SCI}}^{1}\right)\right]$ and $\left[\mathrm{E}\left(\mathrm{AGPA}_{\mathrm{i}, \mathrm{SCI}}^{6}\right)-\mathrm{E}\left(\mathrm{AGPA}_{\mathrm{i}, \mathrm{NON}-\mathrm{SCI}}\right)\right]-\left[\mathrm{E}\left(\mathrm{AGPA}_{\mathrm{i}, \mathrm{SCI}}^{1}\right)-\mathrm{E}\left(\mathrm{AGPA}_{\mathrm{i}, \mathrm{NON}-\mathrm{SCI}}^{1}\right)\right.$, which represent what a person learns about his grade performance in Science relative to his grade performance in other disciplines. Thus, the evidence suggests that, while some students in the Start_Other group do have positive updates about grade performance, learning that a person is especially skilled in Science is quite rare when students are not focusing specifically on Science.

\section{IV.C. Quantifying the importance of learning about performance/ability and other factors}

The descriptive evidence in Section IV.B suggests that the elements of $\mathbf{M}_{\mathrm{i}}$, in particular the academic performance/ability measures related to Science, are likely to play an important role in 
determining whether a student chooses Science as his final major. In this Section we estimate models of college major choice. Our objective is to provide the first direct evidence about the quantitative importance that learning about major-specific academic performance/ability and other factors play in the decision to major in Science. Because, as described in Section IV.A our models are reduced form in nature, we leave aside certain fundamental questions about, for example, the strategy students take after entrance in an effort to find a major with a good match.

We estimate the parameters of equation (1) by taking advantage of the data in the first $(\mathrm{t}=1)$ and last $(\mathrm{t}=6)$ semesters in our data. While it would perhaps be possible to take advantage of data from all six periods, the simplifying focus on these two periods is natural because changes in beliefs about $\mathrm{M}_{\mathrm{i}}$ between these periods reflect the full degree of learning about $\mathrm{M}_{\mathrm{i}}$ during our sample period and because changes in $\operatorname{Pr}_{i, j}^{t}$ between these periods reflect the full extent to which uncertainty about major is resolved during our sample period. Unless otherwise stated, we focus on the 323 students in the composition-constant sample who have no missing information at either $\mathrm{t}=1$ or $\mathrm{t}=6$.

\section{IV.C.1. Estimation of Equation (1) using a dependent variable from $t=6$}

We begin by estimating model parameters using information about the dependent variable at $t=6$. In Section III we found that, by $t=6$, students are quite certain about their final major. As a result, we think of $\mathrm{t}=6$ as corresponding to $\mathrm{t}^{*}$. Then, as described in Section IV.A, the analysis at $\mathrm{t}=6$ follows the standard discrete choice framework in Equations (1)-(4) with the final major (i.e., the stated major at $t=6$ ) as the dependent variable. We specify $X_{i}=\left\{\right.$ MALE $_{\mathrm{i}}$, Math_ACT $\left.\mathrm{i}_{\mathrm{i}}, V_{\text {Verbal_ACT }}\right\}$ and $\mathrm{M}_{\mathrm{i}, \mathrm{j}}=\left\{\mathrm{AGPA}_{\mathrm{i}, \mathrm{j}}\right.$, $\left.\mathrm{AINCOME}_{\mathrm{i}, \mathrm{j}}\right\}$ so that $E\left(M^{t^{*}}{ }_{i, j}\right)=\left\{E\left(A_{G P A}^{6}{ }_{i, j}\right), E\left(A_{\text {INCOME }}^{6}{ }_{i, j}\right)\right\}$. Choosing $j=E D$ to be the base option, we normalize $\alpha_{\mathrm{ED}}=0$. Finally we assume that $\epsilon_{\mathrm{i}, \mathrm{j}}$ has an Extreme Value Type I distribution with a location parameter of zero and a scale parameter of one.

Estimates of $\alpha_{j}$ and $\beta$ are shown in Table 2. Consistent with what would be expected given the descriptive evidence in Section IV.B.2, the results show that, from both a statistical and quantitative standpoint, $\mathrm{AGPA}_{\mathrm{i}, \mathrm{j}}$ is an especially important determinant of whether a person chooses major $\mathrm{j}$. With respect to the former, the estimated effect and standard error of 3.22 and .27, respectively, imply a t-statistic of approximately twelve. With respect to the latter, the point estimate implies that a .50 increase in AGPA $_{i, j}$ in major $\mathrm{j}$ changes the odds ratio by a factor of $\mathrm{e}^{3.22 \times \cdot 50}=5.0$.

Computing predicted probabilities using the first column of Table 2 can provide a sense of the prominent role of learning about grade performance/ability in the major decision. The average predicted probability of choosing Science is .117 when we use the actual values of $E\left(\operatorname{AGPA}_{\mathrm{i}, \mathrm{j}}^{6}\right)$ for each $\mathrm{i}$ and $\mathrm{j}$. However, the average predicted probability increases by 68\% (to .197) under a counterfactual "no- 
learning” assumption that involves setting $E\left(\mathrm{AGPA}_{\mathrm{i}, \mathrm{j}}^{6}\right)$ equal to the initial value $\mathrm{E}\left(\mathrm{AGPA}_{\mathrm{i}, \mathrm{j}}{ }\right)$ for all $\mathrm{i}$ and $\mathrm{j}^{21}$

While the results point to $\mathrm{AGPA}_{\mathrm{i}, \mathrm{j}}$ playing a particularly prominent role, consistent with the results of Arcidiacono et. al (2010) we also find evidence that, from both a statistical and quantitative standpoint, AINCOME $_{\mathrm{i}, \mathrm{j}}$ is also an important determinant of major choice. With respect to the former, the estimated effect and standard error of .056 and .008, respectively, imply a t-statistic in excess of six. With respect to the latter, the point estimate implies that a $\$ 5,000$ increase in $\mathrm{AINCOME}_{\mathrm{i}, \mathrm{j}}$ in major $\mathrm{j}$ changes the odds ratio by a factor of $\mathrm{e}^{.056 \times 5}=1.32$. The average predicted probability of choosing Science increases by $21 \%$ (from .117 to .142) under the counterfactual “no-learning” assumption that $E\left(\operatorname{AINCOME}_{\mathrm{i}, \mathrm{j}}^{6}\right)=\mathrm{E}\left(\mathrm{AINCOME}_{\mathrm{i}, \mathrm{j}}^{1}\right)$ for all $\mathrm{i}$ and $\mathrm{j}$.

Given our particular interest in Science, a desirable simplification for much of the analysis that follows involves, as in Figures 7B-10B, collapsing the set of alternative majors into a single non-Science major. In this case, the choice set becomes $\{\mathrm{SCI}, \mathrm{NON}-\mathrm{SCI}\}$ with NON-SCI as the base case (so that $\alpha_{\mathrm{NON}-\mathrm{SCI}}$ is normalized to 0 ). We find that this binary specification yields results that are very similar to those in the uncollapsed specification. The first two columns of Table 2 show that the coefficients associated with $\mathrm{AGPA}_{\mathrm{i}, \mathrm{j}}$ and $\mathrm{AINCOME}_{\mathrm{i}, \mathrm{j}}$ remain similar in size (2.65 vs. 3.22 and .048 vs. .056) and both remain statistically significant (t-statistics of 4.85 and 3.31 respectively). Our results quantifying the importance of learning also produce similar results. The average predicted probability of choosing Science increases by 58\% (from .117 to .185) under the counterfactual "no-learning” assumption that $E\left(A_{G P A}{ }_{i, j}\right)=E\left(A A_{i, j}^{1}\right)$ for all $i$ and both $j$, and the average predicted probability of choosing Science increases by $23 \%$ (from .117 to .144) under the counterfactual "no-learning” assumption that $\mathrm{E}\left(\operatorname{AINCOME}_{\mathrm{i}, \mathrm{j}}^{6}\right)=\mathrm{E}\left(\operatorname{AINCOME}_{\mathrm{i}, \mathrm{j}}^{1}\right)$ for all $\mathrm{i}$ and both $\mathrm{j}$.

\section{IV.C.2. Estimation of Equation (1) using a dependent variable from $t=1$}

We can also estimate the model parameters using information about the dependent variable from $\mathrm{t}=1$. In Section III we found that, at $\mathrm{t}=1$, much uncertainty tends to exist about a student's final major. Then, as discussed in Section IV.A, the analysis at $t=1$ follows the framework in equations (5) and (6) with $\operatorname{Pr}^{1}{ }_{i, j}$ as the dependent variable. Given our finding that the model with the binary choice set \{SCI, NON-SCI\} provides conclusions about the choice of Science that are similar to those obtained with the full choice set, we focus on the binary model here.

The key difference between the $t=1$ analysis and the $t=6$ analysis is that Equations (5) and (6) require knowledge of $G$, the distribution of the random variable $E\left(\mathrm{M}^{\mathrm{t}^{*}}\right)^{1}$ representing i's beliefs at $\mathrm{t}=1$ about

\footnotetext{
${ }^{21}$ The use of the term "no-learning" is a misnomer to the extent that the variance of the belief distribution may also have changed from $\mathrm{t}=1$ to $\mathrm{t}=6$ and our approach does not attempt to hold this constant.

For this sample, the average perceived probability is .118 at $\mathrm{t}=1$ and .182 at $\mathrm{t}=6$.
} 


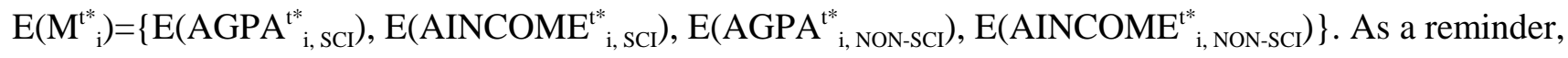
$\mathrm{E}\left(\mathrm{M}^{\mathrm{t}^{*}}{ }_{\mathrm{i}}\right)$ is observed directly in our data at $\mathrm{t}^{*}$. However, what is needed here is, $\mathrm{E}\left(\mathrm{M}^{\mathrm{t}^{*}}{ }_{\mathrm{i}}\right)^{1}$, person i's beliefs at time $\mathrm{t}=1$ about what $\mathrm{E}\left(\mathrm{M}^{\mathrm{t}^{*}}\right)$ will turn out to be. Because the distribution describing these beliefs, $\mathrm{G}$, is not elicited directly by a single survey question, we must construct it from several sources of information in the BPS. Here we provide an outline of our approach, leaving a detailed description for Appendix B.

For the sake of illustration, we focus here on the construction of beliefs at $t=1$ about E(AGPA $\left.{ }^{t^{*}, \mathrm{SCI}}\right)$. Our construction is built on the notion that the ultimate value of $\mathrm{E}\left(\mathrm{AGPA}^{\mathrm{t}^{*}, \mathrm{SCI}}\right)$ is determined by an updating process that occurs as a person proceeds through school. In the spirit of Bayesian updating we specify an updating rule in which the updated mean $\mathrm{E}\left(\mathrm{AGPA}^{\mathrm{t}^{*} \text {, SCI }}\right)$ depends on the initial mean $\mathrm{E}\left(\mathrm{AGPA}_{\mathrm{i}, \mathrm{SCI}}\right)$ and a noisy signal of the person's academic performance. Equation (7) suggests that grade performance between $t=1$ and $t^{*}$ is an appropriate noisy signal and we refer to this grade performance as GPA_Early $_{\mathrm{i}}$. Since E(AGPA $\left.{ }^{\mathrm{t}^{*}, \mathrm{sCI}}\right)$ and E(AGPA $\left.{ }_{\mathrm{i}, \mathrm{SCI}}\right)$ are observed in our survey data and GPA_Early is observed in administrative data, the unknown parameters of the updating rule can be estimated. Given student i's starting point $\mathrm{E}\left(\mathrm{AGPA}_{\mathrm{i}, \mathrm{SCI}}\right)^{1}$, the estimated updating rule tells student $\mathrm{i}$ what $\mathrm{E}\left(\mathrm{AGPA}^{\mathrm{t}^{*}}{ }_{\mathrm{i}, \mathrm{SCI}}\right)$ will be for each realized value of GPA_Early ${ }_{\mathrm{i}}$. Then, the distribution G describing i's beliefs about

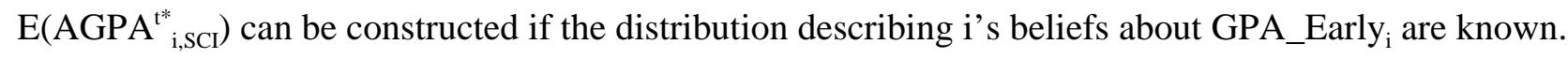
Under the assumption (discussed in more detail in Appendix B) that, at the time of entrance, students believe that they will settle on a college major rather quickly, the belief distribution of GPA_Early ${ }_{\mathrm{i}}$ is obtained directly from Question 2 (Appendix) which asks about grade performance in the early portion of college. As described in Appendix B, we take a similar approach for constructing the distribution describing beliefs at $\mathrm{t}=1$ about the other elements of $\mathrm{E}\left(\mathrm{M}^{\mathrm{t}^{*}}\right)$.

With the binary choice set, the second line in equation (6) becomes (9) $\left.\operatorname{Prob}\left\{\epsilon_{\mathrm{i}}: \int 1\left(\alpha_{\mathrm{SCI}} \mathrm{X}_{\mathrm{i}}+\beta\left[\mathrm{E}\left(\mathrm{M}^{\mathrm{t}^{*}, \mathrm{SCI}}\right)^{1-E}\left(\mathrm{M}^{\mathrm{t}^{*}}{ }_{\mathrm{i}, \mathrm{NON}-\mathrm{SCI}}\right)^{1}\right]+\epsilon_{\mathrm{i}, \mathrm{SCI}}-\epsilon_{\mathrm{i}, \mathrm{NON}-\mathrm{SCI}}>0\right) \mathrm{g}\left(\mathrm{E}\left(\mathrm{M}^{\mathrm{t}^{*}}{ }_{\mathrm{i}}\right)^{1}\right) \mathrm{dE}\left(\mathrm{M}^{\mathrm{t}^{*}}\right)^{1}\right)^{1} \operatorname{Pr}_{\mathrm{i}, \mathrm{j}}\right\}$. This integral will be strictly increasing in $\epsilon_{\mathrm{i}, \mathrm{diff}}=\epsilon_{\mathrm{i}, \mathrm{SCI}}-\epsilon_{\mathrm{i}, \mathrm{NON}-\mathrm{SCI}}$ over the range $(0,1)$ so that, for any value of $\operatorname{Pr}_{i, S C I}^{1} \in(0,1)$, there will exist a unique value of $\epsilon_{i, \text { diff }}$ such that the condition in equation (9) is satisfied. The likelihood contribution for person i from equation (6) is the density h of $\epsilon_{\mathrm{i} \text {,diff }}$ evaluated at this unique value. For example, with $\epsilon_{\mathrm{i}, \mathrm{SCI}}$ and $\epsilon_{\mathrm{i}, \mathrm{NON}-\mathrm{SCI}}$ having independent Extreme Value distributions, $\mathrm{h}$ is a Logit density function. The model can then be estimated by maximum likelihood. ${ }^{22}$

In practice, we modify the $t=1$ model slightly to relax the assumption that the student faces no

\footnotetext{
${ }^{22}$ In practice, we assign a value of .99 if $\operatorname{Pr}^{1}{ }_{i, S C I}=1.0$ and assign a value of .01 if $\operatorname{Pr}^{1}{ }_{\mathrm{i}, \mathrm{SCI}}=0.0$, in essence assuming that a small amount of measurement error exists at the two extremes. We find that results do not change substantially when we use .95 and .05 instead. The non-MLE approach in Blass et al. (2010) does not require this type of adjustment of reported probabilities.
} 
uncertainty about factors other than those included explicitly in $\mathrm{M}_{\mathrm{i}}$. We assume at $\mathrm{t}=1$ that $\epsilon_{\mathrm{i} \text {,diff }}=\epsilon_{\mathrm{i} \text {,diff }}{ }^{*}+\mathrm{v}$, where $\epsilon_{\mathrm{i}, \mathrm{diff}}{ }^{*}$ follows the standard assumption of being known to the student but not by the econometrician and $v$ represents factors which are not known to the student or econometrician at time $t$ but whose value will be realized by the student by $t^{*}$ (i.e., uncertainty about $v$ will be resolved by the time the final decision is made at $\mathrm{t}^{*}$ ). The $\mathrm{t}=1$ model is discussed in more detail in Appendix B. Here we note two things. First, from an operational standpoint, the presence of the $v$ component introduces an additional integral into the student computation in equation (9). Second, in this model the variance of $\epsilon_{\mathrm{i} \text {,diff }}{ }^{*}$ can be identified subject to a normalization of the variance of $v$.

Results are shown in the third column of Table 2 . As with the $t=6$ case, we find that a student's academic performance $\mathrm{AGPA}_{\mathrm{i}, \mathrm{j}}$ is statistically significant at all traditional levels (t-statistic= 11.97). ${ }^{23}$ In Section IV.C.1, the estimates from our $\mathrm{t}=6$ analysis indicated a prominent role of learning about grade performance/ability in the major decision. Here we reexamine the role of learning using our estimates from Column 3. Specifically, we first compute predicted reported probabilities at $t=1$ using the actual values of E(AGPA ${ }_{i, j}$ ) for each $i$ and $j$. We then examine how different predicted reported probabilities would have been at $t=1$ if students had started school with their final beliefs by setting $E\left(A_{G P A}{ }_{i, j}\right)$ equal to the final value $E\left(A_{G P A}^{6}{ }_{i, j}\right)$ for each $i$ and $j$. In each case we assume that students do not anticipate resolving any uncertainty about $\mathrm{E}\left(\mathrm{AGPA}^{\mathrm{t}^{*}}{ }_{\mathrm{i}, \mathrm{j}}\right)$ after $\mathrm{t}=1 .^{24}$ We again find that learning about ability is important in determining a student's major; the average predicted probability of choosing Science is $27 \%$ higher (.178 versus .140) in the former scenario than in the latter scenario.

There are several plausible explanations for why the importance of learning about grade performance is found to be somewhat different in this section (basing estimation on a dependent variable from $t=1$ ) than in Section IV.C.1 (basing estimation on a dependent variable from $t=6$ ). In addition to the conceptual exercise being somewhat different, it could be the case that students' views/preferences about the importance of grade performance change over time during school or it could be the case that the assumptions needed to construct beliefs at $\mathrm{t}=1$ about $\mathrm{E}\left(\mathrm{M}^{\mathrm{t}^{*}}{ }_{\mathrm{i}}\right)$ in this section are somewhat problematic. Regardless, given that our project should be viewed as an in-depth case study, the consistency (across time periods and specifications) of the finding that learning about academic performance plays a crucial role in the final choice of major is more important than quantifying the exact size of the effect.

\footnotetext{
${ }^{23}$ One cannot directly compare the coefficients across columns in Table 2 because the estimated variance of the $\epsilon_{\mathrm{i} \text {,diff }} *$ in column 3 is not the same as the normalized variance (that accompanies the extreme value assumption) in the other columns.

${ }^{24}$ That is, in the first scenario the student assumes that $E\left(\operatorname{AGPA}^{t^{*}}{ }_{i, j}\right)$ will be equal to $E\left(\operatorname{AGPA}^{1}{ }_{i, j}\right)$. In the second scenario the student assumes that $E\left(\mathrm{AGPA}^{t^{*}, \mathrm{j}}\right)$ will be equal to $\mathrm{E}\left(\mathrm{AGPA}_{\mathrm{i}, \mathrm{j}}\right)$
} 


\section{IV.C.3. A specification with changes in beliefs between $t=1$ and $t=6$}

Sections IV.C.1 and IV.C.2 identify the importance of learning by estimating models in which it is a person's beliefs about $\mathrm{M}_{\mathrm{i}, \mathrm{j}}$ at a given time $\mathrm{t}$ that enters the specification, and then comparing the predicted probabilities associated with these actual beliefs at $\mathrm{t}$ with predicted probabilities associated with beliefs at $\mathrm{t}$ that represent a non-learning counterfactual. Here we examine the robustness of our primary conclusion that learning about grade performance/ability plays a prominent role in the choice of Science - to a specification in which the amount that a person learns about $\mathrm{M}_{\mathrm{i}, \mathrm{j}}$ during school enters the specification directly.

From the standpoint of specifying a model in which changes in beliefs about $\mathrm{M}_{\mathrm{i}}$ enter directly, the central conceptual question is whether the change in beliefs is sufficient to push the student into Science (or push the student out of Science) given how close to the margin of indifference he was at the time of entrance. Then, focusing on the binary outcome variable that takes a value of one if a person's final major is Science, we estimate a logit model including as explanatory variables both measures of how much a student has learned during school (i.e., [E(AGPA $\left.\left.{ }_{i, S C I}^{6}\right)-E\left(\mathrm{AGPA}_{\mathrm{i}, \mathrm{NON}-\mathrm{SCI}}^{6}\right)\right]-\left[\mathrm{E}\left(\mathrm{AGPA}_{\mathrm{i}, \mathrm{SCI}}^{1}\right)\right.$ $\left.\mathrm{E}\left(\mathrm{AGPA}_{\mathrm{i}, \mathrm{NON}-\mathrm{SCI}}\right)\right]$ and $\left[\mathrm{E}\left(\mathrm{INCOME}_{\mathrm{i}, \mathrm{SCI}}^{6}\right)-\mathrm{E}\left(\mathrm{INCOME}_{\mathrm{i}, \mathrm{NON}-\mathrm{SCI}}^{6}\right)\right]-\left[\mathrm{E}\left(\mathrm{AINCOME}_{\mathrm{i}, \mathrm{SCI}}^{1}\right)-\right.$ $\left.\mathrm{E}\left(\mathrm{AINCOME}_{\mathrm{i}, \mathrm{NON}-\mathrm{SCI}}^{1}\right)\right]$ ) and measures related to how close to the margin a student was at the time of

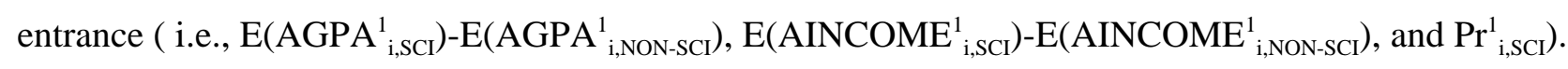

As shown in Table 3, we find that the amount that a person learns has a statistically important effect on whether he becomes a Science major; the estimate (std. error) for $\left[E\left(\mathrm{AGPA}_{\mathrm{i}, \mathrm{SCI}}^{6}\right)-\mathrm{E}\left(\mathrm{AGPA}_{\mathrm{i}, \mathrm{NON} \text {-SCI }}^{6}\right)\right.$ - $^{6}$ [E(AGPA $\left.\left.{ }_{\mathrm{i}, \mathrm{SCI}}^{1}\right)-\mathrm{E}\left(\mathrm{AGPA}_{\mathrm{i}, \mathrm{NON}-\mathrm{SCI}}\right)\right]$ is 2.410 (.687). Consistent with our earlier findings, we find that the effect of learning is quantitatively important; the average predicted probability of choosing Science increases by $54 \%$ (from .117 to .181) under the counterfactual assumption that no learning takes place about academic performance (i.e., setting [E(AGPA $\left.\left.{ }_{i, S C I}^{6}\right)-E\left(A_{G P A}{ }_{i, N O N-S C I}\right)\right]-\left[E\left(A_{G P A}{ }_{i, S C I}\right)-\right.$ $\left.\mathrm{E}\left(\mathrm{AGPA}_{\mathrm{i}, \mathrm{NON}-\mathrm{SCI}}\right)\right]=0$ for all students.

\section{IV.C.4 Discussion of Potential Omitted Variables}

Given the parsimonious specification for $\mathrm{M}_{\mathrm{i}}$, it is natural to consider the issue of omitted variables that might be correlated with AGPA $_{\mathrm{i}, \mathrm{j}}$. Perhaps most obvious in this respect is a student's interest level in major j. Figures 5E, 11A, and 11B show sample average values of INTEREST $\mathrm{t}_{\mathrm{t}, \mathrm{j}, \mathrm{j}}$, 's current interest in major $\mathrm{j}$ at time $\mathrm{t}$ as elicited in the last column of Question $1 .{ }^{25}$ In terms of descriptive statistics of interest, there are a couple of obvious things to note. First, Figure 5E shows that there is non-trivial interest in

\footnotetext{
${ }^{25}$ We use somewhat different notation for the Interest variable than for the other variables to reflect that the elicited information about Interest at time t reflects a student's current level of interest at time $t$ while the elicited information about other variables reflects a belief at time t about a constant true value.
} 
Science at entrance, with Science being the median major in terms of sample average interest at $\mathrm{t}=1$.

Second, a comparison of, for example, Figure 11A to Figure 7A suggests that there is a strong relationship between a student's current interest in a topic and his beliefs about grade performance. This is confirmed in more formal tests. For example, the sample correlation between $\mathrm{E}\left(\mathrm{AGPA}_{\mathrm{i}, \mathrm{SCI}}^{\mathrm{t}}\right)$ and INTEREST $\mathrm{t}_{\mathrm{i}, \mathrm{SCI}}$ is .543 at $\mathrm{t}=1$ and .484 at $\mathrm{t}=6$ and the sample correlation between $\left[\mathrm{E}\left(\mathrm{AGPA}_{\mathrm{i}, \mathrm{Sci}}^{6}\right)-\mathrm{E}\left(\mathrm{AGPA}_{\mathrm{i}, \mathrm{Sc}}\right)\right.$ ] and [INTEREST $_{6, \mathrm{i}, \mathrm{Sci}}-$ INTEREST $\left._{1, \mathrm{i}, \mathrm{Sci}}\right]_{\text {is } .340 .{ }^{26}}$

Unfortunately, the fact that the survey questions elicits a student's current interest in major j creates a potential endogeneity concern because current interest in a major $\mathrm{j}$ is likely to be affected by how many classes a person has taken in $\mathrm{j}$ in the past. This concern would imply that a student's major decision may influence his current interest level when what we wish to identify is the reverse. ${ }^{27}$ As a result, it does not

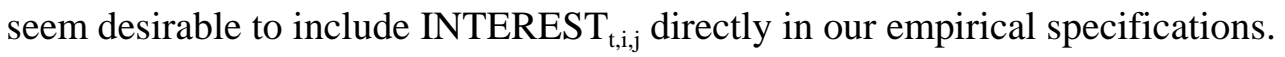

Given that INTEREST ${ }_{\mathrm{t}, \mathrm{i}, \mathrm{j}}$ is not included, whether the estimated effect that $\mathrm{AGPA}_{\mathrm{i}, \mathrm{j}}$ has on major choice should be viewed as a causal effect depends on the relevance of the various underlying reasons for the correlation found between E(AGPA ${ }_{\mathrm{i}, \mathrm{j}}^{\mathrm{j}}$ )and $\operatorname{INTEREST}_{\mathrm{t}, \mathrm{i}, \mathrm{j}}$. The most obvious potential reason for the correlation is that AGPA may have a direct influence on INTEREST. For example, it seems likely that students who have a difficult time understanding course material in a particular major may have difficulty appreciating the subject matter or find studying unenjoyable/stressful. However, excluding INTEREST from our specification is not problematic in this scenario given our interest in identifying the total causal effect of $\mathrm{AGPA}_{\mathrm{i}, \mathrm{j}}$ - the correlation simply identifies one avenue through which the total causal effect of $\mathrm{AGPA}_{\mathrm{i}, \mathrm{j}}$ may arise.

Problematic scenarios are ones in which the correlation between $\operatorname{INTEREST}_{t, \mathrm{i}, \mathrm{j}}$ and $\mathrm{E}\left(\mathrm{AGPA}_{\mathrm{i}, \mathrm{j}}^{\mathrm{t}}\right)$ is present for other reasons. The most obvious possibility is that a lack of interest in a major such as Science could cause a person to believe he will perform poorly in the major. However, because it seems reasonable to believe that study effort is the most likely avenue through which a lower interest in major $\mathrm{j}$ would affect $\mathrm{E}\left(\mathrm{AGPA}_{\mathrm{i}, \mathrm{j}}^{\mathrm{t}}\right)$, this possibility can be examined directly. We find no evidence of a relationship between INTEREST $_{\mathrm{t}, \mathrm{i}, \mathrm{Sci}}$ and E(ASTUDY $\left.\mathrm{i}_{\mathrm{i}, \mathrm{Sci}}\right)$ or a relationship between changes in INTEREST $_{\mathrm{t}, \mathrm{i}, \mathrm{Sci}}$ and changes in

\footnotetext{
${ }^{26}$ At all traditional significance levels, we reject the null hypothesis of a zero population correlation in all three cases.

${ }^{27}$ The endogeneity concern would also suggest that some portion of the change in INTEREST $\mathrm{t}_{\mathrm{t}, \mathrm{j}, \mathrm{int}}$ that is observed across semesters might have been anticipated by a student who realizes that interest will tend to increase as he receives exposure to $\mathrm{j}$. This would be problematic given our desire to understand the role that learning per se plays in the major decision.
} 
$\mathrm{E}\left(\mathrm{ASTUDY}_{\mathrm{i}, \mathrm{Sci}}^{\mathrm{t}}\right) .^{28}$ In addition, we can approach this issue more formally by estimating the choice models using ABILITY ${ }_{i, j}$ instead of APGA $A_{i, j}$. Despite the fact that the ability measure likely suffers from substantial measurement error (due, in part, from the necessity of making assumptions about the effect of studying), we continue to find a significant effect. For example, when ABILITY ${ }_{i, j}$ replaces APGA $_{i, j}$ in Column 1 of Table 2, a test of the null hypothesis that ABILITY $_{\mathrm{i}, \mathrm{j}}$ has no effect is rejected with a t-statistic of $5.80 .{ }^{29}$

\section{Conclusion}

We find that students enter college as open to a major in math or science as to any other major, but that a large number of students move away from math and science after realizing that their grade performance will be substantially lower than expected. Further, our results indicate that changes in beliefs about grade performance arise because students realize that their ability in math/science is lower than expected rather than because students realize that they are not willing to put the required effort into math or science majors. Our measure of ability likely captures a variety of factors related to a student's propensity at the time of college entrance to understand math or science, including not only his innate intelligence but also his background preparation. As such, the findings suggest the potential importance of policies at younger ages which lead students to enter college better prepared to study math or science.

${ }^{28}$ For the composition-constant sample, the sample correlation between E(ASTUDY ${ }_{\mathrm{i}, \text { sCI }}^{\mathrm{i}}$ ) and INTEREST $_{\mathrm{t}, \mathrm{SSCI}}$ is .052 at $\mathrm{t}=1$ and .075 at $\mathrm{t}=6$ and the sample correlation between [E(ASTUDY ${ }_{\mathrm{i}, \mathrm{Sc}}$ )- $^{-}$ E(ASTUDY $\left.{ }_{i, S c i}\right)$ ] and [INTEREST ${ }_{6, i, S c i}-$ INTEREST $\left._{1, i, S c i}\right]_{\text {in }} .074$. The p-values associated with the three estimates are .346, .176, and .185, respectively.

\footnotetext{
${ }^{29}$ Another potentially problematic scenario is one in which the correlation between E(AGPA ${ }_{\mathrm{i}, \mathrm{sc}}^{\mathrm{t}}$ ) and INTEREST $_{\mathrm{t}, \mathrm{S}, \mathrm{Sci}}$ exists because each is influenced by a common third factor. Seemingly the most logical common factor of this type is a background factor such as whether a person's parents work in a Science occupation. However, if such background factors are the primary factor driving the correlation, one would expect students with much higher levels of interest in Science at $t=1$ to continue to have much higher levels of interest in Science at $t=6$ (than students with lower levels of interest at $t=1$ ) even if they learn that their grade performance/ability in Science is lower than expected. Figure 11A shows that much of the difference in INTEREST $\mathrm{I}_{\mathrm{t}, \mathrm{SCI}}$ for the Leave_Science and Start_Other groups disappears after the former group realizes that their grade performance will not be particularly high. Given that some differences in INTEREST ${ }_{\mathrm{t}, \mathrm{iSCl}}$ between the two groups would be expected to persist because the Leave_Science group has received more exposure to Science than the Start_Other group, Figure 11A does not seem to provide much evidence in support of this common background factor story.
} 


\section{References}

Altonji, Joseph. "The Demand for and Return to Education When Education Outcomes are Uncertain," Journal of Labor Economics, 1993, vol. 11, no. 1, 48-83.

Arcidiacono, Peter. “Ability Sorting and the Returns to College Major,” Journal of Econometrics, Vol. 121, Nos. 1-2 (August, 2004), 343-375.

Arcidiacono, Peter, Hotz, Joseph, and Kang, Songman, "Modeling College Major Choices using Elicited Measures of Expectations and Counterfactuals,” Duke University working paper, 2010.

Barsky, Robert, Kimball, Miles, Juster, F. Thomas, and Shapiro, Matthew. "Preference Parameters and Behavioral Heterogeneity: An Experimental Approach in the Health and Retirement Survey,” The Quarterly Journal of Economics, May 1997, 537-579.

Beffy, Magali, Fougere, Denis, Maurel, Arnaud, "Choosing the Field of Study in Post-Secondary Education: Do Expected Earnings Matter?” The Review of Economics and Statistics, Forthcoming.

Black, Dan and Jeffrey Smith, Evaluating the Returns to College Quality with Multiple Proxies for Quality.” Journal of Labor Economics 24(30: 701-728.

Blass, Asher, Lach, Saul, and Manski, Charles. "Using Elicited Choice Probabilities to Estimate Random Utility Models: Preferences for Electricity Reliability,” International Economic Review, 2010.

Carneiro, Pedro, Hansen, Karsten, and Heckman, James, “Estimating Distributions of Counterfactuals with an Application to the Returns to Schooling and Measurement of the Effect of Uncertainty on Schooling Choice,” International Economic Review, 2005.

Cunha, Flavio, Heckman, James, and Navarro, Salvador, "Separating Uncertainty from Heterogeneity in Life Cycle Earnings,” Oxford Economic Papers, 2005, 57(2), 191-261.

COSEPUP (Committee on Science, Engineering, and Public Policy), "Rising Above the Gathering Storm: Energizing and Employing America for a Brighter Economic Future.” The National Academies Press (2007).

Dominitz, Jeff. “Earnings Expectations, Revisions, and Realizations,” The Review of Economics and Statistics, August 1998, 374-388.

Dominitz, Jeff and Manski, Charles. "Eliciting Student Expectations of the Returns to Schooling," Winter 1996, 1-26.

Dominitz, Jeff and Manski, Charles. "Using Expectations Data to Study Subjective Income Expectations,” Journal of American Statistical Association, September 1997, 855-867.

Dominitz, Jeff and Manski, Charles. "How Should We Measure Consumer Confidence (sentiment)? Evidence form the Michigan Survey of Consumers,” Working paper 9926, National Bureau of Research, 2003.

Juster, T., “Consumer Buying Intentions and Purchase Probability: An Experiment in Survey Design,” 
Journal of the American Statistical Association 61 (1966), 658-96.

Manski, Charles, "Schooling as Experimentation: a reappraisal of the post-secondary drop-out phenomenon,” Economics of Education Review, Volume 8 number 4, 1989, 305-312.

Manski, C., "The Use of Intentions Data to Predict Behavior: A Best Case Analysis,” Journal of the American Statistical Association 85 (1990), 934-940.

Manski, C., “Measuring Expectations,” Econometrica, 72 (5), (2004), 1329-1376.

Montmarquette, C, Cannings, Kathy, and Mahseredjian, Sophie, "How Do Young People Choose College Majors?,” Economics of Education Review, Elsevier, 21(6), (2002) 543-556, December.

Smith, Jeffrey, "Heterogeneity and Higher Education," in Michael McPherson and Morton Owen Schapiro (eds.) Succeeding in College: What it Means and How to Make it Happen. New York: College Board, 131-144.

Stinebrickner, Todd and Stinebrickner, Ralph, “Time-Use and College Outcomes,” Journal of Econometrics, 121 (1-2) July-August (2004), 243-269.

Stinebrickner, Todd and Stinebrickner, Ralph, "The Effect of Credit Constraints on the College DropOut Decision: A Direct Approach Using a New Panel Study,” American Economic Review. December (2008a)

Stinebrickner, Todd and Stinebrickner, Ralph, "The Causal Effect of Studying on Academic Performance,” Frontiers in Economic Policy and Analysis (Frontiers), Berkeley Electronic Press (2008b).

Stinebrickner, Todd and Stinebrickner, Ralph, "Learning about Academic Ability and the College Drop-Out Decision” (2009).

Zafar, Basit, “College Major Choice and the Gender Gap,” working paper (2008)

Zafar, Basit, “How Do College Students Form Expectations?” Journal of Labor Economics, Forthcoming. 
Table 1 Descriptive statistics

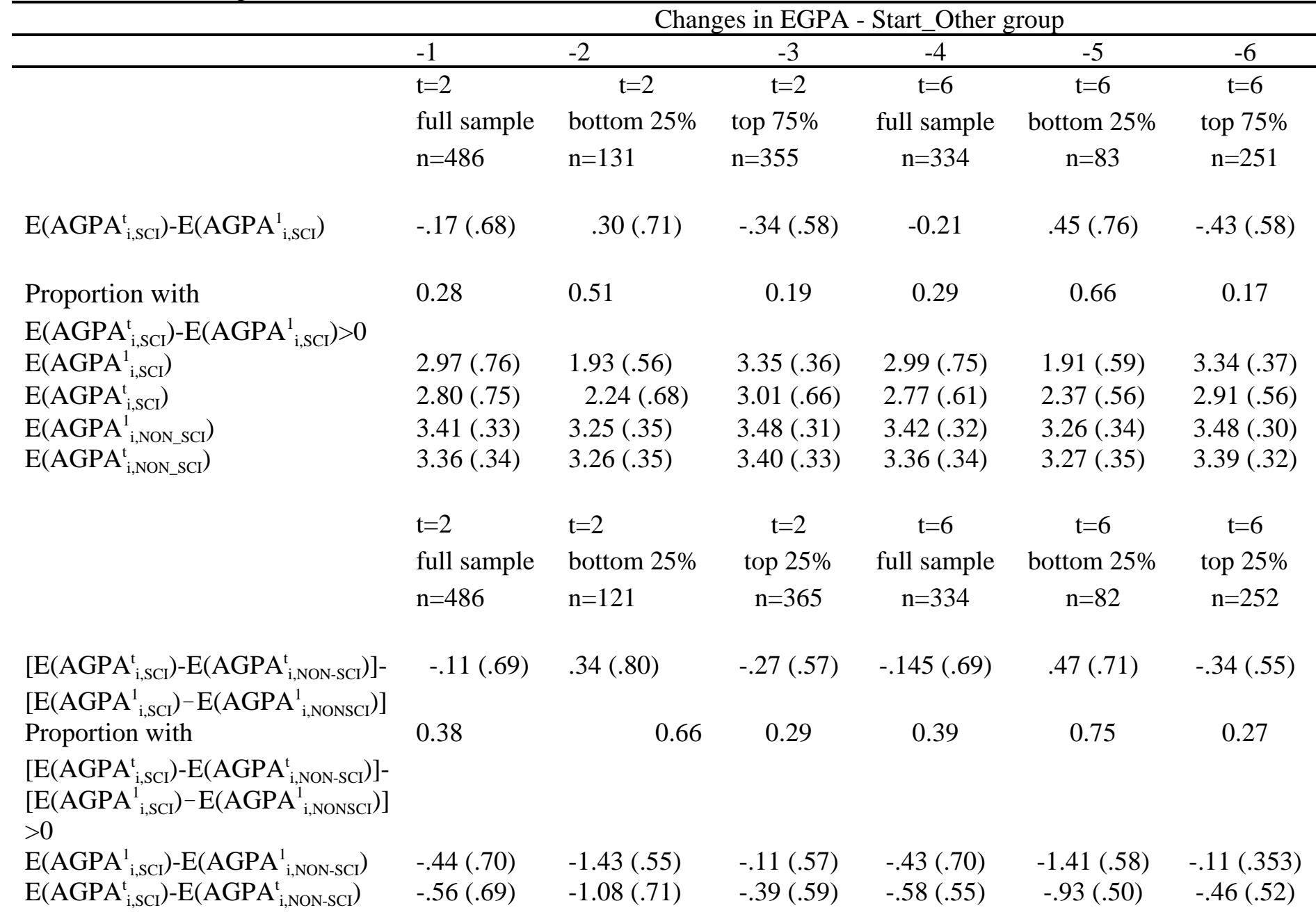

Notes: The descriptive statistics in the Table show mean (standard deviation).

In first panel: Bottom $25 \%$ refers to students with $\mathrm{E}\left(\mathrm{AGPA}_{\mathrm{i}, \mathrm{SCI}}\right) \leq 2.5$ and Top $75 \%$ refers to students with

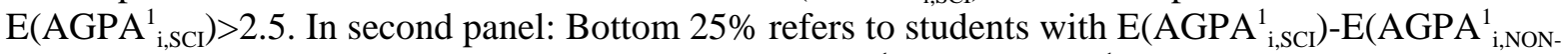
sCI $) \leq-.795$ and Top $75 \%$ refers to students with $\mathrm{E}\left(\mathrm{AGPA}_{\mathrm{i}, \mathrm{SCI}}{ }\right)-\mathrm{E}\left(\mathrm{AGPA}_{\mathrm{i}, \mathrm{NON}-\mathrm{SCI}}\right)>-.795$. 
Table 2 Estimates of models of major choice from IV.C.1 $(\mathrm{t}=6)$ and IV.C.2 $(\mathrm{t}=1)$

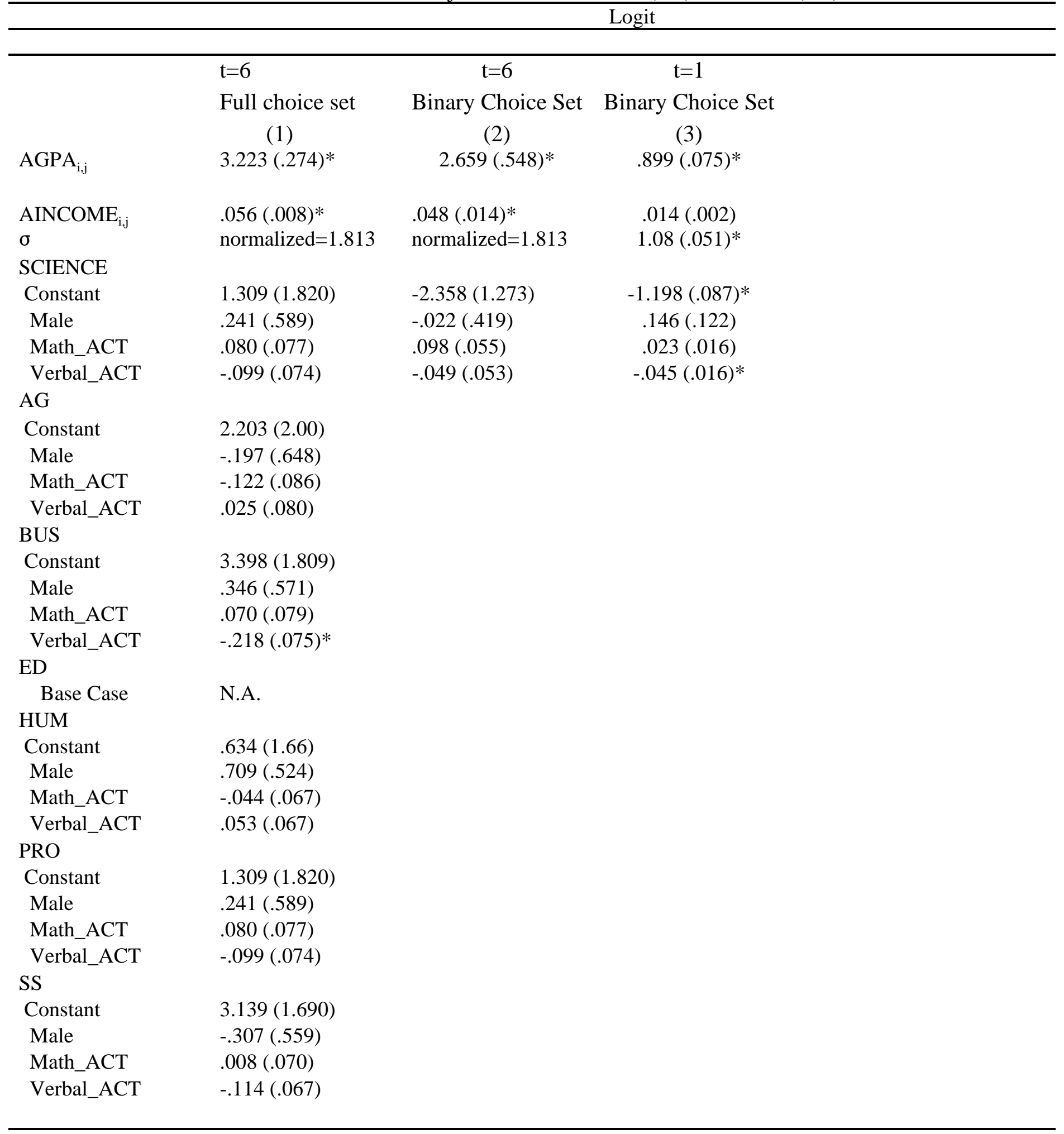

Notes: Table shows estimate (std. error). * Significant at 5\% 
Table 3 Estimates of model of major choice from IV.C.3

Logit - dependent variable stated choice is Science at $\mathrm{t}=6$

\begin{tabular}{|c|c|}
\hline $\begin{array}{l}{\left[\mathrm{E}\left(\mathrm{AGPA}^{6}{ }_{\mathrm{i}, \mathrm{SCI}}\right)-\mathrm{E}\left(\mathrm{AGPA}^{6}{ }_{\mathrm{i}, \mathrm{NON}-\mathrm{SCI}}\right)\right]-} \\
{\left[\mathrm{E}\left(\mathrm{AGPA}^{1}{ }_{\mathrm{i}, \mathrm{SCI}}\right)-\mathrm{E}\left(\mathrm{AGPA}^{1}{ }_{\mathrm{i}, \mathrm{NON}-\mathrm{SCI}}\right)\right]}\end{array}$ & $2.410(.687)^{*}$ \\
\hline $\begin{array}{l}{\left[\mathrm{E}\left(\mathrm{AINCOME}^{6}{ }_{\mathrm{i}, \mathrm{SCI}}\right)-\mathrm{E}\left(\mathrm{AINCOME}^{6}{ }_{\mathrm{i}, \mathrm{NON}-\mathrm{SCI}}\right)\right]-} \\
{\left[\mathrm{E}\left(\mathrm{AINCOME}_{\mathrm{i}, \mathrm{SCI}}\right)-\mathrm{E}\left(\mathrm{AINCOME}_{\mathrm{i}, \mathrm{NON}-\mathrm{SCI}}\right)\right]}\end{array}$ & $.045(.018)^{*}$ \\
\hline $\mathrm{E}\left(\mathrm{AGPA}_{\mathrm{i}, \mathrm{SCI}}^{1}\right)-\mathrm{E}\left(\mathrm{AGPA}_{\mathrm{i}, \mathrm{NON}-\mathrm{SCI}}\right)$ & $3.609(1.058)^{*}$ \\
\hline $\mathrm{E}\left(\mathrm{AINCOME}_{\mathrm{i}, \mathrm{SCI}}^{1}\right)-\mathrm{E}\left(\mathrm{AINCOME}_{\mathrm{i}, \mathrm{NON}-\mathrm{SCI}}^{1}\right)$ & $.038(.019)^{*}$ \\
\hline $\operatorname{Pr}_{i, S C I}^{1}$ & $.061(.011)^{*}$ \\
\hline Constant & $-5.896(1.867)^{*}$ \\
\hline Male & -.501 (.529) \\
\hline Math_ACT & $.117(.069)$ \\
\hline Verbal_ACT & $-.0006(.065)$ \\
\hline
\end{tabular}

Notes: Table shows estimate (std. error). * Significant at 5\% 
Figure 1A Avg. perceived probability

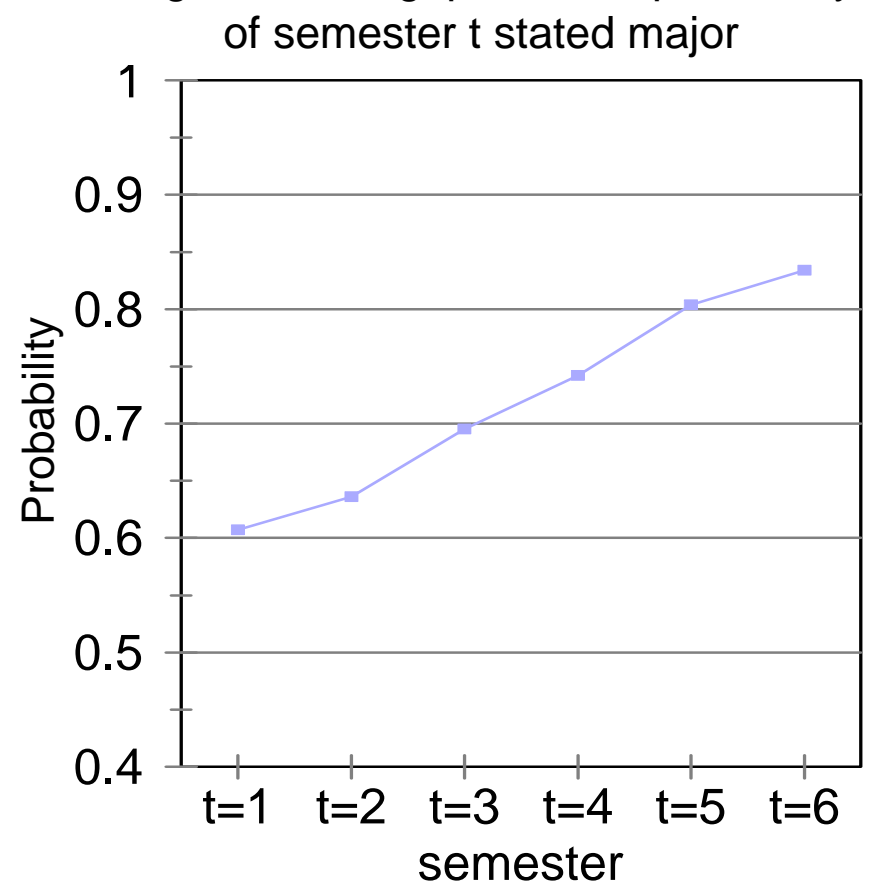

Figure 1B Avg. perceived probability

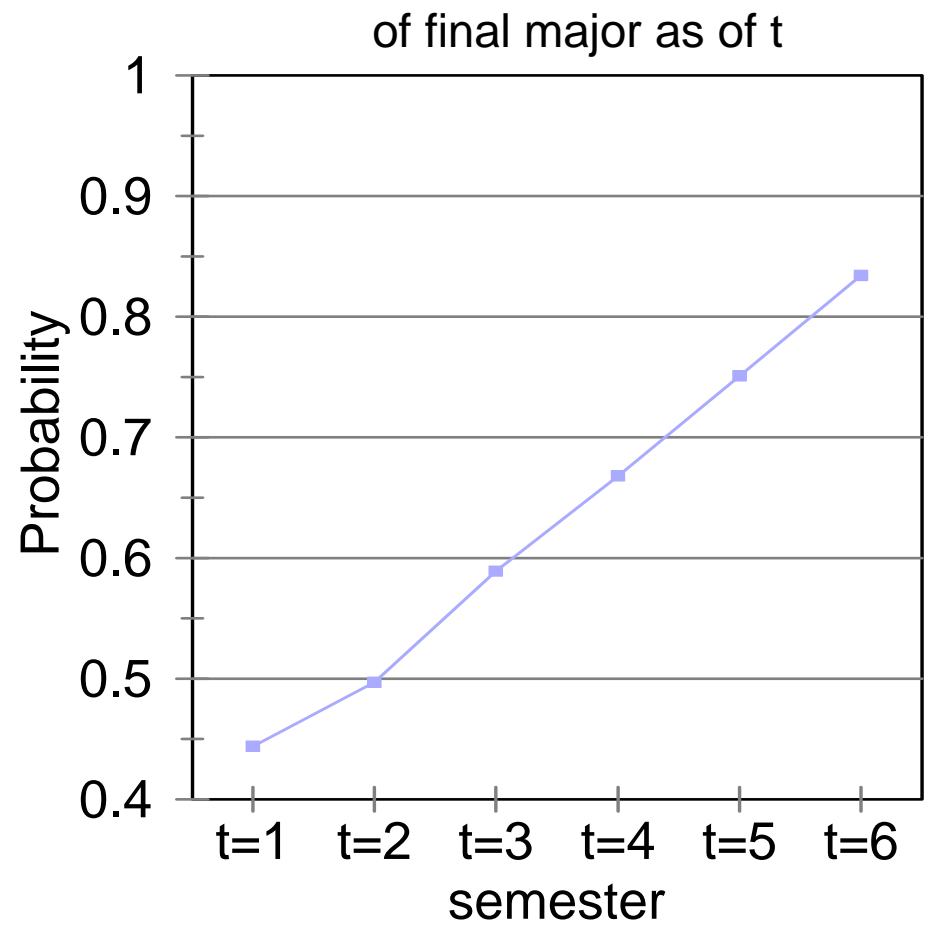


Figure 2A Proportion with stated

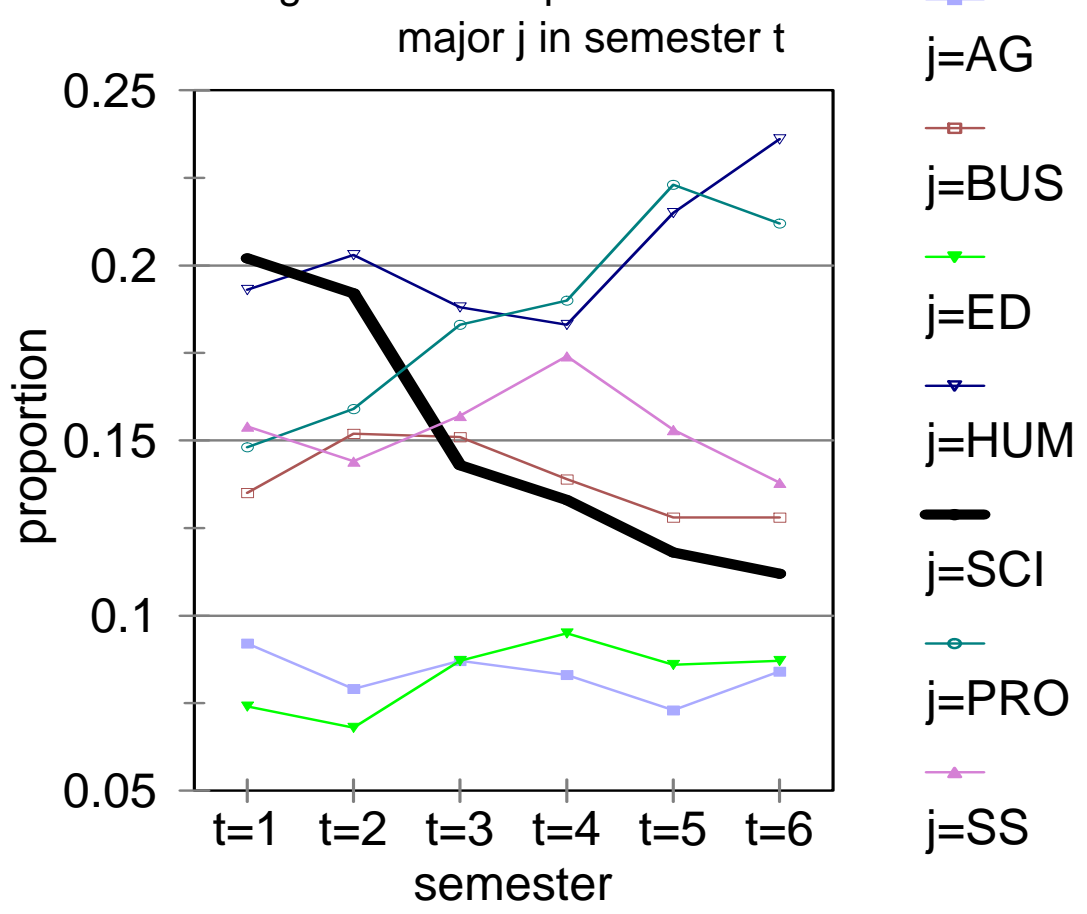

Figure 2B Avg. perceived probability

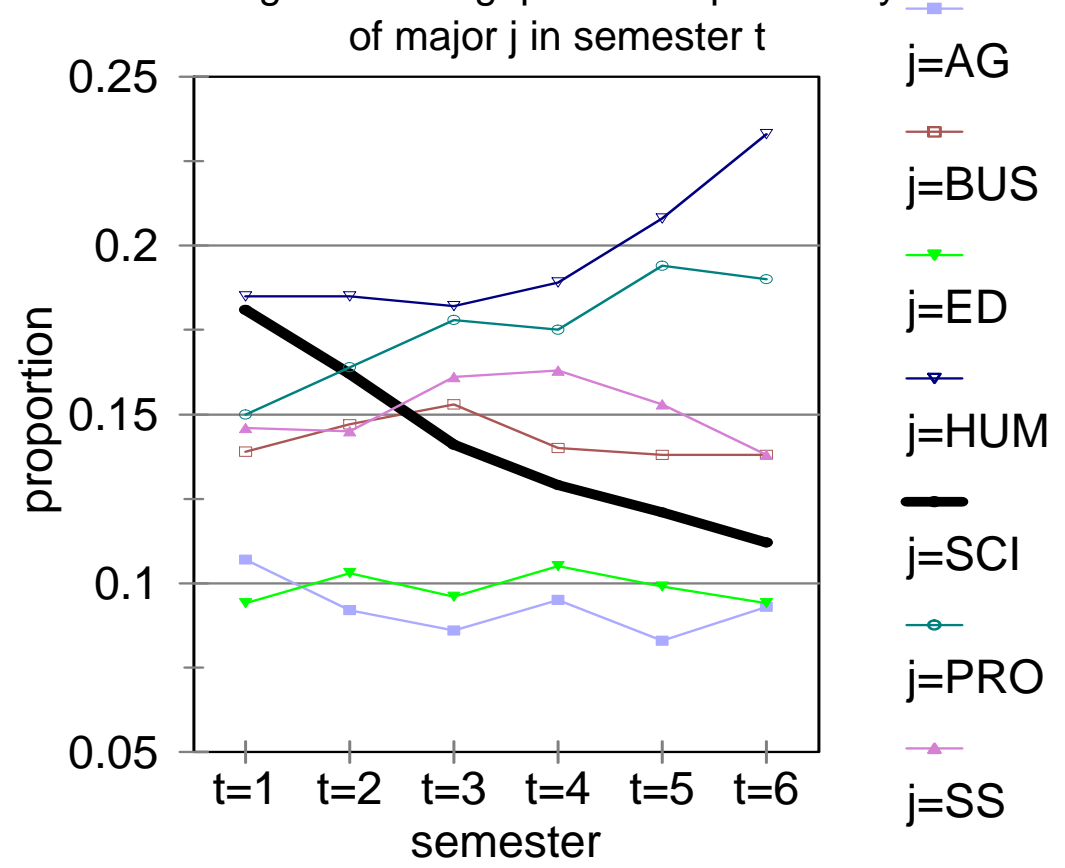


Figure 3A Actual probability of staying in starting major $\mathrm{j}$

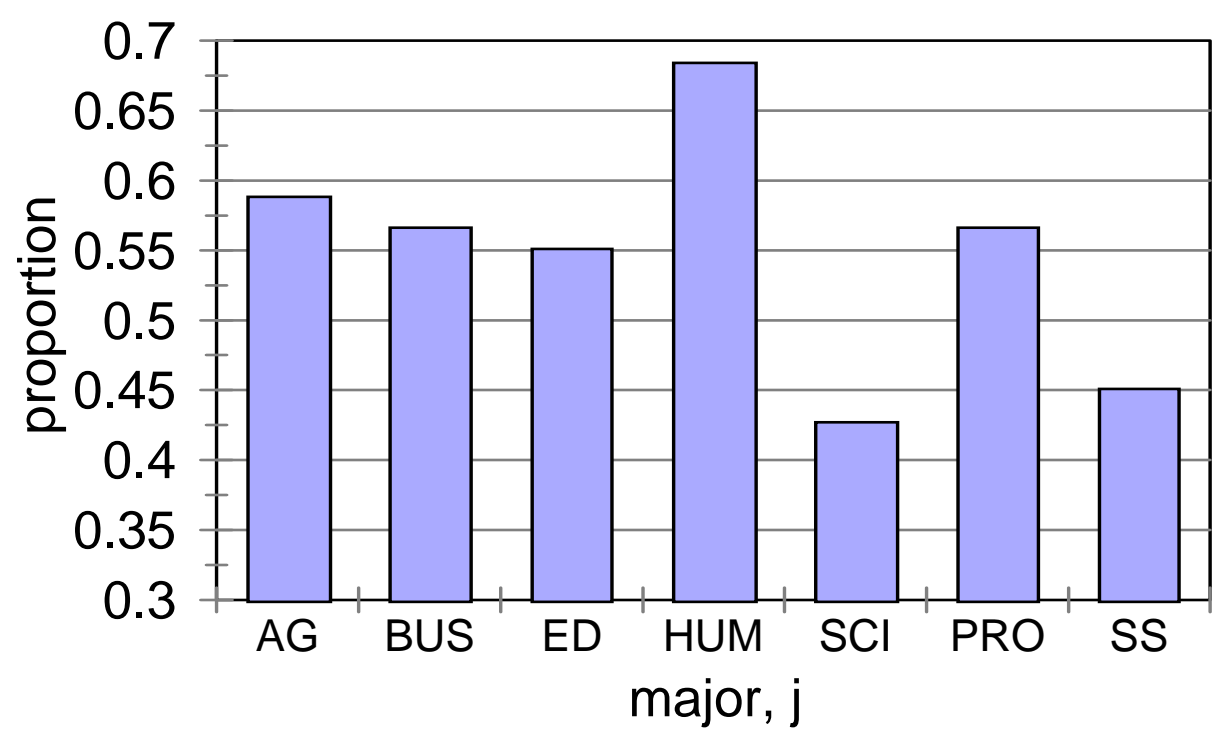

Figure 3B Avg. perceived probability at $\mathrm{t}=1$ of staying in starting major $\mathrm{j}$

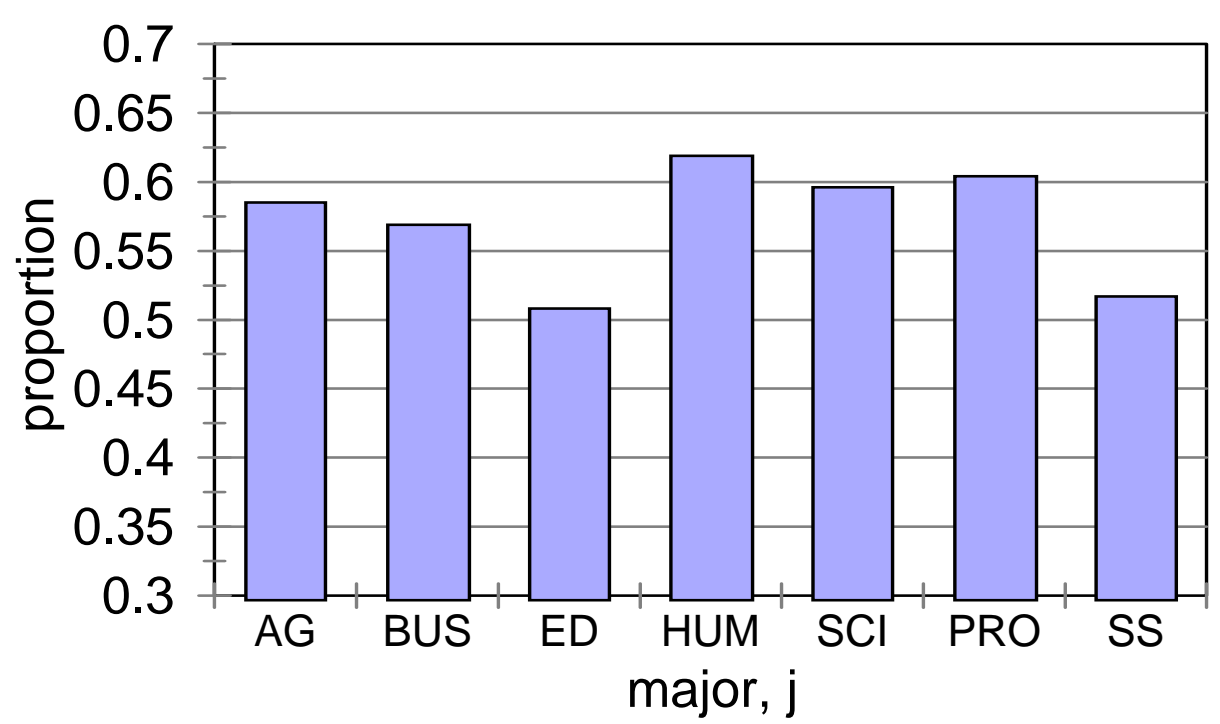


Figure 4A Actual probability of changing to final major $\mathrm{j}$

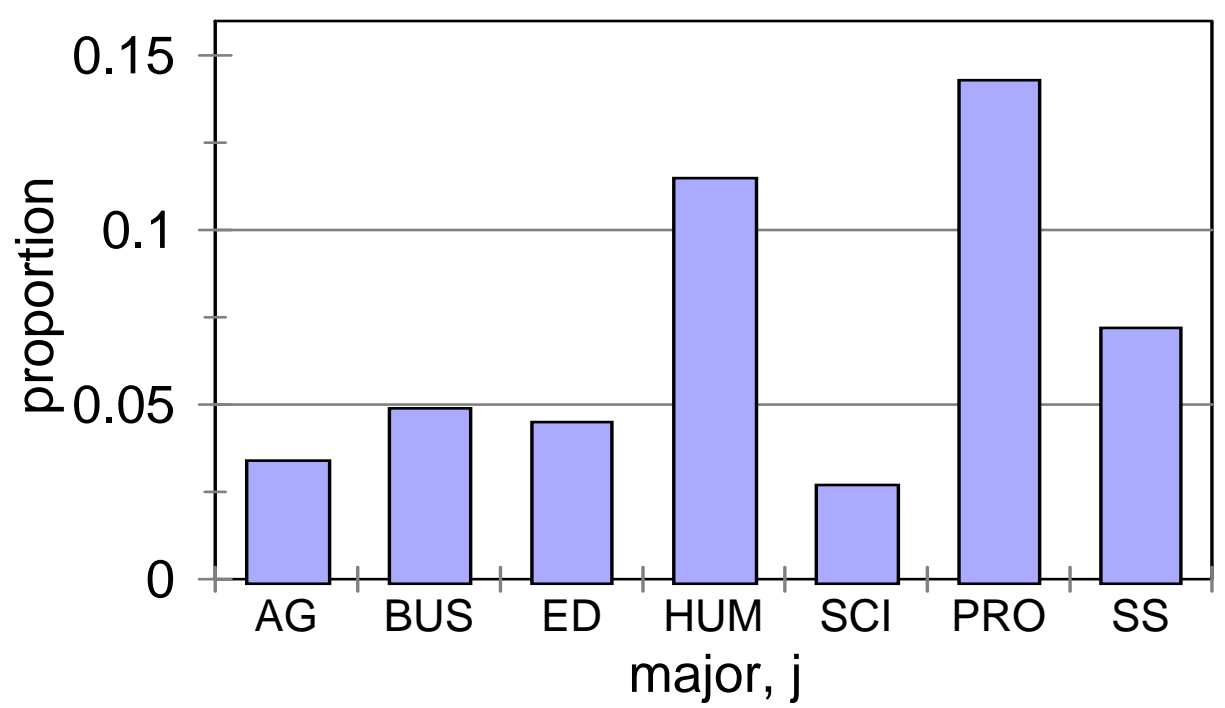

Figure 4B Avg. perceived probability at $t=1$ of changing to final major $j$

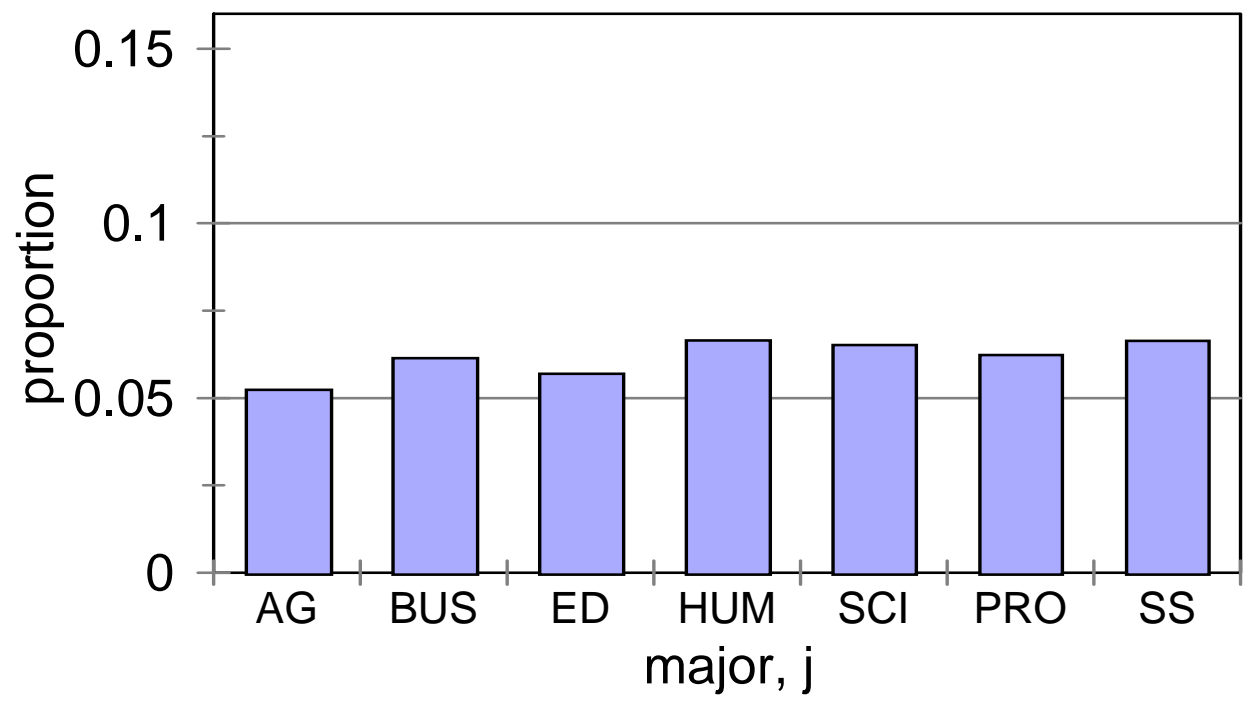


Figure 5A Avg. $E(A G P A(t, i, j))$

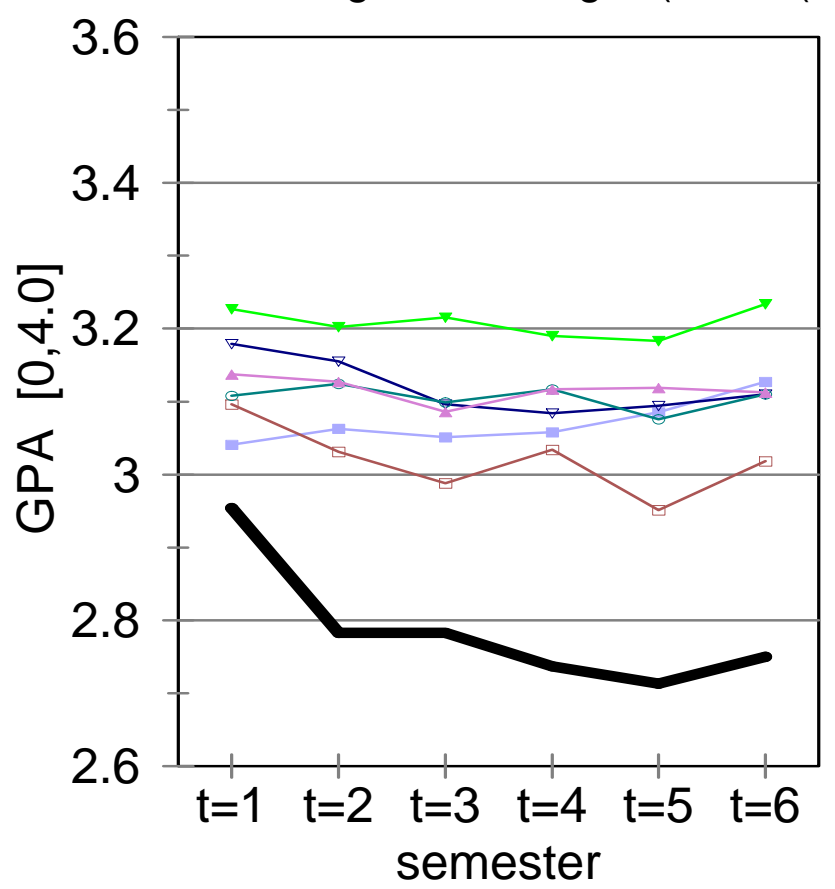

AG

$\square-$

BUS

$\rightarrow$

ED

$\overrightarrow{H U M}$

SCI

$\rightarrow$

PRO

SS

Figure 5B Avg. E(ASTUDY(t,i,j))

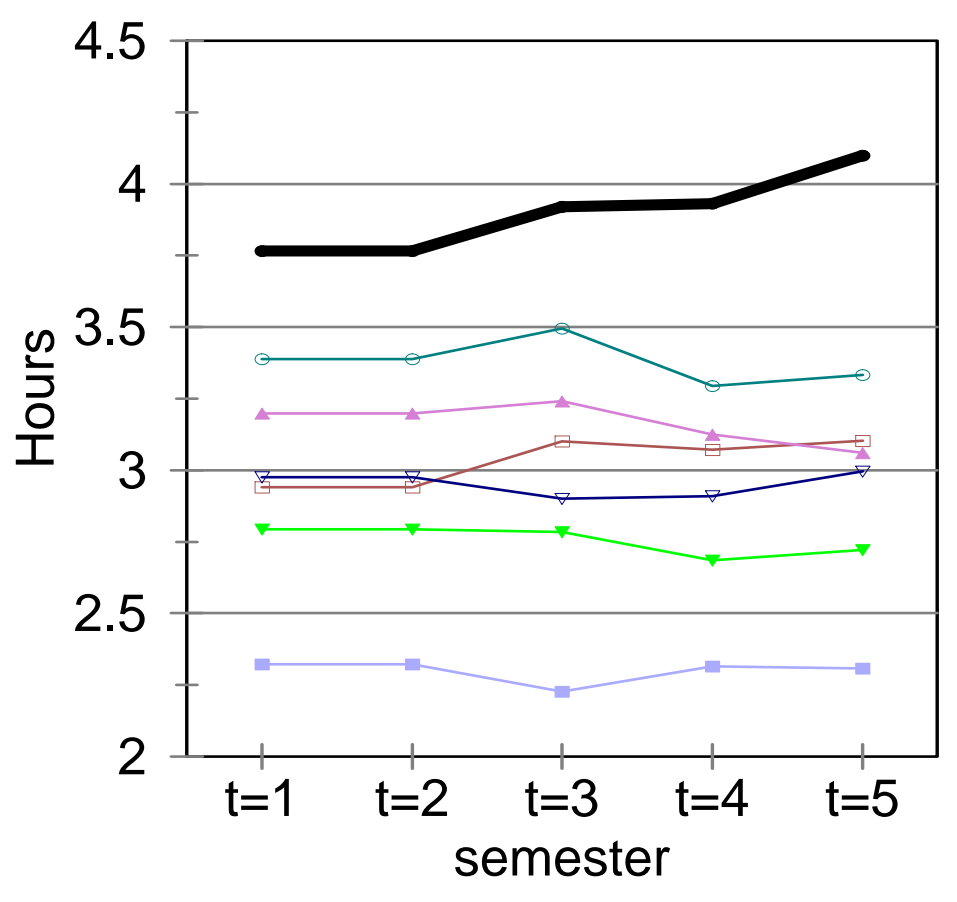

$j=A G$

$\rightarrow$

$j=B U S$

$\rightarrow$

$j=E D$

$\rightarrow$

$j=H U M$

T-

$\mathrm{j}=\mathrm{SCl}$

$\rightarrow$

$\mathrm{j}=\mathrm{PRO}$

$\rightarrow$

$\mathrm{j}=\mathrm{SS}$ 


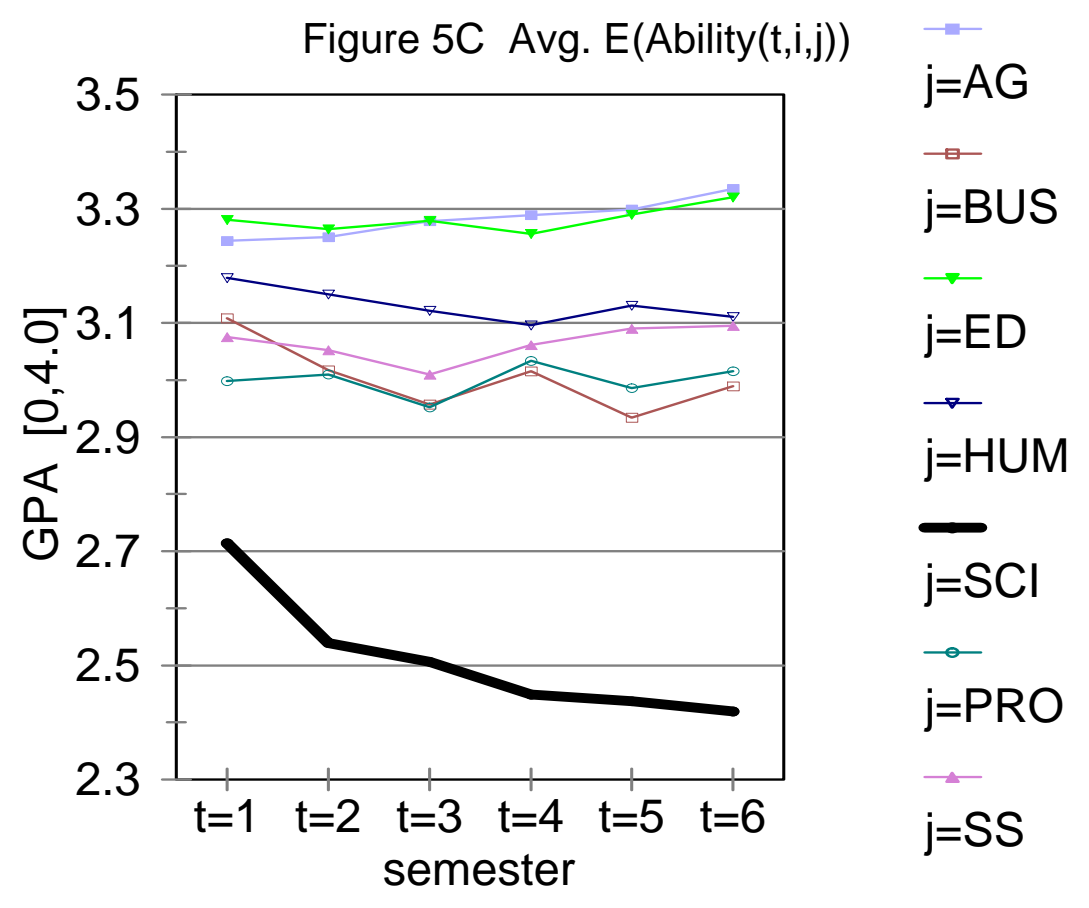

Figure 5D Avg. E(AINCOME(t,i,j))
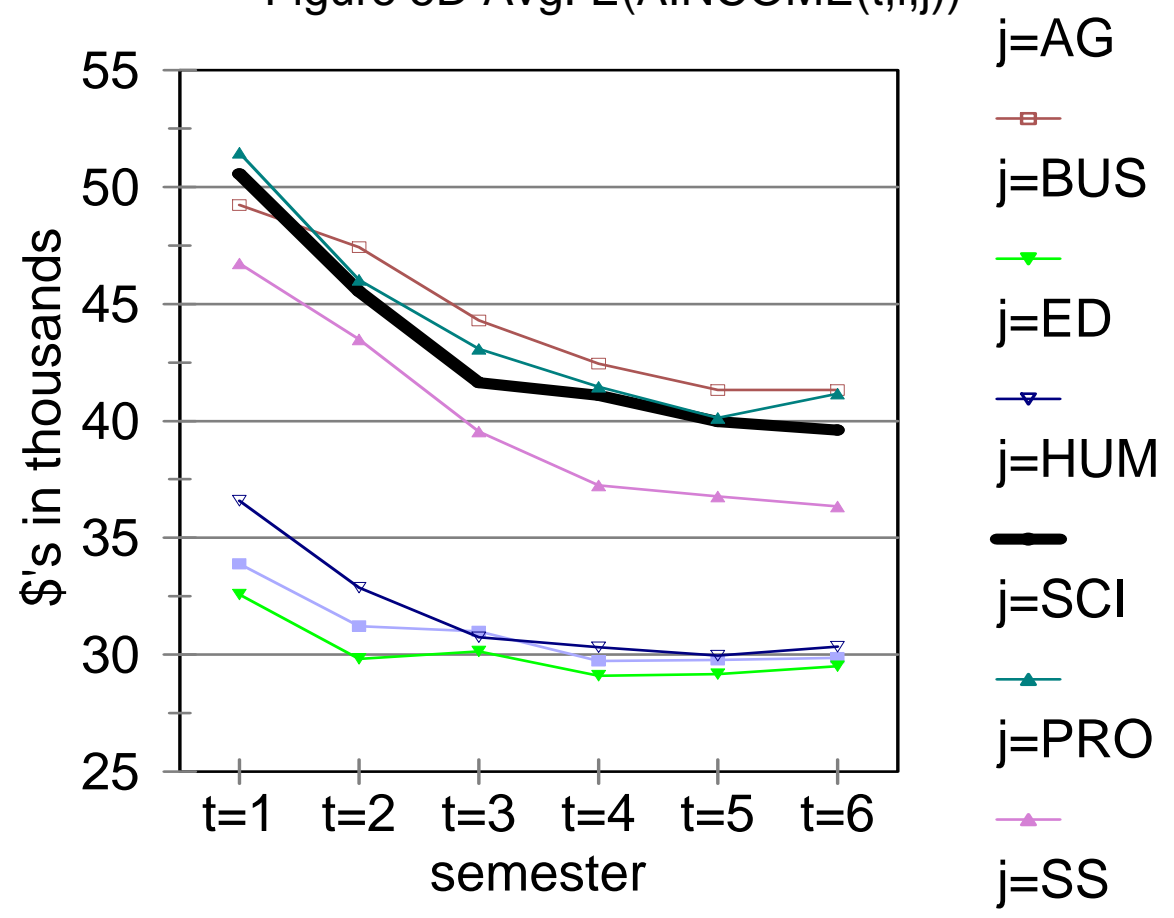
Figure 5E Avg. INTEREST(i,j)
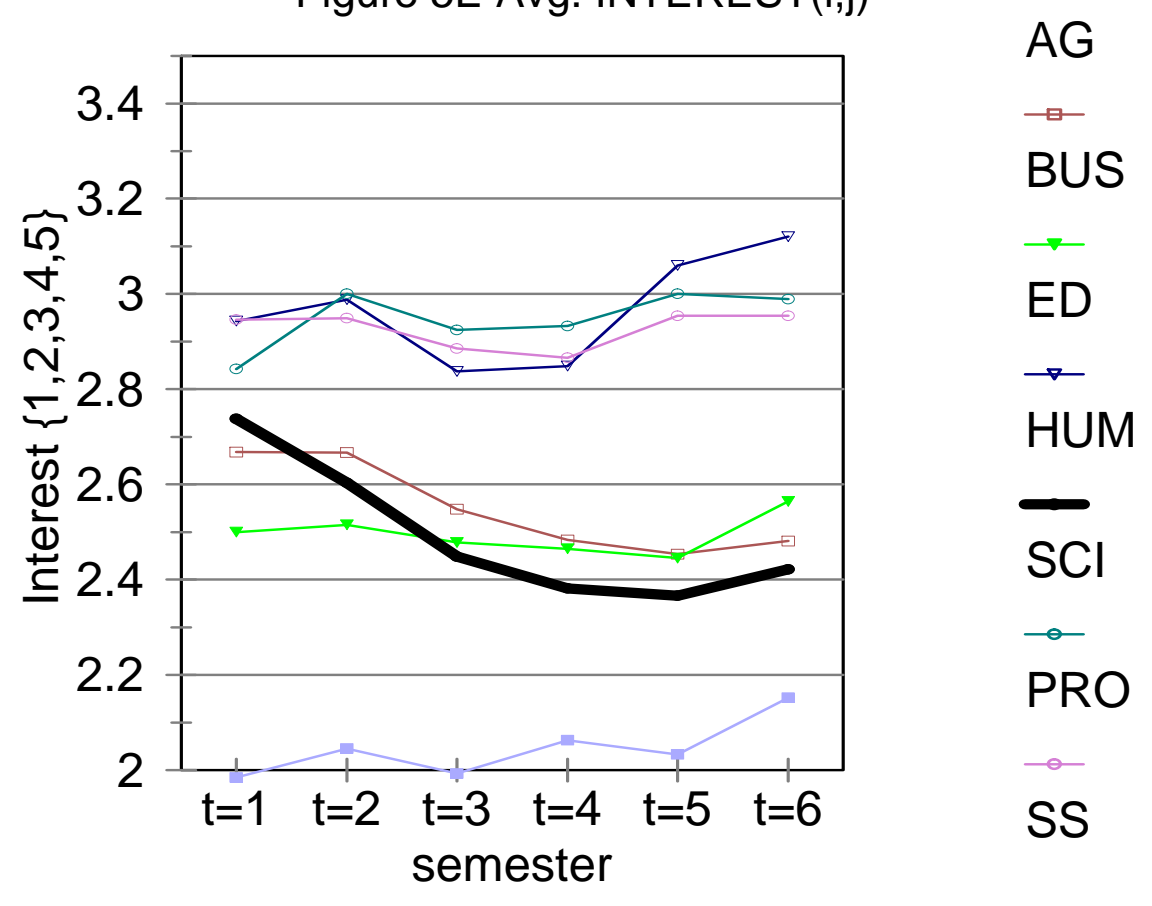
Figure 6 Avg. perceived probability of

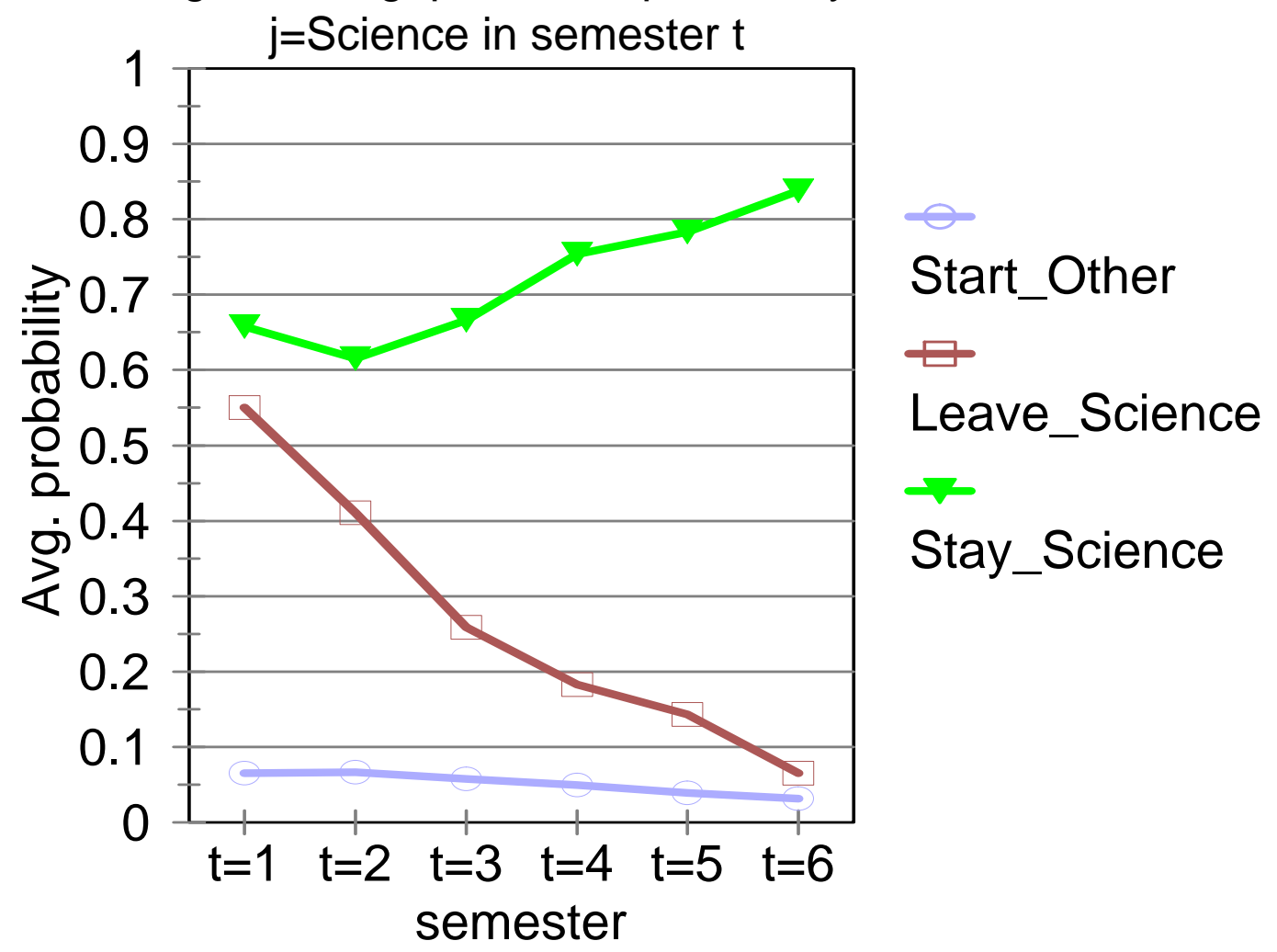


Figure 7A Avg. E(AGPA(t,i,SCI))

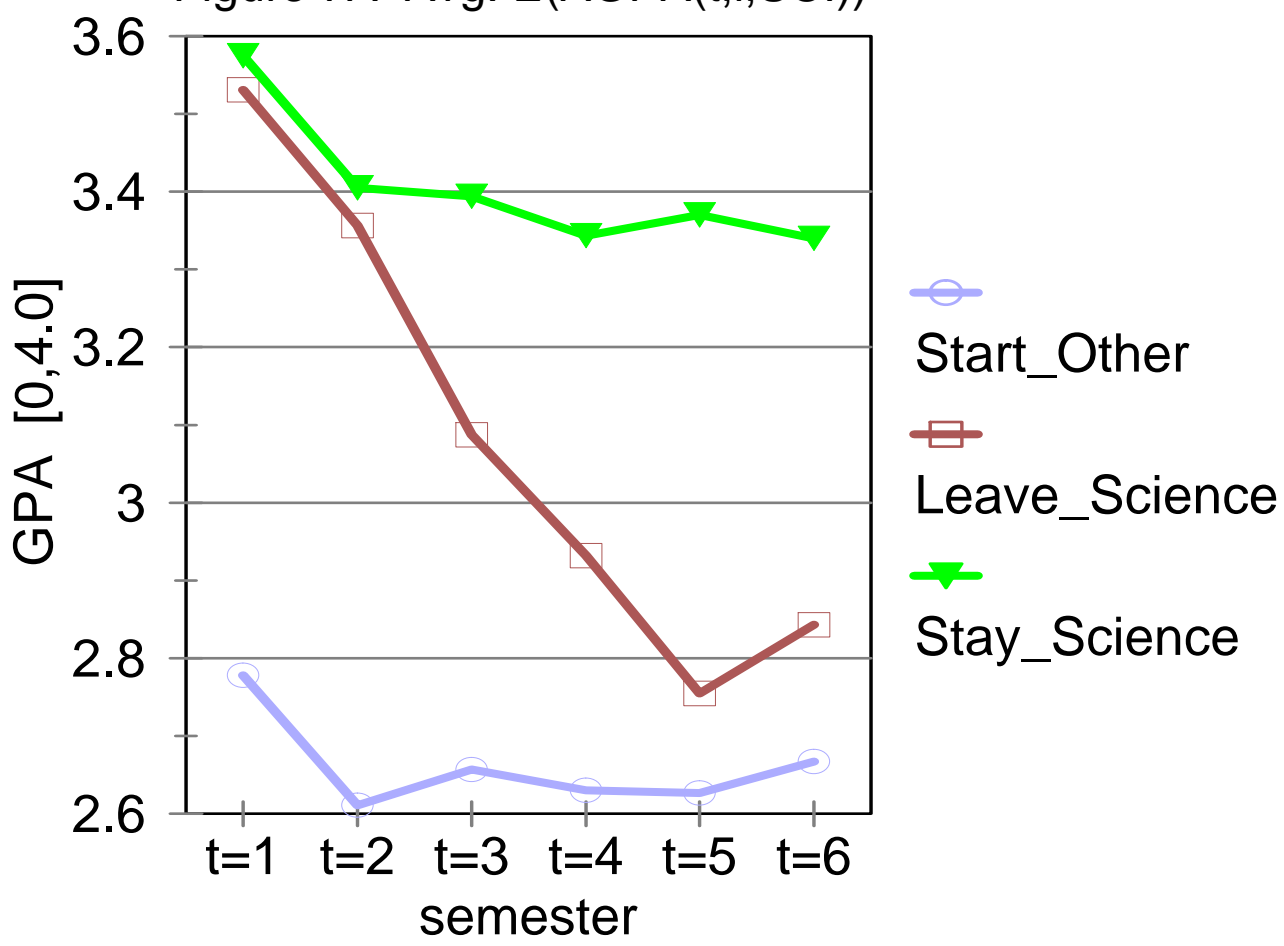

Figure 7B Avg. E(AGPA(t,i,NON-SCl)

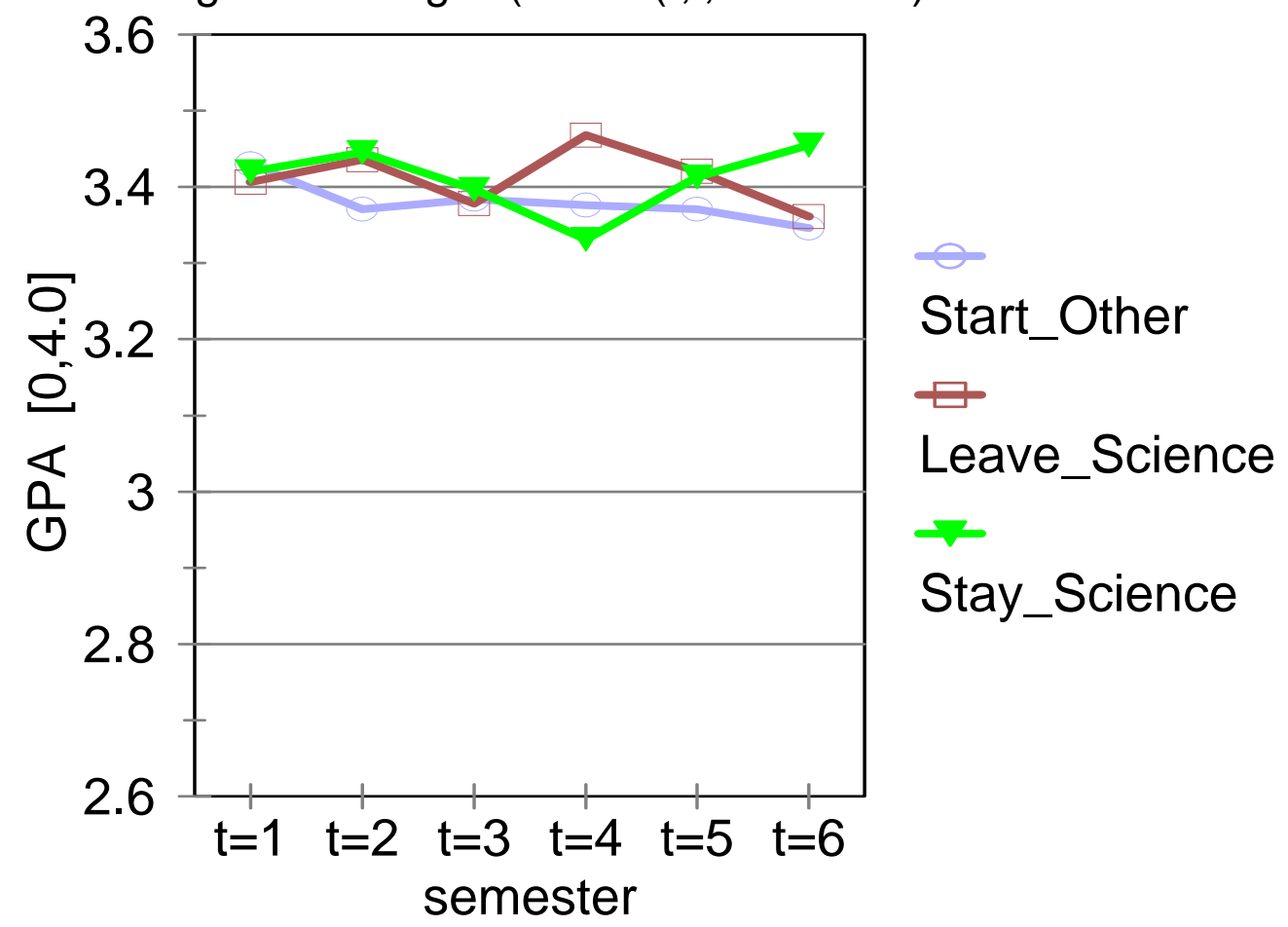


Figure 8A Avg. E(ASTUDY(t,i,SCI))

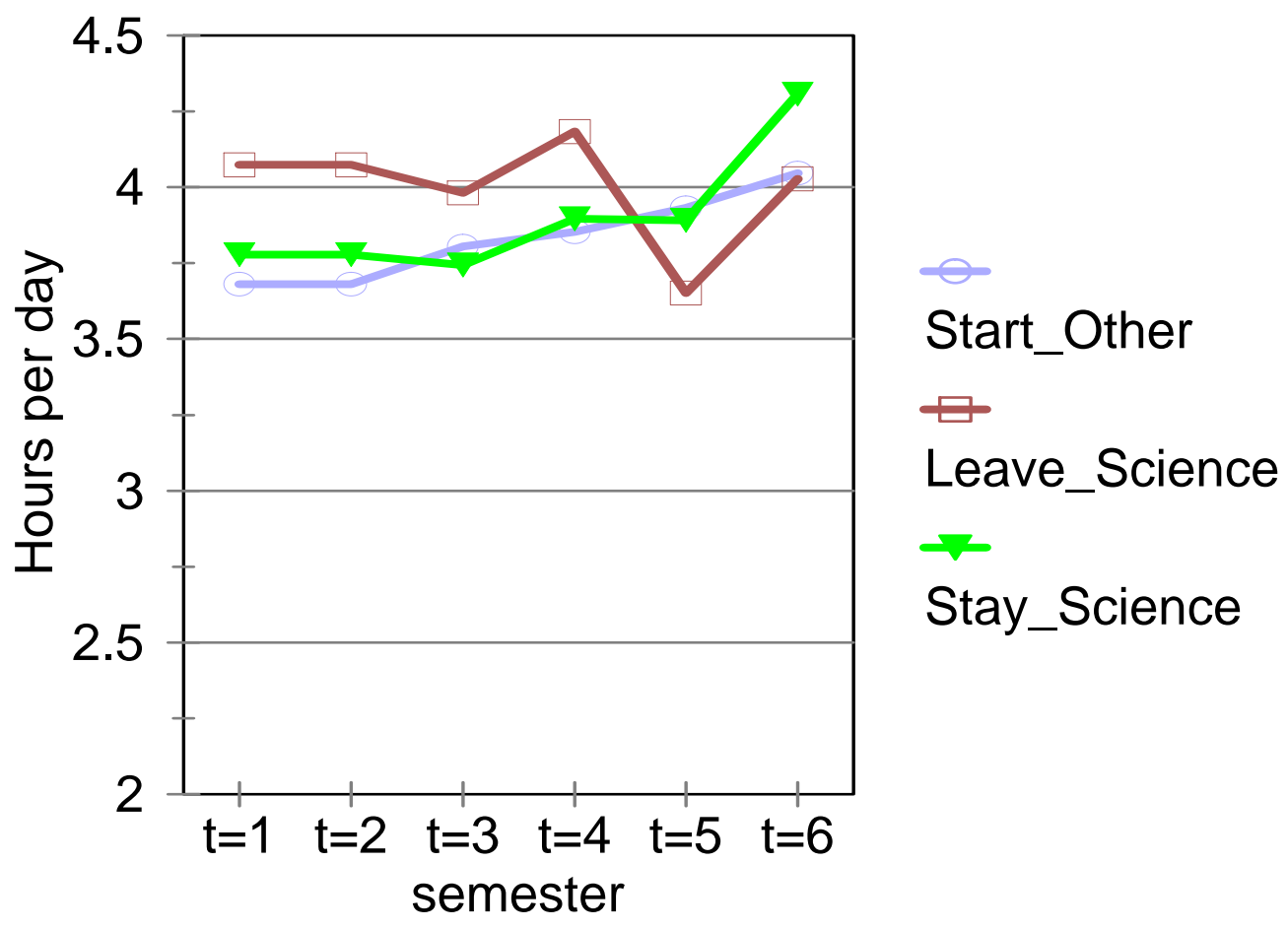

Figure 8B Avg. E(ASTUDY(t,i,NON-SCI))

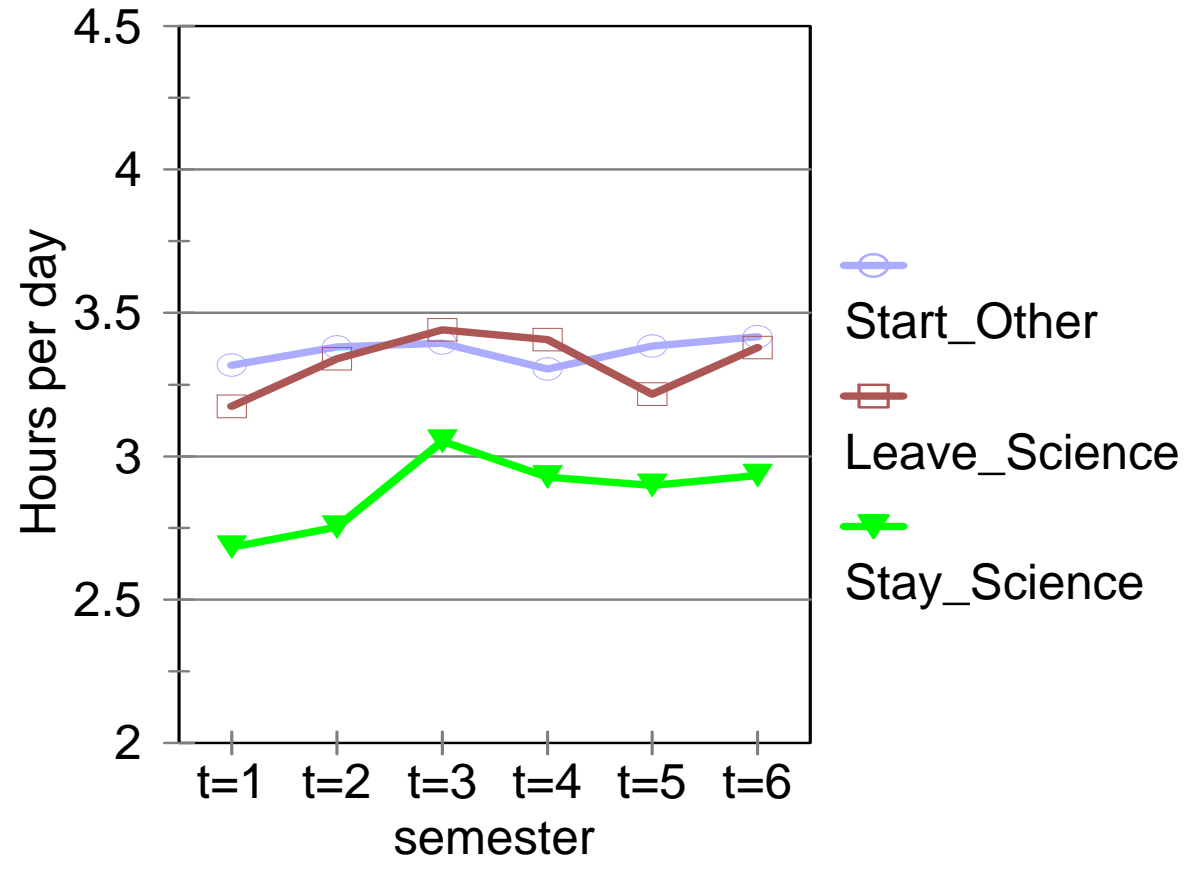


Figure 9A Avg. E(ABILITY(t,i,SCI))

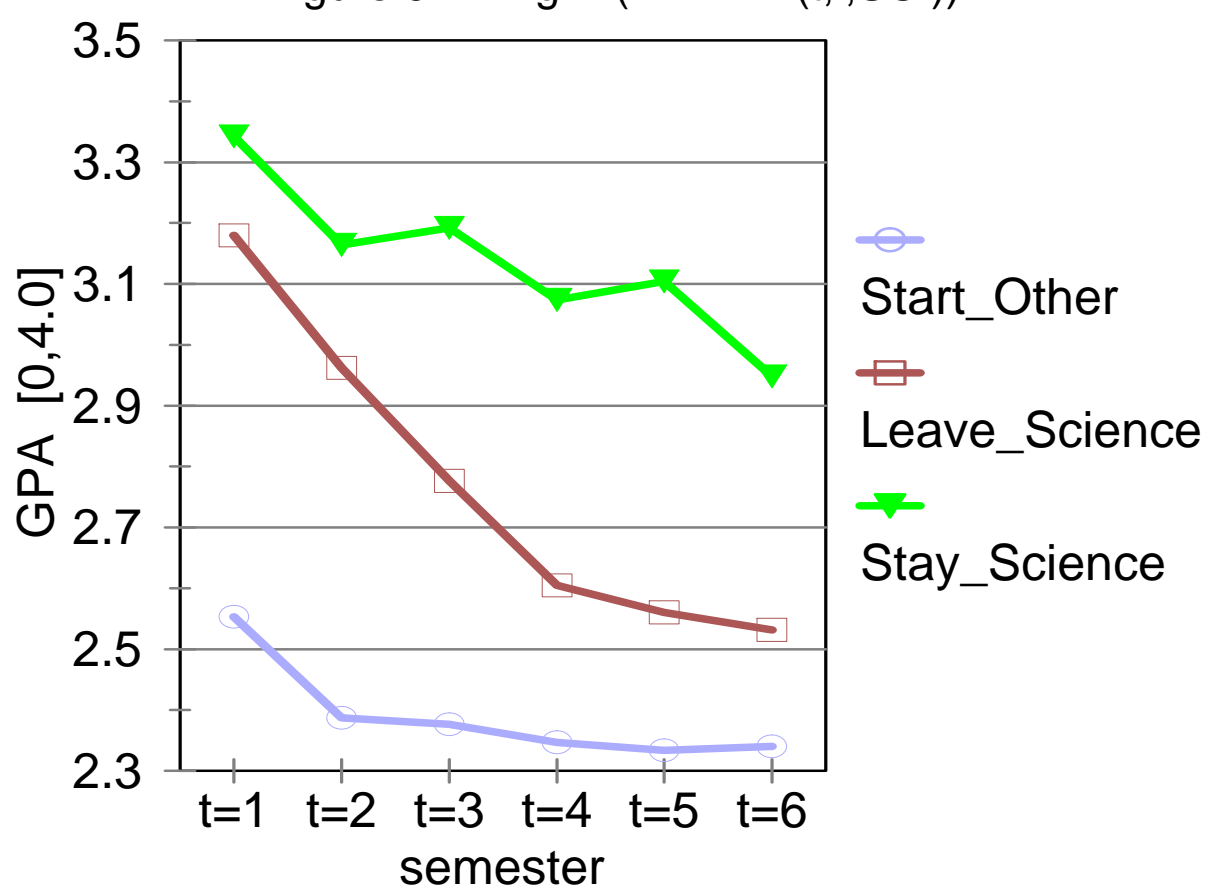

Figure 9B Avg. E(ABILITY(t,i,NON-SCI))

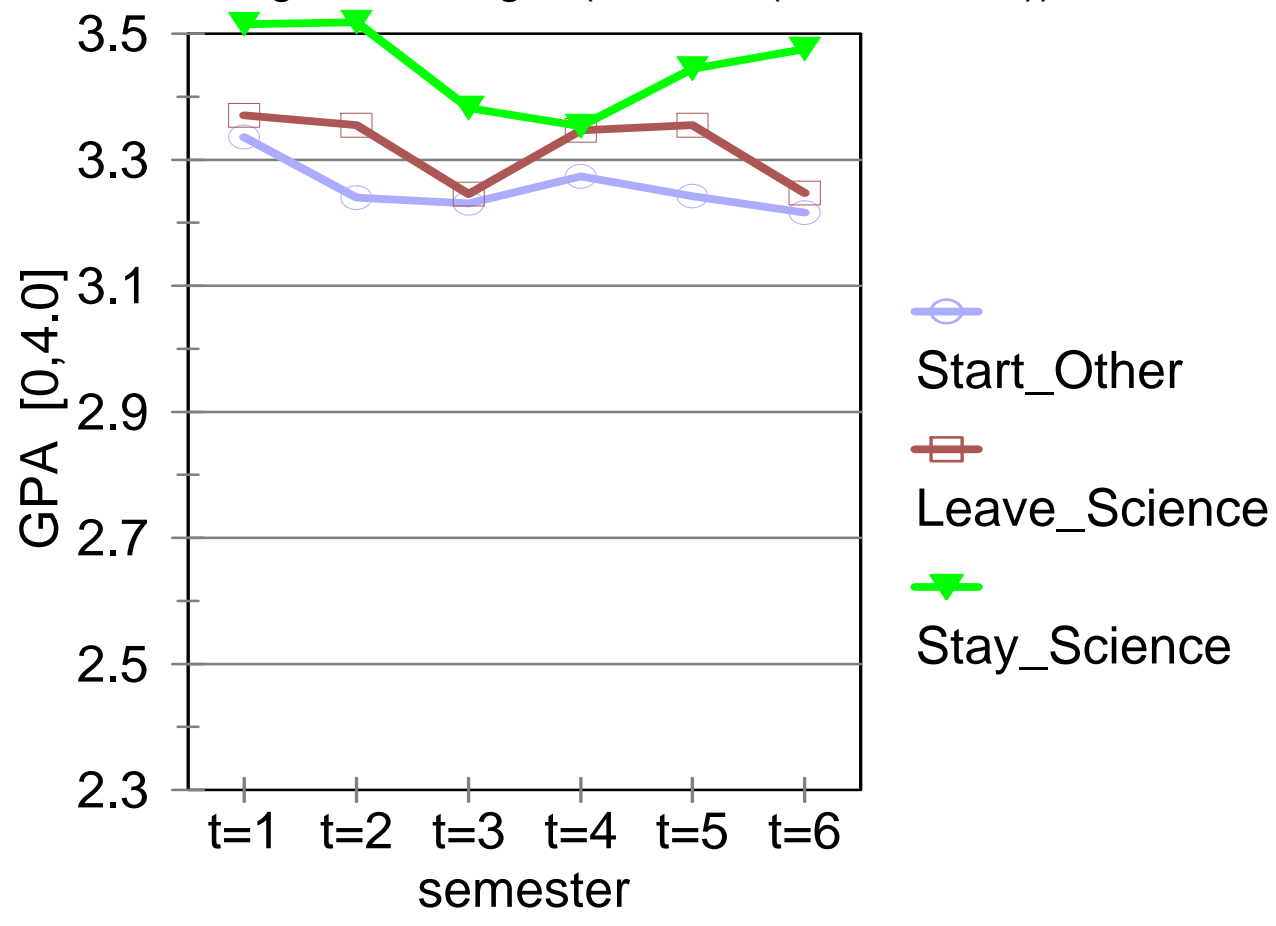


Figure 10A Avg. E(AINCOME(t,i,SCl)

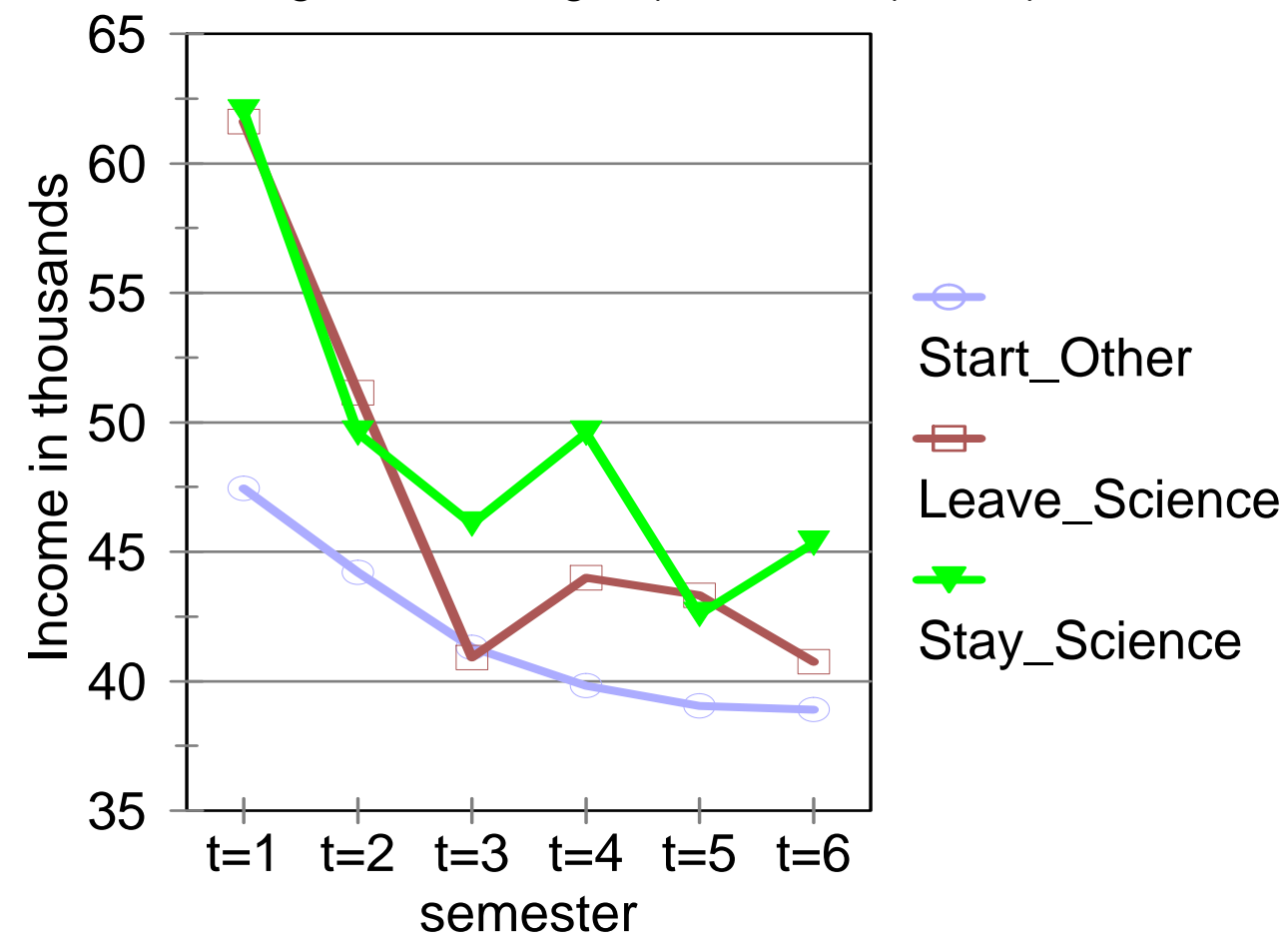

Figure 10B Avg. E(AINCOME(t,i,NON-SCl)

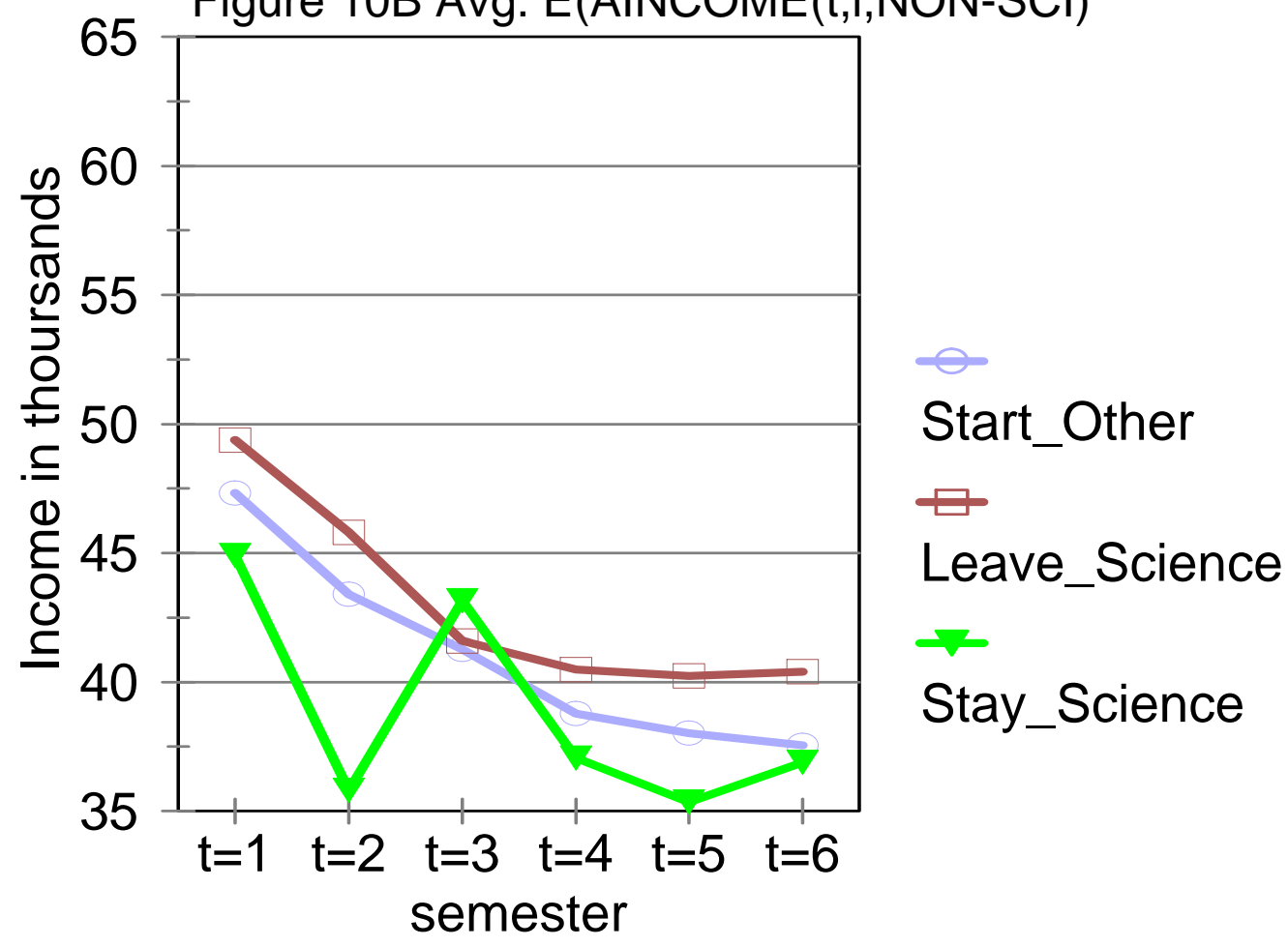


Figure 11A Avg. INTEREST(t,i,SCl)

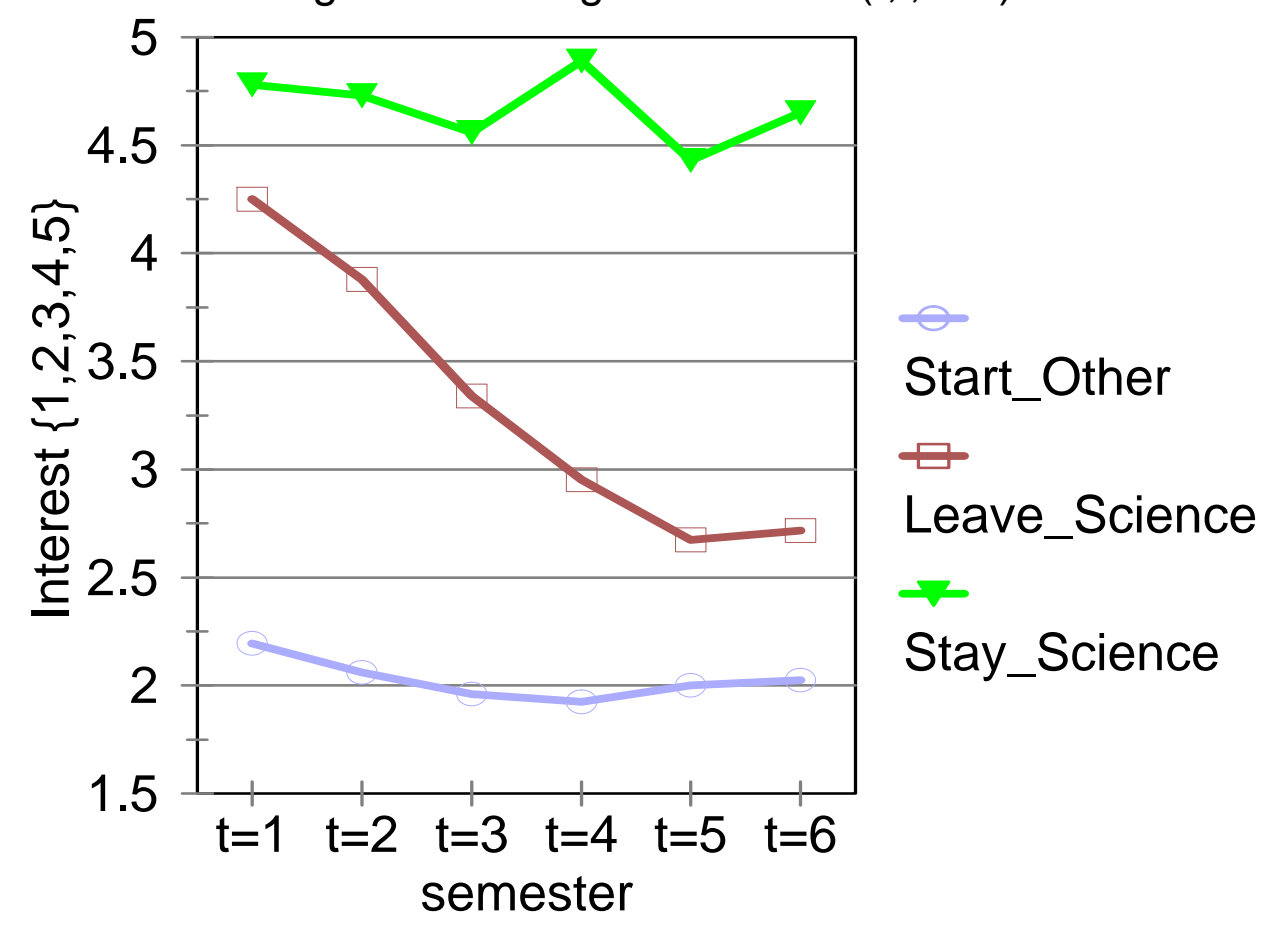

Figure 11B Avg. INTEREST(t,i,NON-SCI)

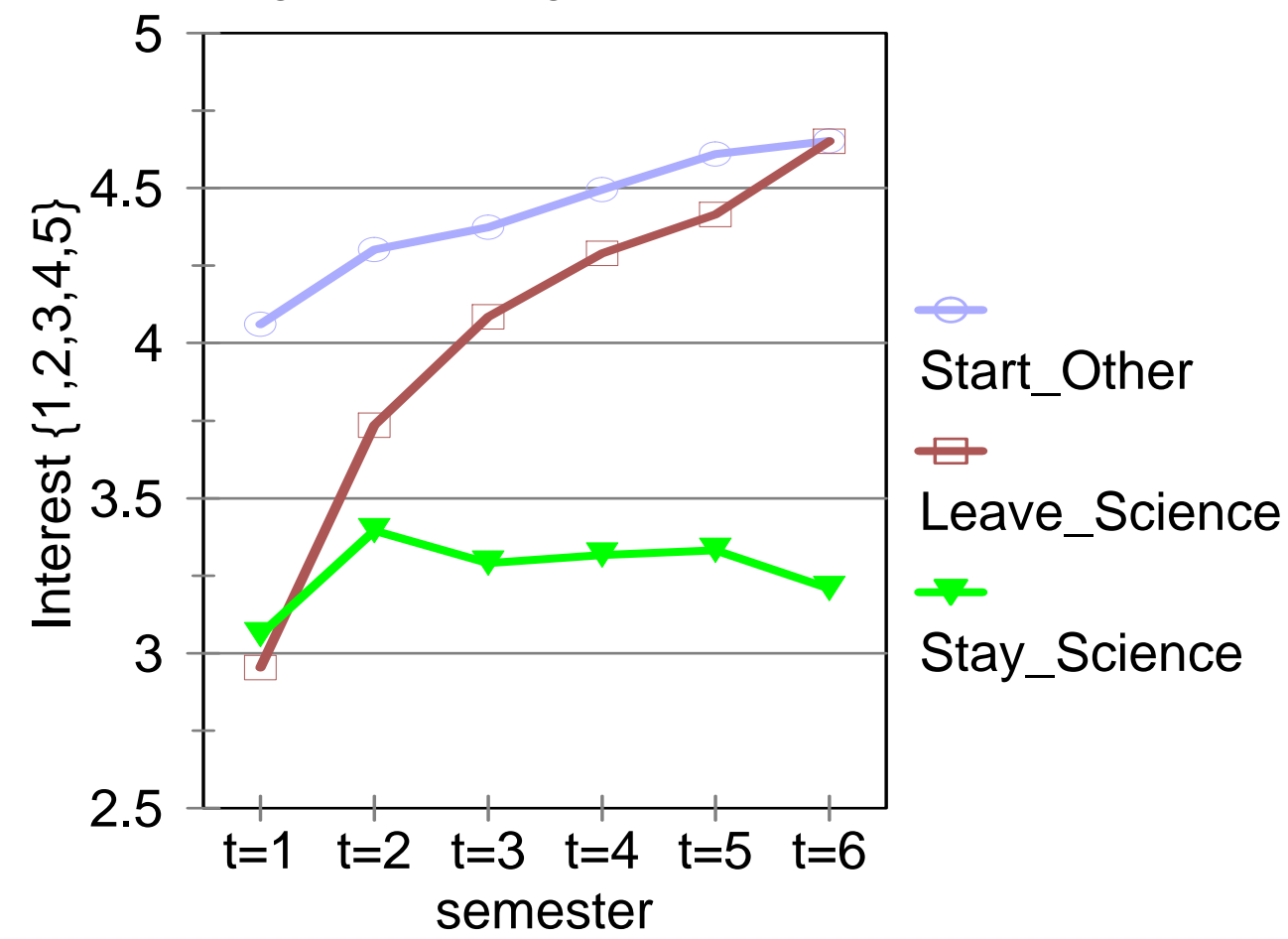




\section{Appendix A: Survey Questions}

Question 1. We realize that you may not be sure what area of study you will eventually graduate with. In the first column below are listed possible areas of study. In the second column write down the percent chance that you will end up with this area of study (note: the percent chance for each particular area of study should be between 0 and 100 and the numbers in the percent chance column should add up to 100). In the third column, please write down the grade point average (GPA) you would expect to receive in a typical semester in the future if you had each of these areas of study. In the fourth column write down the yearly income you would expect to earn at age 28 (or 10 years from now if you are now 20 years of age or older) if you graduated with each of these areas of study. In the fifth column, write down how interesting you find each particular area of study. In this column enter a number 1-5 where 1 =extremely interested, $2=$ quite interested, $3=$ =some interest, $4=$ =very little interest, $5=$ not interested.

Please fill out all remaining columns even if you have a zero in the percent chance column for a particular area of study.

Humanities include Art, English, Foreign Languages, History, Music, Philosophy, Religion, and Theatre.

Natural Science and Math includes Biology, Chemistry, Computer Science, Physics and Mathematics.

Professional Programs include Industrial Arts, Industrial Technology, Child Development, Dietetics, Home Economics, Nutrition, and Nursing.

Social Sciences include Economics, Political Science, Psychology and Sociology.

**When considering Expected GPA in an area of study consider ALL courses you will take if you have that area of study-including both courses that are required for your major and all other courses.**

Area of study $\quad$ Percent Expected GPA Expected Yearly Interest Level in Area of Study

$\begin{array}{cccl}\text { Chance } & (0.00-4.00) & \text { Income Age 28 } & \text { 5. Extremely interested } \\ \text { (See above) } & * * & \text { (in dollars) } & \text { 4. Quite interested } \\ & & & \text { 3. Some interest } \\ & & \text { 2. Very little interest } \\ & & \text { 1. Not interested }\end{array}$

1.Agriculture

(and Natural Resources)

2.Business

3.Elementary Education

4. Humanities

5.Natural Science \& Math

6. Professional Programs

7. Social Sciences
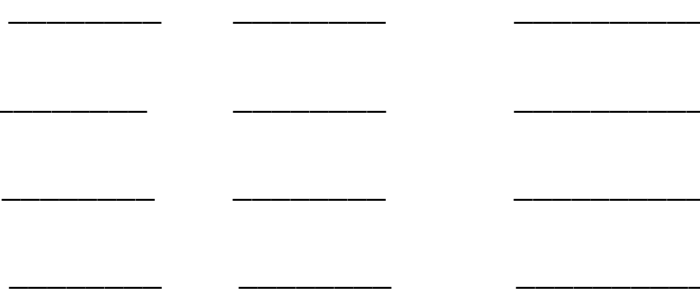

1. Not interested

Note: Numbers in the second column (percent chance) should each be between 0 and 100 and should add up to 100. Note: $A=4.0, B=3.0, C=2.0, D=1.0, F=0.0$. So numbers in third column (GPA) should be between 0.00 and 4.00. 
Question 2. We realize that you do not know exactly how well you will do in classes. However, we would like to have you describe your beliefs about the grade point average that you expect to receive in the first semester. Given the amount of study-time you indicated in question $\mathrm{H}$, please tell us the percent chance that your grade point average will be in each of the following intervals. That is, for each interval, write the number of chances out of 100 that your final grade point average will be in that interval.

Note: The numbers on the six lines must add up to 100.

Interval Percent Chance (number of chances out of 100).

$[3.5,4.00]$

[3.0, 3.49]

$[2.5,2.99]$

$[2.0,2.49]$

$[1.0,1.99]$

$[0.0$, .99]

Note: $A=4.0, B=3.0, C=2.0, D=1.0, F=0.0$ 


\section{Appendix B: The $t=1$ Model}

\section{B.1 Estimation of beliefs at $t=1$}

Beliefs at $\mathrm{t}=1$ about $\mathrm{E}\left(\mathrm{AGPA}^{\mathrm{t}^{*}}{ }_{\mathrm{i}, \mathrm{SCI}}\right)$

We assume that students update according to

(B.1) $\mathrm{E}\left(\mathrm{AGPA}^{\left.\mathrm{t}^{*}{ }_{\mathrm{i}, \mathrm{SCI}}\right)}\right) \mathrm{E}\left(\mathrm{AGPA}_{\mathrm{i}, \mathrm{SCI}}^{1}\right)+\delta_{\mathrm{SCI}}\left[\mathrm{GPA}\right.$ Early $_{\mathrm{i}}-\mathrm{E}\left(\mathrm{GPA}\right.$ Early $\left.\left._{\mathrm{i}}^{1}\right)\right]$

where GPA_Early ${ }_{i}^{1}$ is the random variable representing a student's beliefs at $\mathrm{t}=1$ about

GPA_Early ${ }_{\mathrm{i}}$, a student's GPA between $\mathrm{t}=1$ and $\mathrm{t}$. Roughly speaking, this updating rule is

motivated by the spirit of Bayesian updating since in the Bayesian model the posterior mean can

be written as the prior mean plus the proportion of the gap between the noisy signal and the prior mean that the person believes to be permanent in nature (S\&S, 2009). ${ }^{1}$ We note that Equation (B.1) represents one of many updating rules that would be reasonable. Rather than attempting to examine robustness to a large number of alternatives, we view our $\mathrm{t}=1$ results as simply being one piece of evidence. We note that our evidence from $t=6$ does not require us to make similar assumptions.

As discussed in detail in Section IV, E(AGPA $\left.{ }^{t^{*}, \mathrm{SCI}}\right)$ and $\mathrm{E}\left(\mathrm{AGPA}_{\mathrm{i}, \mathrm{SCI}}\right)$ are elicited using Question 1. Given an assumption about the value of $t^{*}$, the actual grade performance GPA_Early $y_{i}$ can be observed in administrative data. We do not observe what students anticipate at entrance about how long it will take to settle on a college major. We assume that a student believes that his final major will be chosen relatively quickly, specifically assuming that students think of $\mathrm{t}^{*}$ as being equal to three. ${ }^{2}$ Given that having extra time to choose a major will tend to be more beneficial if a student anticipates learning much during school, this assumption is generally consistent with the finding in S\&S (2009) that students are too certain about, for example, grade performance at the time of entrance. Then, E(GPA_Early ${ }_{\mathrm{i}}{ }_{\mathrm{i}}$ ) can be calculated as the mean from Question 2 (Appendix A) which elicits beliefs at $\mathrm{t}=1$ about the distribution of grade performance during the early portion of college. An estimate of $\delta_{\mathrm{SCI}}$ can then be obtained from an OLS regression suggested by (B.1). With $t^{*}=3$, the regression is (B.2) $\mathrm{E}\left(\mathrm{AGPA}_{\mathrm{i}, \mathrm{SCI}}^{3}\right)=\mathrm{E}\left(\mathrm{AGPA}_{\mathrm{i}, \mathrm{SCI}}{ }\right)+\delta_{\mathrm{SCI}}\left[\mathrm{GPA} \mathrm{Early}_{\mathrm{i}}-\mathrm{E}\left(\mathrm{GPA} \mathrm{Early}_{\mathrm{i}}{ }_{\mathrm{i}}\right)\right]+\mathrm{v}_{\mathrm{i}, \mathrm{SCI}} \cdot$

Let $\mathrm{E}\left(\mathrm{AGPA}^{\mathrm{t}^{*}, \mathrm{SCI}}\right)^{1}$ be a random variable whose distribution represents beliefs at $\mathrm{t}=1$

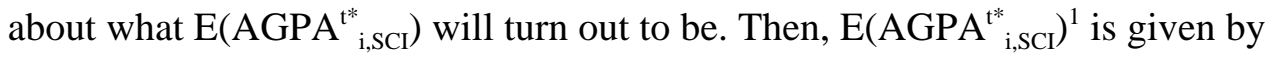

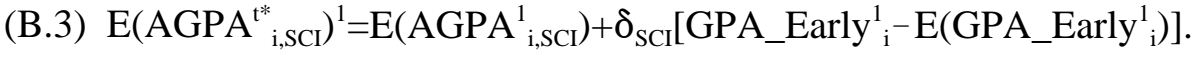

${ }^{1}$ From an internal consistency standpoint, it seems desirable for $\left.\mathrm{E}_{\left(\mathrm{AGPA}^{1} \mathrm{iSCI}\right.}\right)$ to be equal to the average updated value of $\mathrm{E}\left(\mathrm{AGPA}^{\mathrm{t}^{*}, \mathrm{SCI}}\right)$. This serves as a motivation for this particular updating form.

${ }^{2}$ What matters for this section is what a student believes about how long he will take to make a decision, not what the institutional rules say about the time at which a student must declare a major. 
Given an estimate of $\delta_{\mathrm{SCI}}$, the distribution of $\mathrm{E}\left(\mathrm{AGPA}^{\mathrm{t}^{*}, \mathrm{SCI}}\right)^{1}$ can be constructed for each person because Question 2 elicits the distribution of the RV GPA_Early ${ }_{i}^{1}$ which represents beliefs about grade performance GPA_Early ${ }_{\mathrm{i}}$.

In reality, what a person learns about his grade performance/ability in Science from observing his actual grades, GPA_Early, will depend on, for example, how many Science classes he is taking. This implies that it is desirable to allow $\delta_{\mathrm{SCI}}$ to vary depending on whether or not student $\mathrm{i}$ has a starting major of science. To do this, we stratify the sample into the group who have a starting major of Science and the group who have a starting major of non-science. We then estimate the OLS regression in B.2 for each of the two groups and construct the distribution in equation (B.3) for each group.

For $\delta_{\text {SCI }}$ we find an estimate (std.) of .491 (.084) for students who have a starting major of science and we find an estimate (std.) of .183 (.094) for students who do not have a starting major of science. Thus, the findings are consistent with the notion that the amount that a student learns about their academic performance/ability in science depends to a large extent on whether he is taking science classes.

\section{Beliefs at $\mathrm{t}=1$ about $\mathrm{E}\left(\mathrm{AGPA}^{\mathrm{t}}{ }_{\mathrm{i}, \mathrm{NON}-\mathrm{SCI}}\right)$}

Similarly, letting $\mathrm{E}\left(\mathrm{AGPA}^{\mathrm{t}^{*}}{ }_{\mathrm{i}, \mathrm{NON}-\mathrm{SCI}}\right)^{1}$ be a random variable whose distribution represents beliefs at $\mathrm{t}=1$ about what $\mathrm{E}\left(\mathrm{AGPA}^{\mathrm{t}^{*}}{ }_{\mathrm{i}, \mathrm{NON}-\mathrm{SCI}}\right)$ will turn out to be, the analog to $\mathrm{B}$.3 is given by (B.4) $\mathrm{E}\left(\mathrm{AGPA}^{\mathrm{t}^{*}}{ }_{\mathrm{i}, \mathrm{NON}-\mathrm{SCI}}\right)^{1}=\mathrm{E}\left(\mathrm{AGPA}_{\mathrm{i}, \mathrm{NON}-\mathrm{SCI}}{ }^{1}\right)+\delta_{\mathrm{NON}-\mathrm{SCI}}\left[\mathrm{GPA}\right.$ Early $\left._{{ }_{\mathrm{i}}}{ }^{-\mathrm{E}}\left(\mathrm{GPA} \mathrm{Early}_{\mathrm{i}}{ }_{\mathrm{i}}\right)\right]$.

We estimate $\delta_{\text {NON_SCI }}$ by OLS using the analog to equation B.2, (B.5) $\mathrm{E}\left(\mathrm{AGPA}_{\mathrm{i}, \mathrm{NON}-\mathrm{SCI}}^{3}\right)=\mathrm{E}\left(\mathrm{AGPA}_{\mathrm{i}, \mathrm{NON}-\mathrm{SCI}}\right)+\delta_{\mathrm{NON}-\mathrm{SCI}}\left[\mathrm{GPA}{ }_{-}\right.$Early $_{\mathrm{i}}-\mathrm{E}\left(\mathrm{GPA} \_\right.$Early $\left.\left.^{1}{ }_{\mathrm{i}}\right)\right]+\mathrm{v}_{\mathrm{i}, \mathrm{NON}-\mathrm{SCI}}$.

For $\delta_{\text {NON-SCI }}$ we find an estimate (std.) of .113 (.077) for students who have a starting major of science and we find an estimate (std.) of .201 (.041) for students who do not have a starting major of science.

Beliefs at $\mathrm{t}=1$ about E(AINCOME $\left.{ }_{\mathrm{i}, \mathrm{SCI}}^{*}\right)$ and $\mathrm{E}\left(\mathrm{AINCOME}_{\mathrm{i}, \mathrm{NON}-\mathrm{SCI}}\right)^{\mathrm{*}}$

The updating equations related to future income take into account that a person's beliefs about future income may become more positive when his grade performance is good. The updating equations analogous to equations (B.3) and (B.4) are

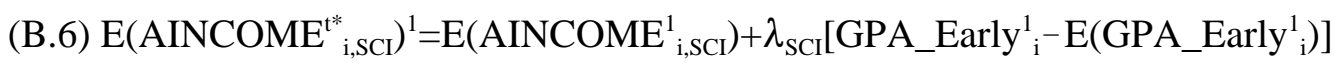
and

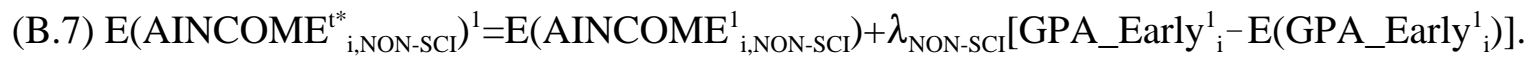
We estimate $\lambda_{\text {SCI }}$ and $\lambda_{\text {NON-SCI}}$, respectively, by OLS using equations analogous to B.2 and B.5 (B.8)E(AINCOME $\left.{ }_{i, \mathrm{SCI}}^{3}\right)=\mathrm{E}\left(\mathrm{AINCOME}_{\mathrm{i}, \mathrm{SCI}}\right)+\lambda_{\text {SCI }}\left[\mathrm{GPA}\right.$ Early $_{\mathrm{i}}-\mathrm{E}\left(\mathrm{GPA}_{-}\right.$Early $\left.\left.^{1}{ }_{\mathrm{i}}\right)\right]+\mathrm{v}_{\mathrm{i}, \mathrm{SCI}}$ 


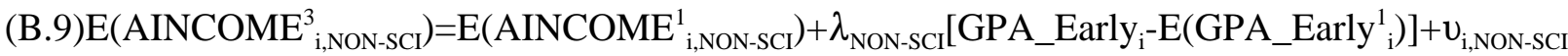

For $\lambda_{\text {SCI }}$ we find an estimate (std.) of 10.718 (6.858) for students who have a starting major of science and we find an estimate (std.) of 1.790 (5.664) for students who do not have a starting major of science. For $\lambda_{\text {NON-SCI }}$ we find an estimate (std.) of -.088 (2.12) for students who have a starting major of science and we find an estimate (std.) of 4.85 (3.29) for students who do not have a starting major of science.

\section{B.2 Details of $t=1$ model}

With the binary choice set $\{\mathrm{SCI}, \mathrm{NON}-\mathrm{SCI}\}$ and with $\mathrm{M}_{\mathrm{i}, \mathrm{j}}$ containing AGPA $_{\mathrm{i}, \mathrm{j}}$ and $\mathrm{AINCOME}_{\mathrm{i}, \mathrm{j}}$, the likelihood contribution for person i described after equation (9) can be written as

$$
\begin{aligned}
& \text { i }\left(\epsilon_{\mathrm{i}} \text {,diff }{ }^{*}\right): \epsilon_{\mathrm{i}} \text {,diff }{ }^{*} \text { satisfies }
\end{aligned}
$$

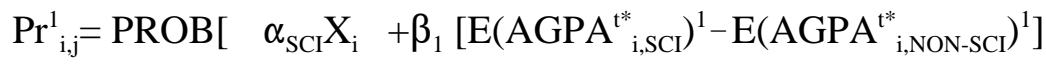

$$
\begin{aligned}
& +\beta_{2}\left[\mathrm{E}\left(\mathrm{AINCOME}^{\mathrm{t}^{*} \mathrm{SCI}}\right)^{1}-\mathrm{E}\left(\mathrm{INCOME}^{\mathrm{t}^{*}}{ }_{\mathrm{i}, \mathrm{NON}-\mathrm{SCI}}\right)^{1}\right]+\mathrm{v} \\
& \left.+\epsilon_{\mathrm{i}, \mathrm{diff}} *>0\right] \text {. }
\end{aligned}
$$

Substituting E(AGPA $\left.{ }^{t^{*}, \mathrm{SCI}}\right)^{1}, \mathrm{E}\left(\mathrm{AGPA}^{\mathrm{t}^{*}}{ }_{\mathrm{i}, \mathrm{NON}-\mathrm{SCI}}\right)^{1}, \mathrm{E}\left(\mathrm{AINCOME}^{\mathrm{t}^{*}, \mathrm{SCI}}\right)^{1}$, and $\mathrm{E}\left(\mathrm{INCOME}^{\mathrm{t}^{*}, \mathrm{NON}-\mathrm{SCI}}\right)^{1}$ from equations B.3, B.4, B.6, and B.7 and rearranging so that all of the random variables are on the left side of the probability expression yields

$$
\begin{aligned}
& \text { (B.11) } \mathrm{L}_{\mathrm{i}}=\mathrm{h}\left(\epsilon_{\mathrm{i}, \mathrm{diff}} *\right): \epsilon_{\mathrm{i} \text {,diff }} * \text { satisfies } \\
& \operatorname{Pr}^{1}{ }_{i, j}=\operatorname{PROB}\left[\quad \beta_{1}\left(\delta_{\text {SCI }}-\delta_{\text {NON-SCI }}\right) \text { GPA_Early }{ }_{i}^{1}\right. \\
& +\beta_{2}\left(\lambda_{\text {SCI }}-\lambda_{\text {NON-SCI }}\right) \text { GPA_Early }{ }_{i}^{1} \\
& +\mathrm{v}<\alpha_{\mathrm{SCI}} \mathrm{X}_{\mathrm{i}} \\
& +\beta_{1}\left[\mathrm{E}\left(\mathrm{AGPA}_{\mathrm{i}, \mathrm{SCI}}^{1}\right)-\mathrm{E}\left(\mathrm{AGPA}_{\mathrm{i}, \mathrm{NON}-\mathrm{SCI}}^{1}\right)-\left(\delta_{\mathrm{SCI}}-\delta_{\mathrm{NON}-\mathrm{SCI}}\right) \mathrm{E}\left(\mathrm{GPA} \mathrm{Early}_{\mathrm{i}}{ }_{\mathrm{i}}\right)\right] \\
& +\beta_{2}\left[\mathrm{E}\left(\mathrm{INCOME}_{\mathrm{i}, \mathrm{SCI}}^{1}\right)-\mathrm{E}\left(\mathrm{INCOME}_{\mathrm{i}, \mathrm{NON}-\mathrm{SCI}}\right)-\left(\lambda_{\mathrm{SCI}}-\lambda_{\text {NON-SCI }}\right) \mathrm{E}\left(\mathrm{GPA}_{\mathrm{N}} \mathrm{Early}_{\mathrm{i}}{ }_{\mathrm{i}}\right)\right] \\
& \left.+\epsilon_{\mathrm{i}, \mathrm{diff}} *\right] \text {. }
\end{aligned}
$$

The terms on the right side of the probability expression are known to the student, including $\epsilon_{\mathrm{i} \text {,diff }} *$ which represents the portion of $\epsilon_{\mathrm{i}, \mathrm{SCI}}-\epsilon_{\mathrm{i}, \mathrm{NON}-\mathrm{SCI}}$ that is known to the student at $\mathrm{t}=1$. Uncertainty about the choice of final major arises from the terms on the left side of the probability expression with the uncertainty being about: 1) grade performance in the early portion of school, GPA_Early ${ }_{\mathrm{i}}$, which influences how the person updates his beliefs about $\mathrm{E}\left(\mathrm{AGPA}^{\mathrm{t}^{*}, \mathrm{SCI}}\right), \mathrm{E}\left(\mathrm{AGPA}^{\mathrm{t}^{*}}{ }_{\mathrm{i}, \mathrm{NON}-\mathrm{SCI}}\right)$, $\mathrm{E}\left(\mathrm{AINCOME}^{\mathrm{t}^{*}}{ }_{\mathrm{i}, \mathrm{SCI}}\right), \mathrm{E}\left(\mathrm{AINCOME}^{\mathrm{t}^{*}, \mathrm{NON}-\mathrm{SCI}}\right)$ and 2$) \mathrm{v}$ which represents the portion of $\epsilon_{\mathrm{i}, \mathrm{SCI}}-\epsilon_{\mathrm{i}, \mathrm{NON}-\mathrm{SCI}}$ that is not known by the person with certainty. Consistent with our earlier specifications, we assume that h has a logit density function. In a general form which allows flexibility in the standard deviation $\sigma:$ 
$\mathrm{h}\left(\epsilon_{\mathrm{i}, \mathrm{diff}}{ }^{*}\right)=(\gamma / \sigma) \exp \left[\gamma \epsilon_{\mathrm{i}, \mathrm{diff}} * / \sigma\right] /\left[\left(1+\exp \left[\gamma \epsilon_{\mathrm{i}, \mathrm{diff}} * / \sigma\right]\right)^{2}\right]$ where $\gamma$ is the constant 1.83799327...

If we assume that $\mathrm{v}$ is normal with a mean of 0 and a standard deviation of $\mathrm{v}$, then we can write $\mathrm{v}=\mathrm{vZ}$ where $\mathrm{Z}$ is a standard normal random variable.

Given that $\delta_{\mathrm{SCI}}, \delta_{\mathrm{NON}-\mathrm{SCI}}, \lambda_{\mathrm{SCI}}$, and $\lambda_{\mathrm{NON}-\mathrm{SCI}}$ are estimated outside the model as described in Appendix B.1 and the distribution of GPA_Early ${ }_{\mathrm{i}}^{1}$ is elicited directly by Question 2, the parameters to be estimated are $\alpha_{\mathrm{SCI}}, \beta_{1}, \beta_{2}, \mathrm{v}$, and $\sigma$. To see that the full set of parameters is not identified, note that multiplying each of the parameters $\alpha_{\mathrm{SCI}}, \beta_{1}, \beta_{2}$, v by some scale factor $\pi$ causes the value of $\epsilon_{\mathrm{i} \text {,diff }} *$ that satisfies the probability condition in equations (B.10) and (B.11) to change by a factor of $\pi$ for each $i$. Then, multiplying $\sigma$ by the same factor $\pi$ guarantees that the likelihood contribution remains the same for each i (up to a scaling constant $1 / \pi$ ). Thus, we normalize $v=1$ and estimate the remaining parameters.

For estimation, we assume that GPA_Early ${ }^{1}$ has a multi-level uniform distribution - the density is uniform within each of the grade categories in Question 2 in which the reported probability is non-zero, with the reported probability in a particular grade category determining the height of the uniform density in that grade category relative to the height in the other categories. We estimate the model by Maximum Likelihood taking advantage of an estimator for the probability expression in B.1 which uses simulation to perform the integration over GPA_Early ${ }_{\mathrm{i}}^{1}$.

$$
\begin{aligned}
& \mathrm{L}_{\mathrm{i}}=\mathrm{h}\left(\epsilon_{\mathrm{i}, \text { diff }} *\right): \epsilon_{\mathrm{i}, \text { diff }} * \text { satisfies } \\
& \operatorname{Pr}_{\mathrm{i}, \mathrm{j}}^{1}=1 / \mathrm{K} \sum \Phi\left[\alpha_{\mathrm{SCI}} \mathrm{X}_{\mathrm{i}}\right. \\
& +\beta_{1}\left[\mathrm{E}\left(\mathrm{AGPA}_{\mathrm{i}, \mathrm{SCI}}^{1}\right)-\mathrm{E}\left(\mathrm{AGPA}_{\mathrm{i}, \mathrm{NON}-\mathrm{SCI}}^{1}\right)-\left(\delta_{\mathrm{SCI}}-\delta_{\mathrm{NON}-\mathrm{SCI}}\right) \mathrm{E}\left(\mathrm{GPA} \mathrm{Early}_{\mathrm{i}}{ }^{1}\right)\right]
\end{aligned}
$$

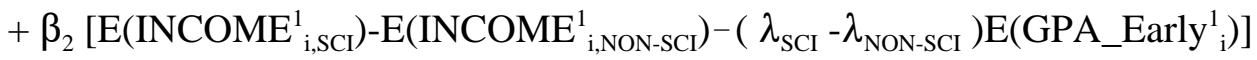

$$
\begin{aligned}
& +\epsilon_{\mathrm{i}, \mathrm{diff}} * \\
& -\beta_{1}\left(\delta_{\text {SCI }}-\delta_{\text {NON_SCI }}\right) \text { GPA_Early }{ }_{i}^{1}(k) \\
& \left.-\beta_{2}\left(\lambda_{\mathrm{SCI}}-\lambda_{\text {NON-CI }}\right) \text { GPA_Early }{ }_{\mathrm{i}}^{1}(\mathrm{k})\right]
\end{aligned}
$$

where GPA_Early ${ }_{i}^{1}(\mathrm{k})$ is the $\mathrm{k}^{\text {th }}$ of $\mathrm{K}$ draws of GPA_Early ${ }_{\mathrm{i}}^{1}(\mathrm{k})$ from the multi-level uniform density elicited in Survey Question 2, the summation is over the K draws, and $\Phi$ is the cumulative distribution function of $\mathrm{v}$, which, as described above, is assumed to be normal with a mean of zero and a standard deviation of $\mathrm{v}=1$. 